\title{
The Neuropsychiatry and Neuropsychology of
}

\section{Lipoid Proteinosis}

\author{
HB Thornton \\ Dissertation presented for the Degree of Doctor of Philosophy at \\ Stellenbosch University
}

Promoters: Prof. DJ Stein

Prof. GA Baker

December 2006 


\section{Declaration}

I, the undersigned, hereby declare that the work contained in this dissertation is my own original work and that I have not previously in its entirety or in part submitted it at any university for a degree.

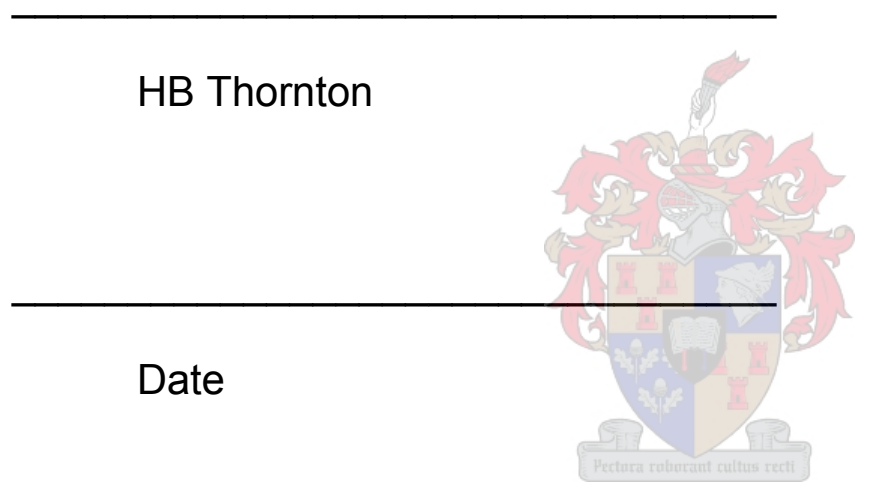




\section{Abstract}

Lipoid Proteinosis (LiP) is a rare hereditary disease, which often results in bilateral, symmetrical and circumscribed calcifications in the mesial temporal region (especially the amygdala). While several case studies have been published on individuals with this illness, there have been few systematic investigations of the neuropsychiatry and neuropsychology of a series of patients. Thirty-seven LiP patients were extensively assessed with standardized neuropsychiatric and neuropsychological measures. Of these, 27 patients from the Northern Cape in South Africa were matched (for age, gender, education, language, geographical area) with 53 controls. There was a high incidence of neuropsychiatric disorders in LiP (more than half of the subjects reported a history of depression or anxiety and $12 \%$ had a diagnosis of schizophrenia). Despite a wide variance, LiP subjects performed poorly on facial recognition for emotions and on most neuropsychological measures including intelligence, recall and executive functioning. These findings are consistent with involvement of the mesial temporal areas in mood, anxiety, and psychotic symptoms, and in the cognitive-affective processes. Future work aimed at delineating the associations between the clinical and neuropsychological findings reported here, for example, with brain-imaging techniques, is needed. 


\section{Abstrak}

Lipoïed-proteïnose (LiP) is 'n seldsame oorerflike siekte wat dikwels bilaterale, simmetriese en duidelik afgebakende kalsifikasies in die mid-temporale area (veral die amigdala) veroorsaak. Verskeie gevallestudies ten opsigte van individue met hierdie siekte is al gepubliseer, maar min sistematiese ondersoeke omtrent die neuropsigiatrie en neurosielkunde van ' $n$ reeks pasiënte is nog gedoen. Uitgebreide neuropsigiatriese en neurosielkunde evaluering deur middel van gestandaardiseerde meetinstrumente van sewe en dertig persone met LiP is gedoen. Sewe en twintig van hierdie persone van die Noord-Kaap in Suid-Afrika verteenwoordig, is afgepaar (volgens ouderdom, geslag, opvoeding, taal en geografiese area) met 53 kontroles. Daar was 'n hoë voorkoms van neuropsigiatriese versteurings in LiP (meer as die helfte van die proefpersone rapporteer ' $n$ geskiedenis van depressie of angs en $12 \%$ is gediagnoseer met skisofrenie). Ten spyte van 'n wye variansie het die LiP proefpersone swak gevaar met gesigsherkenning vir emosies en op meeste neuropsigologiese meetinstrumente, insluitend intelligensie, herroeping en uitvoerende funksies. Hierdie bevindinge stem ooreen met die rol wat die mid-temporale areas in gemoed-, angs- en psigotiese simptome speel, sowel as in die kognitief-affektiewe prosesse. Verdere navorsing ten opsigte van die assosiasie tussen die kliniese en neurosielkunde bevindinge wat uit hierdie ondersoek na vore gekom het, byvoorbeeld, breinskanderingstegnieke, is nodig. 


\section{Acknowledgments}

I wish to thank the following people for their invaluable assistance:

To Linda Coetzee, and all the wonderful staff at the Stellenbosch Medical School Library who have given of their services most generously.

To Dot, who has reviewed the papers and added dear critique and insights.

To my family, for all their support.

To Professor Dan Stein, Professor Gus Baker, Professor Michele Ramsay, Professor Trefor Jenkins, Professor Daan Nel, Dr Jack van Honk, Dr Ralph Adolphs, Erika

Steenberg, Melany Hendriks, Elspeth Burke, Lydia van Niekerk, Lindie Cloete, Debbie Alexander, Renée de Witt, Johnny Daniels, Nicole Andrews, Zilla Stekhoven, Fiona Naudé, Dr Chiwoza Bandawe and Dr Catherine Orrell for all their help.

To Sister Gesie Basson and the wonderful Northern Cape community nurses, who ferried, organized, cajoled, supported, and looked after researchers and participants alike, and for their invaluable insights.

And finally, but not least in my thoughts, my gratitude goes to all the participants of this study, for their honesty, insights, willingness and time.

I wish to thank the following organizations for their financial support: the Medical Research Council, the Harry Crossley Foundation and the Cannon Collins Educational Trust for Southern Africa. 
Conference presentations / Lectures arising from the research:

- A training workshop on lipoid proteinosis was presented to the Northern Cape community nurses (March 2003)

- The research was presented at the University of Stellenbosch Academic Year Day, and won the prize for the best research presentation in Neuroscience (August 2003)

- The research was presented at Valkenberg Hospital (2004)

- The South African Clinical Neuropsychology Association (SACNA) conference (February 2006)

- Neurology meeting at Groote Schuur Hospital (March 2006)

- The results of the research were presented at Valkenberg Hospital (July 2006) 


\section{Publications arising from the research:}

- Van Hougenhouck-Tulleken W, Chan I, Hamada T, Thornton H, Jenkins T, McClean WHI, McGrath SJA, Ramsay M. Clinical and molecular characterization of Lipoid Proteinosis in Namaqualand. South Africa. Br J Derm 2004;151: 413423.

- Thornton HB, Nel D, Thornton D, Van Honk J, Baker G, Stein D. The neuropsychiatry and neuropsychology of lipoid proteinosis. Submitted July 2006 and under consideration for publication with the Journal of Neuropsychiatry and Clinical Neurosciences.

\section{Applicable normative data}

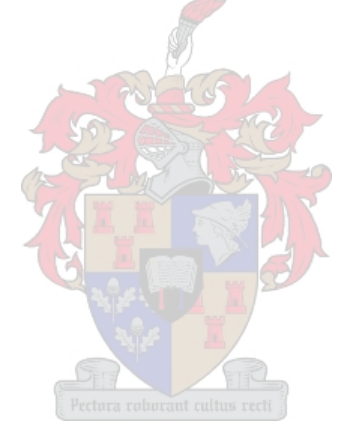

This research has also served to generate normative data for "Coloured" South Africans from a rural area with impoverished educational levels. The norms have already been used clinically at various Western Cape hospitals (Valkenberg Hospital, Tygerberg Hospital, Groote Schuur Hospital, and Lentegeur Hospital). 


\section{Contents}

\begin{tabular}{|c|c|c|}
\hline & $\begin{array}{l}\text { Title page } \\
\text { Declaration } \\
\text { Abstract (English) } \\
\text { Abstract (Afrikaans) } \\
\text { Acknowledgements } \\
\text { Contents page }\end{array}$ & $\begin{array}{l}1 \\
2 \\
3 \\
4 \\
5 \\
8\end{array}$ \\
\hline Chapter 1 & Introduction & 12 \\
\hline Chapter 2 & $\begin{array}{l}\text { Lipoid Proteinosis - Epidemiology, Signs and } \\
\text { Aetiology } \\
\text { Epidemiology } \\
\text { Signs } \\
\text { Aetiology }\end{array}$ & $\begin{array}{l}16 \\
16 \\
18 \\
23\end{array}$ \\
\hline Chapter 3 & $\begin{array}{l}\text { Literature review: } \\
\text { Early literature } \\
\text { Small numbers and methodological problems } \\
\text { Psychiatric signs } \\
\text { Neuropsychological signs }\end{array}$ & $\begin{array}{l}24 \\
24 \\
25 \\
26 \\
29\end{array}$ \\
\hline
\end{tabular}




\begin{tabular}{|c|c|c|}
\hline Chapter 4 & $\begin{array}{l}\text { The Amygdala } \\
\text { Animal studies } \\
\text { Humans } \\
\text { Amygdala functioning in living humans } \\
\text { Emotional memory } \\
\text { Emotional judgment }\end{array}$ & $\begin{array}{l}34 \\
35 \\
42 \\
46 \\
49 \\
51\end{array}$ \\
\hline Chapter 5 & $\begin{array}{l}\text { Purpose of this study } \\
\text { Aim and Hypothesis }\end{array}$ & $\begin{array}{l}54 \\
56\end{array}$ \\
\hline Chapter 6 & $\begin{array}{l}\text { Subjects and Method } \\
\text { Subjects and Location } \\
\text { Ethics } \\
\text { Inclusion and exclusion criteria } \\
\text { Scales } \\
\text { Statistical analysis }\end{array}$ & $\begin{array}{l}58 \\
58 \\
60 \\
62 \\
64 \\
75\end{array}$ \\
\hline Chapter 7 & $\begin{array}{l}\text { Results } \\
\text { General }\end{array}$ & 77 \\
\hline Chapter 8 & $\begin{array}{l}\text { Results } \\
\text { Psychosocial }\end{array}$ & 85 \\
\hline
\end{tabular}




\begin{tabular}{|c|c|c|}
\hline Chapter 9 & $\begin{array}{l}\text { Results } \\
\text { 'Intelligence' }\end{array}$ & 95 \\
\hline Chapter 10 & $\begin{array}{l}\text { Results } \\
\text { Neuropsychological }\end{array}$ & 102 \\
\hline Chapter 11 & $\begin{array}{l}\text { Results } \\
\text { Neuropsychiatric }\end{array}$ & 110 \\
\hline Chapter 12 & $\begin{array}{l}\text { Discussion and limitations of this study } \\
\text { Discussion } \\
\text { Limitations }\end{array}$ & $\begin{array}{l}131 \\
131 \\
144\end{array}$ \\
\hline Chapter 13 & $\begin{array}{l}\text { Conclusions and recommendations for future } \\
\text { research } \\
\text { Conclusions } \\
\text { Future research }\end{array}$ & $\begin{array}{l}148 \\
148 \\
150\end{array}$ \\
\hline Chapter 14 & Reference List & 152 \\
\hline Appendix I & $\begin{array}{l}\text { Information letter and Informed Consent document } \\
\text { English } \\
\text { Afrikaans }\end{array}$ & $\begin{array}{l}186 \\
187 \\
193\end{array}$ \\
\hline
\end{tabular}




\begin{tabular}{|l|l|l|}
\hline Appendix II & Developing 'Amygdala' Tests & 201 \\
& Emotional Memory & 204 \\
& The Aeroplane Accident & 207 \\
& The Ferryman & 212 \\
\hline Appendix III & History of this study & \\
\hline Appendix IV & The Northern Cape & 215 \\
& & 220 \\
\hline
\end{tabular}




\section{Chapter 1}

\section{Introduction}

Lipoid Proteinosis (LiP), also known as Hyalinosis cutis et mucosae or Urbach-Wiethe Disease (UWD), is a rare hereditary disorder. From the time Urbach and Wiethe ${ }^{1}$ gave the first clear description of the disease in 1929 , a cumulative total of only $250^{2}$ to 300 cases $^{3-5}$ have been reported in the literature. This introductory chapter will familiarize the reader with LiP, and give a brief overview of the literature and the rationale for this study. The rest of the dissertation will give a detailed account of the research, explore the findings, acknowledge the limitations and discuss possibilities for future studies.

Lipoid Proteinosis is characterized by depositions of storage material in the skin and mucous membranes (especially the mouth, pharynx and larynx) ${ }^{3 ; 6 ; 7}$. It is a systemic illness ${ }^{6 ; 8}$ and autopsy studies have shown microscopic deposits of hyaline material in practically every organ - even visceral involvement ${ }^{9}$. These lesions may increase in severity and extent with age $\mathrm{e}^{10 ; 11}$ and significant inter-individual variability is present ${ }^{12}$. LiP generally pursues a benign and chronic course ${ }^{13}$, but with functional and cosmetic sequelea. 
The most classical and common symptom is hoarseness of speech often from birth or infancy ${ }^{10}$, caused by lesions on the oral, pharyngeal and laryngeal mucous membranes. However, brain calcifications in the mesial temporal areas can occur in up to $70 \%$ of adults living with $\mathrm{LiP}^{4}$, potentially causing a wide range of neuropsychiatric and neuropsychological symptoms. These bilateral mesial temporal lesions are predominantly symmetrical and circumscribed (often to the amygdala), and are common in $\mathrm{LiP}^{3 ; 8 ; 14 ; 15}$. Although initially these symptoms were downplayed, underreported and under-researched ${ }^{4 ; 11 ; 14 ; 16}$, recently there has been more attention to assessing with standardized measures, these aspects of the disease and what they may teach us about the brain. Unfortunately until now, the research numbers have been small usually less than four subjects and only recently, approaching a dozen subjects ${ }^{12 ; 17}$.

It is not unsurprising considering the rarity of this illness that few have heard of LiP. Chapter 2 therefore describes the illness - it gives up-to-date knowledge regarding the aetiology of this illness, and tracks the possible genetic history as the gene for LiP was presumably brought to South Africa in 1652 by a founder settler and later transferred into the Nama community in the Northern Cape $e^{2 ; 12 ; 18}$. Chapter 2 also looks at the common symptoms and mortality within LiP. It tracks the more recent explorations into the neurological consequences of this rare disease that can cause bilateral, symmetrical and circumscribed damage to the mesial temporal areas, and the suggestion of specific amygdala involvement, potentially causing LiP patients to struggle with emotional recognition for fear.

Chapter 3 reviews the neurological, neuropsychiatric and neuropsychological consequences. It describes how recent studies have emphasized the role of bilateral 
amygdala involvement and how LiP can potentially provide almost experimental conditions of living human subjects with bilateral amygdala calcifications. Chapter 4 briefly explores our current knowledge about the amygdala and related neuropsychological correlates.

In Chapter 5, the purpose of this study is explained. The vast bulk of literature has focused on single case reports or small case series ${ }^{6 ; 8 ; 15 ; 19-23}$, with only a few recent exceptions ${ }^{12 ; 17}$. This study aimed to be the largest clinical study to date, looking at the neuropsychiatry and neuropsychology and quality of life measures in LiP, using standardized instruments.

Chapter 6 explores the subjects and methods of this study. Subjects predominantly came from the impoverished and rural Northern Cape (NC) and from the Johannesburg area. As the NC subjects typically had little education, matched controls were also sought to allow for the confounding factor of education on the neuropsychological instruments. The information sheets and informed consent documents for this study are discussed under an ethics section, and the inclusion, exclusion and withdrawal criteria explained. Standardized measures looking at psychiatric presentation, psychotic symptoms, mood, attention, memory, executive function, language, facial expression recognition and quality of life were described.

The following six chapters (Chapter $7-11$ ) concentrate on the results of this research. The chapters are divided into demographic results, psychosocial results, results of intelligence tests, neuropsychological results, and neuropsychiatric results of the research. In Chapter 12, there is an overall discussion of the results, as well as 
acknowledgement of the limitations of the study. Finally, in Chapter 13 the conclusions are drawn and recommendations for future research are made. The appendices include the Information Letter and Informed Consent document given to and signed by every participant. It also includes the development of some 'amygdala tests'. Finally (the last two appendices), the history of how this research came about and a brief introduction to the Northern Cape, are included. 


\section{Chapter 2}

\section{Lipoid Proteinosis - Epidemiology, Signs and Aetiology}

\section{Introduction}

Lipoid Proteinosis (LiP), also known as Hyalinosis cutis et mucosae or Urbach-Wiethe Disease (UWD), is a rare hereditary disorder. LiP is transmitted by an autosomal recessive gene ${ }^{2 ; 24 ; 25}$ and affects the sexes equally ${ }^{3 ; 10 ; 26}$. It is a systemic illness $s^{8 ; 9}$, characterized by depositions of storage material (an amorphous hyaline material) in the mucous membranes and $\mathrm{skin}^{3 ; 7 ; 27}$, and autopsy studies have shown microscopic deposits of hyaline material in practically every $\operatorname{organ}^{9 ; 13 ; 28 ; 29}$. The lesions may increase in severity and extent with age ${ }^{10 ; 11}$ and vary in number, location, severity and presentation between individuals ${ }^{11 ; 12}$.

\section{Epidemiology}

From the time Urbach and Wiethe ${ }^{1}$ gave the first clear description of the disease in 1929, a cumulative total of $250^{2}$ to 300 cases $^{3-5 ; 30}$ have been reported in the literature. Since the early 1970 s it has been recognized that South Africa has one of the largest groups of LiP worldwide ${ }^{6 ; 31}$, where approximately one $\operatorname{third}^{32}$ of these patients are thought to live. 


\section{Lipoid Proteinosis in South Africa}

South Africa has the highest prevalence of LiP in the world. A probable founder effect has been strongly suggested, and this was supported by Van Hougenhouck-Tulleken et al ${ }^{12}$ molecular evidence of genetic homozygosity. It is possible that the affected individuals are descendants of two original (related) colonists $^{33}$. It is widely believed that a German settler, Jakobus Cloete, and his sister, Else - some sources say his daughter $^{34}$ - who arrived in the Cape in 1652 and who were among the original white settlers - may have been responsible for bringing the gene for LiP into the country $6 ; 16 ; 31 ; 34$. The combination of founder effect and genetic drift - small number of early immigrants, unusually large families for several generations - helps to explain the high prevalence of LiP in South Africa in the immigrant-descended populations ${ }^{31}$.

Patients with LiP are known predominantly to have European ancestry ${ }^{5}$. Initially, LiP was considered a disease of "white South Africans" and by 1971 between 40 and 50 people were thought to have it although "four were Cape 'coloured' women" ${ }^{34}$. Stine and Smith ${ }^{33}$ note a decreasing frequency of the incidence of LiP in the white Afrikaner South African population. Affected individuals produced $20 \%$ fewer offspring than did an average individual in that population, and a "natural selection" was suggested (i.e. people with the illness marrying less, or having fewer children.).

\section{Lipoid Proteinosis in the Northern Cape}

As noted previously, the incidence of LiP in the white population appeared to decrease with each generation ${ }^{33}$. In approximately 1790 , it is speculated that someone of 
European origin (possibly a Jasper Cloete) married a local Nama inhabitant ${ }^{2 ; 12}$ in Namaqualand (Northern Cape, South Africa), and the gene was transferred to the group "now known as the Coloureds" ${ }^{18}$. Indeed, due to the concentration of LiP in the Northern Cape's Namaqualand, the condition was once referred to as "Upington Disease" - Upington being the largest town in the area ${ }^{32}$. By 2004, a LiP carrier rate of 1 in 9 was found in 100 Namaqualand (Northern Cape) controls, predicting a LiP incidence of 1 in 324 in this community ${ }^{12}$.

Despite the relatively higher incidence of LiP in South Africa, it has only been in the last several years that larger cohorts of the South African populations have been extensively investigated.

\section{Signs}

\section{Hoarseness and Dysphonia}

Often the first clinical sign, and the most striking and common symptom in LiP is hoarseness of speech and weakness of phonation ${ }^{10 ; 13 ; 35}$ resulting from lesions on the oral, pharyngeal and laryngeal mucous membranes. In two thirds of the cases, the voice changes are present at birth or early infancy ${ }^{10 ; 27 ; 36}$.

The intracellular deposition of an amorphous hyaline material involves the mucous membranes of the upper aerodigestive tract (especially the mouth, pharynx and larynx $)^{3 ; 6 ; 7}$. There are consistent clinical features of a thickened sublingual frenulum leading to restricted tongue movement ${ }^{12}$ and possibly poor dental hygiene ${ }^{24 ; 27}$. If hyaline-deposits are found in the salivary glands, then patients may have poor salivation $(\text { xerostomia })^{37}$. 


\section{Dermatological signs}

The other main clinical pathological feature comprises skin infiltration, with scarring on the hyaline material ${ }^{35}$. Characteristically, patients with LiP develop yellowish-white infiltrated papules, plaques and moduli in the skin $^{13}$. During childhood, the skin may be easily damaged by minor trauma or friction, resulting in blisters and varicelliform scar formation ${ }^{24}$. It typically presents with popular, verrucous, pox-like or acneiform scars, and warty skin infiltrations ${ }^{12 ; 38}$, and new research have emerged, showing a role for the ECM1 in skin physiology and homeostasis ${ }^{39}$.

Skin presentations can present in many ways - in some patients, the skin lesions may be sufficiently inconspicuous, and so as to be overlooked ${ }^{11}$. For others, the eye lids only may be affected ${ }^{40}$. However, they may also cover the face, forearms and lower legs, and be extensive and cosmetically disfiguring, especially if there is atrophic scarring (possibly with skin inflammation $)^{13}$. There may be hyperkeratosis of the cutis especially the elbows or knees or photosensitivity ${ }^{41}$. When skin lesions affect the scalp it usually leads to the loss of hair ${ }^{3}$.

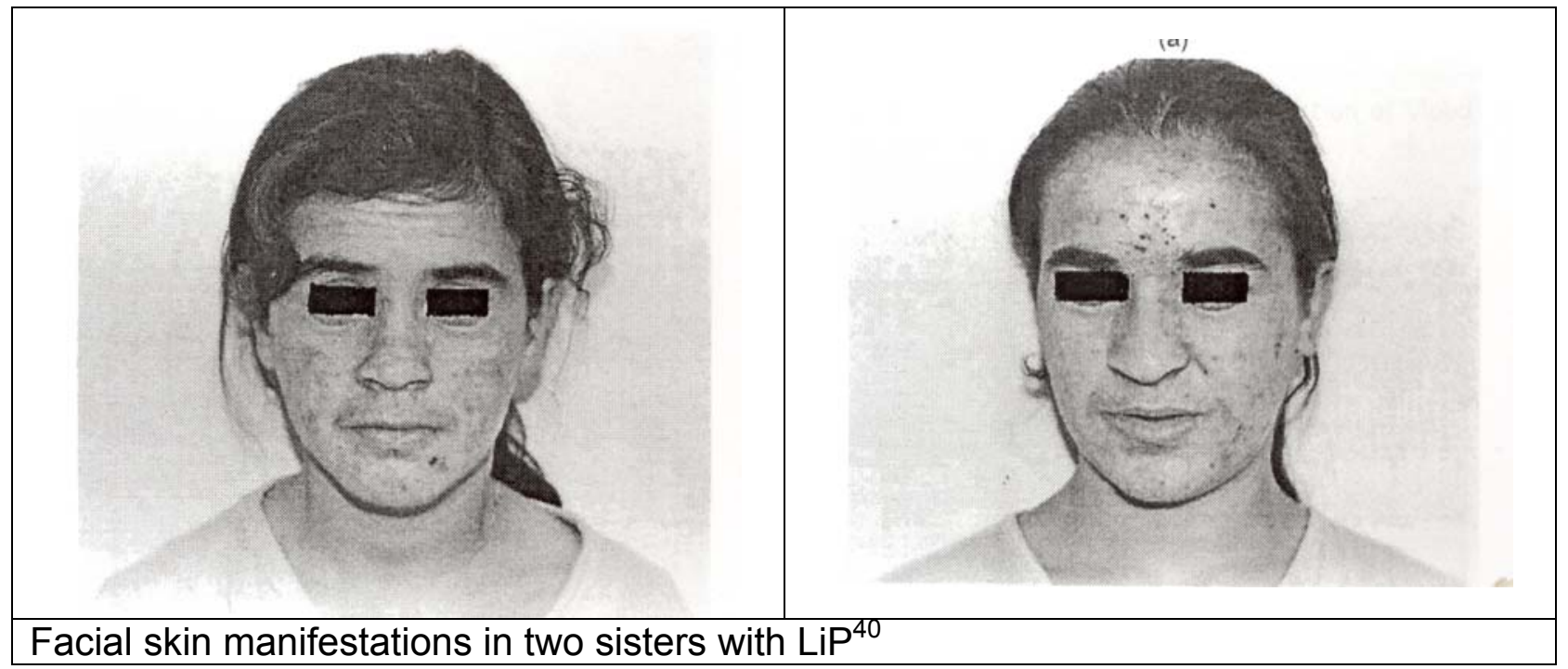




\section{Intracranial calcifications}

Lastly, there may typically be "bean-shaped" calcification (mineralization) in the region of the anteromesial temporal lobes ${ }^{15}$. The term "calcification" is generally used to describe the LiP-associated lesions. The first LiP autopsy established that the endocranial calcifications were deposits of calcium ${ }^{42}$. However, they have also been described as "ossifications". Özbek et $\mathrm{al}^{43}$ used high resolution computer tomography (HRCT) to examine two patients with LiP with symmetrical intracerebral calcifications. With HRCT, a bony texture to the lesions was suggested.

The first mention of bilateral intracranial calcifications in LiP was the article by Ramos e Silva ${ }^{44}$ in 1943 , who noted calcifications in the folds of dura mater. Cranial calcifications were also noted in the falx cerebri, the tentorium ${ }^{45}$, and the hippocampal gyri ${ }^{46 ; 47}$, and endocranial calcifications were found on the first known autopsy done on a person with $\mathrm{LiP}^{42}$. Caplan in $1962^{48}$ and MacKinnon in $1965^{49}$ were of the first to specify temporal involvement in LiP. When Newton et $\mathrm{al}^{8}$ reviewed the literature in 1971 , as many as 26 $(17 \%)$ of the 150 reported cases of LiP had mentioned intracranial calcification in LiP.

By the 1970s, new researchers emphasized that neurological signs and symptoms should be seen as an integral part of the syndrome. Authors concurred that half or more of the LiP population was affected with bilateral, circumscribed and symmetrical calcifications in the medial temporal regions $s^{6 ; 10 ; 14 ; 15}$. There were also been suggestions that there may be progressive neurological involvement. Van Rooy, Swart and Pietrzak $^{16}$ described four South African cases of LiP half of whom had intracranial calcification, and wondered whether or not the other two would later develop the brain 
calcifications. Aroni et $\mathrm{al}^{3}$ considered that "at least $70 \%$ " of patients with LiP older than 10 years of age would have intracranial calcification, implying some sort of later onset for neurologic signs.

Bilateral mesial temporal calcification is common in $\mathrm{LiP}^{3 ; 8 ; 14 ; 15}$ and is associated with neuropsychiatric sequelea including seizure disorder ${ }^{8 ; 14 ; 4}$, and psychotic symptoms ${ }^{5 ; 6 ; 50}$. Mental retardation, ataxia ${ }^{41}$ and dystonia ${ }^{38 ; 51}$ have also been noted to occur.

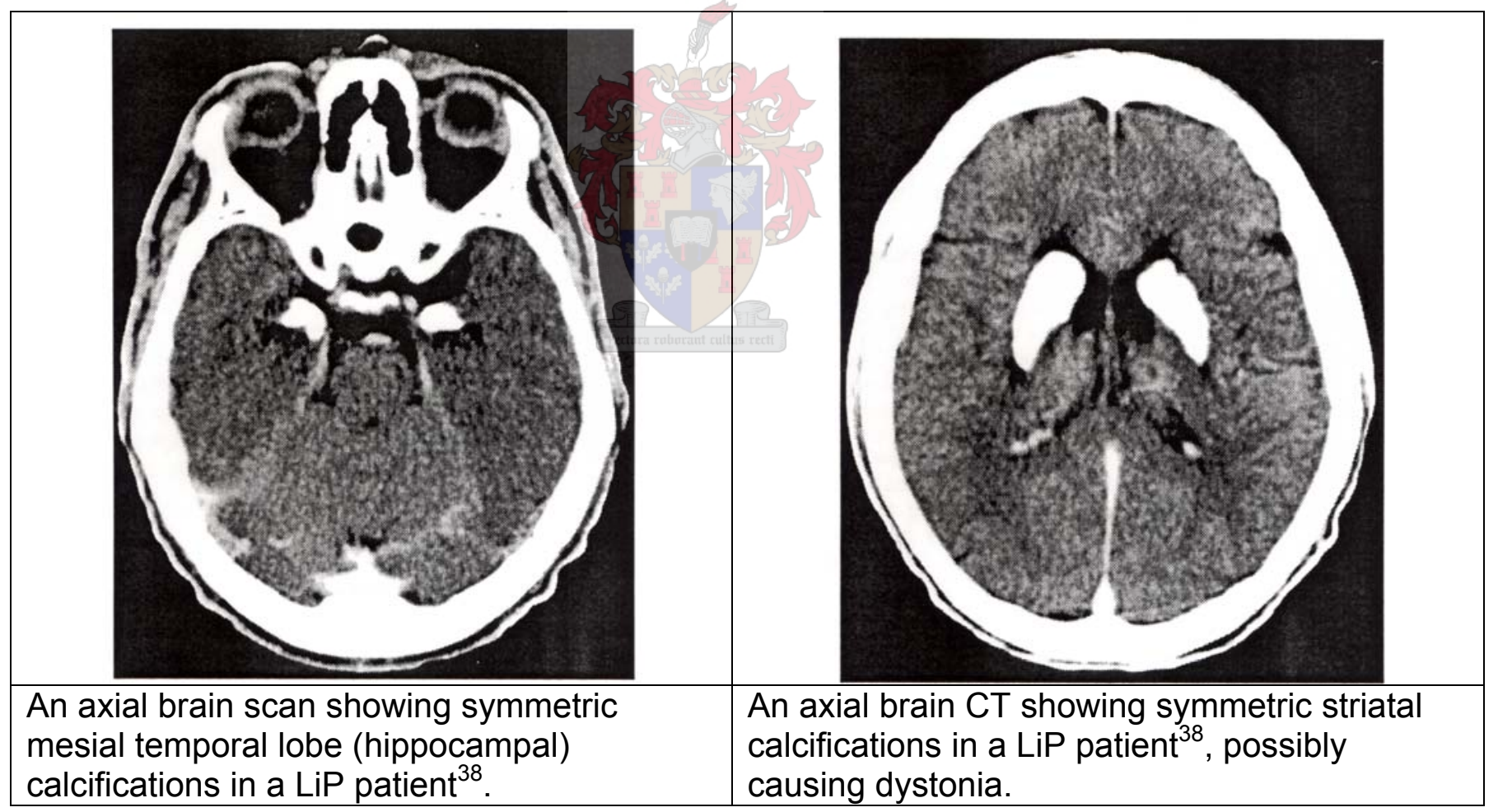




\section{Diagnosis}

Diagnosis has historically been based on clinical evidence and history. The most consistent clinical features for a diagnosis of LiP have been a hoarse voice and a thickened sublingual frenulum leading to restricted tongue movement ${ }^{12}$. Since 2002 the genetic variations response for LiP can be tested for ${ }^{2}$.

Lipoid proteinosis may show protean clinical features and yet remain undiagnosed for many years ${ }^{35}$. Typically, LiP presents with infantile hoarseness ${ }^{27}$ and in at least twothirds of cases voice changes are present at birth or early infancy. However hoarseness and other LiP symptoms may first present in later childhood ${ }^{52}$, puberty ${ }^{53}$, adulthood ${ }^{37}$, or not at all.

\section{Clinical variability}

Van Hougenhouck-Tulleken et $\mathrm{al}^{12}$ observed several consistent clinical features in the LiP patients homozygous for the Q276X mutation in the ECM1 gene. Despite gene homozygosity, they also found considerable clinical variability amongst LiP subjects. The researchers suggested that the actions of genetic and environmental modifiers affect disease severity.

\section{Mortality}

Lipoid proteinosis is compatible with long life ${ }^{13 ; 54}$. However, laryngeal changes - for instance significant laryngeal thickening - may occasionally cause life-threatening symptoms ${ }^{10 ; 43}$ by impeding ventilation or cause asphyxia. In such cases, LiP patients may require a tracheotomy ${ }^{2 ; 3}$ or endolaryngeal intubations and laryngotomy ${ }^{37}$. 


\section{Aetiology}

\section{Genetics}

Hofer's 1973 study of 27 patients $^{10}$ (Sweden) was one of the largest cohorts of LiP

patients ever studied. Parent consanguinity has been relatively common ${ }^{26 ; 28}$ and Rahalkar et $a^{55}$ suggested a $20 \%$ incidence of reported consanguinity. Hofer's hypothesis that LiP was transmitted by an autosomal recessive gene was supported by other authors ${ }^{13}$. It was only recently that LiP was confirmed as an autosomal recessive disorder when Hamada et $\mathrm{al}^{2}$ identified the extracellular matrix protein 1 gene (ECM1) responsible. Hamada et $\mathrm{al}^{2}$ had access to 31 affected individuals, 22 of whom came from the Northern Cape in South Africa.

The extracellular matrix protein 1 (ECM1) was first identified in 1994 as an $85-k D a$ glycoprotein secreted by a mouse osteogenic stromal cell line, and has been found to regulate endochondral bone formation, and to stimulate proliferation of endothelial cells and induce angiogenesis ${ }^{39}$. In 2002, loss-of-function mutations in the ECM1 gene were discovered to be the cause of this rare autosomal recessive genodermatosis, LiP. Large clinical studies suggest homozygosity for a nonsense mutation in exon 7 of the ECM1 gene, Q276X. Van Hougenhouck-Tulleken et al ${ }^{12}$ identified the Q276X gene in all of the 36 South African LiP subjects (both Coloured and Caucasoid) that they examined. Van Hougenhouck-Tulleken et $\mathrm{al}^{12}$ also examined 100 Namaqualand controls, and predicted an incidence of LiP of 1 in 324 in this Northern Cape community. Now that the gene has been identified there are many benefits to be explored; the provision of more detailed information for patients, more accurate diagnoses, improved genetic counseling, carrierscreening, DNA-based prenatal testing, and a platform for the development of new treatments, including somatic gene therapy ${ }^{56}$. 


\section{Chapter 3}

\section{Literature Review}

\section{Early literature}

Early literature on LiP tended to concentrate on the striking dystonia and dermatological signs. There was clear evidence for genetic involvement and from the start, geneticists tracked the illness across the generations, giving prediction of the autosomal nature of the disease decades before the gene was identified, and identifying individuals and families who may be carriers. However in the early literature, neuropsychiatric presentations were not generally acknowledged or emphasized, despite the documented presence of intracranial calcifications and epilepsy.

\section{Absence of neuropsychiatric and neuropsychological signs in the literature}

The LiP literature has made only sporadic referral to the neuropsychiatric symptomatology ${ }^{13 ; 14 ; 1 ; 57}$. In fact, the first LiP-related literature tended to downplay the importance or relevance of neurological features. Feiler-Ofrey et $\mathrm{al}^{11} \mathrm{did}$ an extensive clinical assessment of 10 patients with LiP (from one pedigree) with no mention of neuropsychiatric symptoms, but commented that the disease is systemic and "may involve other viscera and even the central nervous system". Hofer's study of 27 patients in 14 families with $\mathrm{LiP}^{10}$ found the intracranial, calcifications "were not present in any of 
the patients in the present series that were examined in that respect". He reported that one of his 27 subjects had Down's Syndrome. Although he made a reference that the "parasellar, intracerebral calcifications may be associated with epilepsy", he did not report it in any of his patient cohort and there was no further detail or reference to any neurological or radiological examinations. No structured neuropsychiatric instruments were used. Van Rooy, Swart and Pietrzak ${ }^{16}$ described two South African cases of LiP with hippocampal calcification, but the subjects were not considered to have any neuropsychiatric / neuropsychological symptoms and were therefore not assessed in this regard. Botha ${ }^{4}$ agreed that up to $70 \%$ of LiP individuals had been reported to have intracranial calcifications, but suggested these were "asymptomatic".

\section{Small numbers and methodological problems}

In addition to the under emphasis of neuropsychiatric symptoms, most LiP studies have been based on small numbers - partly due to the rarity of the condition. There were rare case presentations $s^{6 ; 51}$ and anecdotal reports ${ }^{8}$ of LiP patients suffering neuropsychiatric symptoms. Some of these LiP patients who were identified, were comprehensively investigated and resulted in many publications, and were partly responsible for early understandings of the amygdala ${ }^{15 ; 19 ; 20 ; 21 ; 58-60}$. For example, Patient SM was extensively assessed $^{19 ; 20 ; 21}$, as was the patient described by Tranel and Hyman ${ }^{15}$, and the two LiP patients by Markowitsch et $\mathrm{al}^{22}$ and Von Cramon et $\mathrm{al}^{23}$. A small number of articles have gone on to detail neurological and neuropsychiatric symptoms in LiP. Unfortunately, many papers have been written on the same few LiP patients available to researchers, potentially with the result that those subjects became over-familiarized with the tests (practice effect). It is only in the last few years that studies have reached up to a dozen participants ${ }^{12 ; 17}$ and for the first time, begun to use controlled studies. Publications 
began to emphasize neurological and neuropsychiatric features (seizures, psychosis, mental retardation), but with relatively minimal formal neuropsychiatric and neuropsychological assessment of the consequences of this illness.

\section{Variability}

It should be recognized that there is significant variability in neuropsychiatric and neuropsychological findings in LiP across subjects. Thus in some findings there is no evidence of psychiatric symptomatology $y^{4 ; 16}$ or evidence of intact intellect ${ }^{8 ; 15 ; 16 ; 43}$. While some of this variation may be explicable on the basis of methodological problems (e.g. different methods of assessing symptomatology, different ages and education levels and languages.), it is likely that there is true heterogeneity in the LiP population.

\section{Psychiatric signs}

The more recent literature has begun to emphasize the neuropsychiatric signs that are prevalent in LiP. These have included descriptions of epilepsy, psychosis, paranoia, rage attacks, depression, anxiety, panic attacks, personality disorders and social disdecorum.

\section{Epilepsy}

Seizure disorder ${ }^{8 ; 14 ; 7}$ is common in LiP. Possible ictal-associated neuropsychiatric symptoms have also been noted; Newton et al $^{8}$ assessed two LiP cases with seizure and rage attacks. One patient felt fearful and anxious during seizure. Epilepsy and personality disorders have been reported in some South African individuals affected with $\mathrm{LiP}^{14}$. 


\section{Psychotic and paranoid symptoms}

Lipoid proteinosis's neurological symptoms may include paranoid behaviour similar to schizophrenia ${ }^{5}$. Emsley and Paster ${ }^{6}$ wrote of two patients with LiP with bilateral medial temporal lobe calcification. Both presented with paranoid symptoms phenomenologicaliy similar to schizophrenia, and had a long-standing history of memory impairment (out of proportion to their intelligence). Emsley and Paster hypothesized that the paranoia may possibly be understood in psychodynamic terms and as a psychological reaction to disfigurement and memory impairment. This is consistent with other literature, which emphasizes the psychosocial impact of the illness ${ }^{33}$. Alternatively, Emsley and Paster ${ }^{6}$ suggested that the paranoia may be due to the patients' intracranial pathology and Salloway et $\mathrm{al}^{61}$ suggested a possible Dysfunctional Limbic Syndrome - based anatomically with the lateral orbitofrontal cortex, the lateral orbitofrontal circuit, the medial orbitofrontal cortex and the limbic system - may explain the symptoms of psychosis, anxiety and panic, and social disdecorum $^{61}$.

Kleinert et $\mathrm{al}^{41}$ assessed a person who presented with paranoid hallucinatory phenomena, paroxysmal rage attacks, depression, and progressive ataxia and paraperesis. A scan showed diffuse bilateral hypodensity of the white matter. Although at first a diagnosis of multiple sclerosis was entertained, this was changed to LiP when the patient later presented with swelling of the tongue and hoarseness, and dermatological signs of LiP. Autopsy results revealed no calcifications but a symmetrical oedema and an old infarction in the pons. 


\section{Depression and suicidality}

Van Rooy, Swart and Pietrzak ${ }^{16}$ stated that depression was frequent and that in patients with LiP, there was an increased risk for suicide. However, no references were provided. Few studies ${ }^{23}$ have mentioned the presence of depression in LiP.

\section{Quality of life}

In an unpublished study, Steenkamp ${ }^{50}$ assessed seven LiP patients, using personality tests (16-PF, IPAT, the Emotional Profile Index or EPI, PHSF Relationship questionnaire) and projective measures (Rotter uncompleted sentences, Thematic Apperception Test or TAT). Correlations between increased severity of the illness and people's increased anxiety, lowered self-esteem, and decreased social interactions were strongly suggested, and therapy for the patients and their parents recommended.

In the largest cohort of LiP patients ever to have been hitherto assessed, Van Hougenhouck-Tulleken et al ${ }^{12}$ examined 36 South African LiP patients. Of these, 8 people completed the Impact of Epilepsy Scale (IES) adapted to being the Impact of Lipoid Proteinosis Scale. The maximum score is 40 (if the LiP affects them a lot) and the minimum score is 8 (if the LiP has no affect at all). The mean score was 15 on this scale. Unemployment and low levels of education were pervasive. These were the first articles to mention the conditions and quality of life measures for subgroups of LiP people. 


\section{Neuropsychological signs}

Besides the neuropsychiatric presentations that have been recorded, cognitive and neuropsychological signs have also been noted. Once again there is marked variability, but some LiP studies have found mental retardation, memory deficits, executive falloff and deficits with cognitive-affective processes.

\section{Mental retardation}

Mental retardation in LiP has been noted ${ }^{13 ; 14 ; 38 ; 62 ; 63}$, but contradictory findings have also been found. Often patients are assessed to have intact intelligence $8 ; 15 ; 16 ; 41 ; 43$, and Siebert, Markowitsch and Bartel ${ }^{17}$ found little cognitive deviation from normal subjects ( $n=10$ LiP patients).

\section{Memory deficits and hippocampal involvement}

In 1953 - at a time when little was known of the relationship between the temporal lobes and memory - Patient H.M. underwent bilateral removal of parts of his anterior medial temporal lobes in an attempt to control his epileptic seizures ${ }^{64 ; 65}$. Twenty-seven years old at the time of the surgery, H.M. lost the capacity to remember any new information (anterograde amnesia) and lost the last 11 years of memories of his life (retrograde amnesia). By his seventh decade, H.M. "remains as it were, a teenager, although his intelligence in other areas [was] largely unimpaired. It is as though time stopped for H.M. around the age of 16 years, and [he lived] in a timeless vacuum, interacting intelligently minute by minute with whatever stimuli impinged directly upon him" ${ }^{65}$. Although the role of the medial temporal lobes (particularly the hippocampus and adjacent cortical structures) for the encoding and storage of new explicit information has 
been confirmed by case studies on patients like H.M., it still remains partially unclear $^{51 ; 66-70}$. It is highly probable that focal diencephalic damage (especially bilateral hippocampal damage) may result in profound anterograde and selective retrograde amnesia, especially with respect to data-based material, and that disconnecting portions of the medial and basolateral limbic circuits has devastating consequences on memory $^{22 ; 71}$.

In LiP, hippocampal calcification has been noted at times ${ }^{6 ; 8 ; 15 ; 16}$. Memory deficits have been reported in LiP and in 1997, Ghika-Schmid et al ${ }^{51}$ reported a sudden transient amnestic syndrome associated with bilateral haemorrhage of the hippocampi, probably due to Urbach-Wiethe disease. When this resolved, significant bilateral hippocampal structural damage remained evident, but there was only a mild degree of amnesia. Teive et $\mathrm{al}^{38}$ reported a 24-year-old man with LiP with bilateral symmetrical hippocampal and striatal calcifications. He was known with mental retardation and the researchers thus concluded that formal memory testing did not comply.

In 1997, a 62-year-old patient thought to have LiP presented with a sudden transient amnestic syndrome associated with bilateral hemorrhage of the hippocampi ${ }^{51}$. He was extensively neuropsychologically assessed on several different occasions, including tests of language (Boston Naming Test), concentration (Digit Span), memory (Wechsler Memory Scale), executive tests (fluency tasks, Wisconsin Card-Sorting Test, Stroop test, Rey-Osterreith Complex Figure), intelligence tests (Ravens) and emotional recognition tests. The patient's results were generally in the defective range. In auditory recognition, all emotional categories except fear could be recognized by the patient. Visually, surprise and contempt were misrecognized. Although this subject had bilateral 
hippocampal damage, the in/ability to recognize fear is more commonly associated with bilateral amygdala damage ${ }^{19,20}$.

\section{Recognition of fear, emotional memory and amygdala damage}

In LiP, bilateral calcifications are reported to occur throughout the medial temporal lobes - but often amygdala calcifications have been emphasized and confirmed with neuroimaging ${ }^{8}$. Patients with LiP with bilateral amygdala damage have been reported to have decreased ability to recognize the emotion of fear ${ }^{19 ; 58}$, difficulty with emotionallyloaded memory ${ }^{72 ; 73}$, and impaired executive control over social behaviour ${ }^{15}$.

Newton et $\mathrm{al}^{8}$ assessed two patients with LiP, both of whom had seizures and one of whom had "rage attacks". These, Newton and colleagues speculated, were due to the patients' bilateral amygdaloid calcifications. Patient SM had LiP and had bilateral calcification confined to the amygdala ${ }^{19 ; 58}$. She was unable to identify the emotion of fear in pictures of human faces and could not draw a fearful face, even though other emotions such as happiness, sadness, anger, and disgust were identified and drawn within the normal range. Neither did she have difficulty identifying the names of familiar

faces. In addition, two other LiP patients ${ }^{72 ; 73}$ did not show any enhancement of recall of emotional material.

Markowitsch et $\mathrm{al}^{22 ; 72}$ assessed a brother (B.P.) and sister (C.P.) with LiP, both of whom had circumscribed bilateral symmetrical damage to the amygdaloid region. In addition there was decreased glucose metabolism at the cingular and thalamic levels. The two patients were tested by a German-form of the Riversmead Behavioural Memory Test, the Famous Events Questionnaire, recall of the Rey-Osterreith Figure, and the 
Weschler Memory Scale-Revised. Both patients showed selective memory deficits and one of the patients had marked affective-emotional fluctuations ${ }^{23}$. The Wisconsin Card Sorting Test, and the Tower of Hanoi were used to assess cognitive flexibility, and both patients were in the normal range. Both patients were given two personality questionnaires and C.P. (but not B.P.) showed heightened agitability, irritability, and a tendency towards depression.

In 1990, Tranel and Hyman published an article on an extensive neuropsychological investigation of a patient with LiP with bilateral amygdala damage ${ }^{15}$. The hippocampalamygdala transition area also had microscopic deposition of calcium, with structural abnormality (as opposed to complete ablation). The patient was a 23-year-old woman with normal intellect and language function. However there were significant defects in nonverbal visual memory, in social behaviour, and in "executive control" functions (e.g. self-monitoring, social judgment).

The LiP subjects of Adolphs et al ${ }^{21}$ and Calder and Young ${ }^{74}$ showed significant impairment in recognizing fear although individual performances ranged from severely impaired to essentially normal. In addition, while most subjects were impaired on several negative emotions in addition to fear, no subject was impaired in recognizing happy expressions.

In an article published in 2003, Siebert, Markowitsch and Bartel, assessed $10 \mathrm{LiP}$ subjects ${ }^{17}$. Compared to controls, the subjects differed emotionally - evident in their judgment of all emotions of facial expressions, and in an odour-figure association test as well as in remembering negative and positive pictures. SPECT and PET confirmed 
principal bilateral symmetrical damage in the amygdaloid region in more than half of the subjects, lending credibility that LiP subjects can be used to gain information about the amygdala and may represent a platform to study the effects of bilateral amygdala damage in living humans.

In conclusion, although there is true heterogeneity within the LiP population, which may represent a variable and slowly progressive degenerative process in the brain, some of the variation across the studies may be explicable on the basis of relatively small sample sizes and other methodological problems (e.g. different methods of assessing symptomatology). 


\section{Chapter 4}

\section{The Amygdala}

This chapter focuses on our current knowledge about the amygdala and related neuropsychological correlates. The amygdala is a small structure, located deep in the anterior part of the temporal lobe ${ }^{75}$, consisting of a number of nuclei with differing input and output pathways.

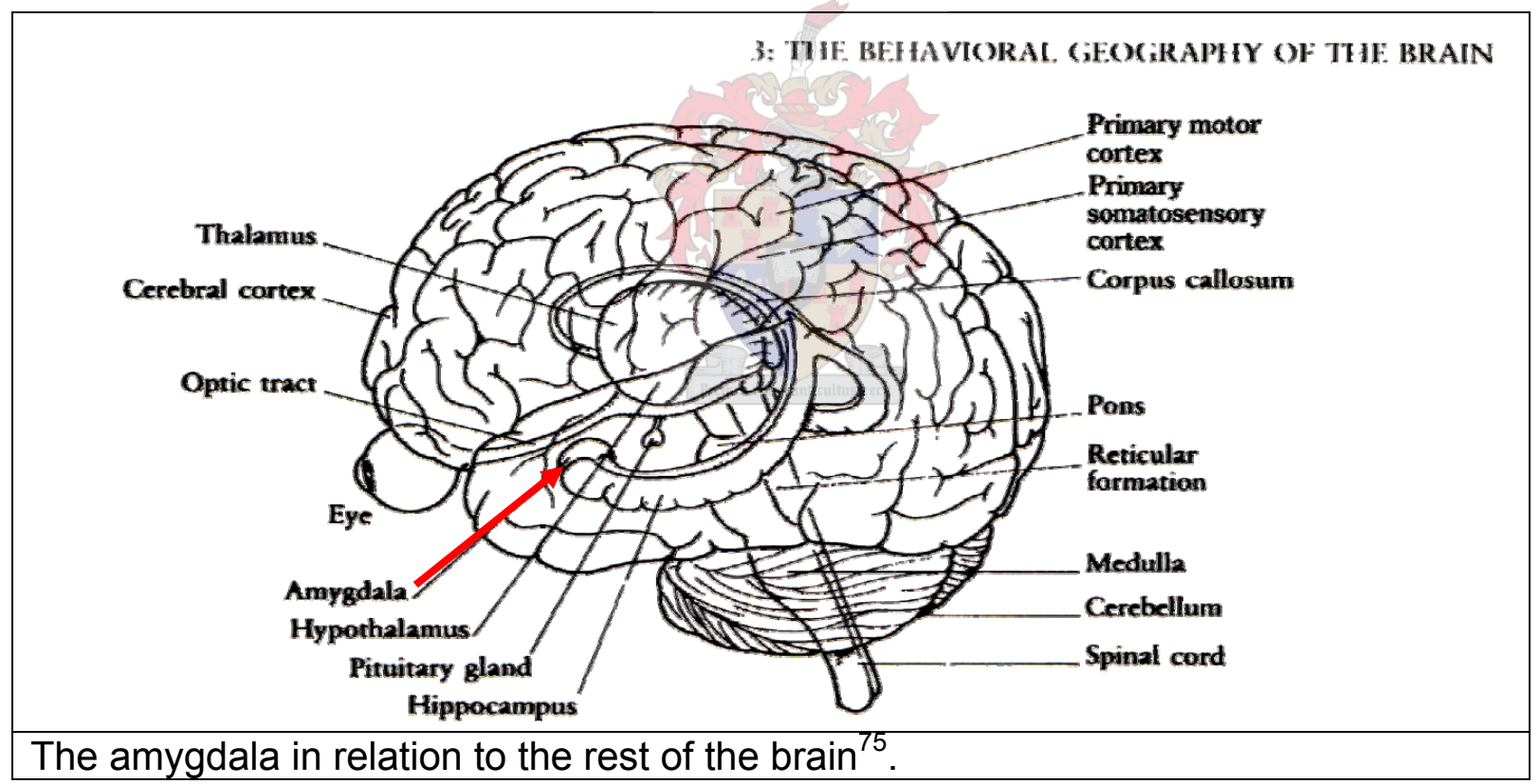

In the last decade research on the amygdala has more than doubled ${ }^{78}$. New techniques in brain imaging and the convergence of findings from primate (including human) and rodent studies have made it possible to speculate on the role of the amygdala in living 
humans and possibly on conditions (e.g. schizophrenia) which can affect emotional and social behaviour.

Unsurprisingly the complex anatomical underpinnings of the amygdalar complex have resulted in diverse models of amygdalar function ${ }^{76}$. Traditionally, most of our knowledge about the functioning of the amygdala has come from animal studies ${ }^{76-79}$.

\section{Animal studies}

In 1939 Klüver and Bucy ${ }^{80}$ described monkeys that had undergone bilateral temporal lobectomies. The monkeys had a striking absence of emotional reactions normally associated with stimuli or conditions eliciting fear or anger. The authors referred to this complete loss of fear and anger as "psychic blindness". There were also profound changes in social behaviour and increased sexual (both heterosexual and homosexual) behaviour.

Changes in the emotional and social behaviour of monkeys with amygdaloid lesions were often interpreted as due to a loss of the ability to evaluate environmental stimuli as potential threats. However this conclusion has recently been challenged. Amaral et al ${ }^{81}$ re-investigated the relationship between amygdala lesions and social behaviour in rhesus monkeys and found normal - sometimes even increased - social interactions. While they agreed that the amygdala did have a role in modulating the amount of social behaviour in which an organism will participate, they argued against the belief that the amygdala was an essential component of the neural network for social cognition. In another study, Prather, Lavenex and Mauldin-Joudain ${ }^{82}$ found that neonatal amygdala 
lesions in macaque monkeys dissociated a system that mediated social fear from one that mediated fear of inanimate objects, and that much of the age-appropriate social repertoire of social behaviour remained present. They also argued that amygdala lesions early in development have different effects on social behaviour than lesions produced in adulthood.

\section{Conditioning}

Classical conditioning - the simplest form of associative learning - is one of the most studied paradigms in behavioral psychology ${ }^{83}$. Lesion studies have been used to identify some of the anatomical structures involved in classical conditioning. In fearconditioning, the unconditioned stimulus (US) is aversive and the behavioural response is measured in terms of a dependent variable, such as autonomic responses.

Results from animal studies strongly suggest that different types of fear-conditioned behaviour are mediated by separate nuclei within the amygdala, and that the anxiogenic systems in the various nuclei may be differentially involved ${ }^{84}$. The basolateral complex $(B L)$ of the amygdala seems to be significant for linking objects with current stimulusvalue, and the behaviours and goal-directed actions associated with the value ${ }^{85}$ - e.g. a reduction in the value of a food reward reduced conditioned responses to conditioned stimuli. However, there was no reduction of response with reduction of award if there were neurotoxic lesions to the basolateral amygdala (and no such reduction if the lesions were in the central amygdala) ${ }^{86 ; 87}$. Some rat and monkey studies have indicated that the absence of stimulus value associations weakens or eliminates the ability of stimuli that are paired with reward, to support new association learning ${ }^{88-92}$. Infusion of the protein synthesis inhibitor anisomycin into the lateral and basal nuclei of the 
amygdala shortly after training, prevents consolidation of fear memories. Nader, Schafe and Le Doux ${ }^{93}$ found that consolidated fear memories when reactivated, returned to a labile state which required de novo protein analysis for reconsolidation. However, not all studies have been consistent. In some rat studies it was also evident that even after removal of the basolateral amygdala, rats were able to maintain a preoperative association of a reward value ${ }^{94}$.

The central nucleus of the amygdala (CE) on the other hand, has been linked with Pavlovian approach and avoidance in response to specific conditioned stimuli ${ }^{95 ; 96}$. In rat studies, removal of the central nucleus has abolished selective conditioned orienting ${ }^{97}$ and may suggest that certain stimulus-reward learning operates through modulation of nigrostriatal dopamine projections by the central nucleus of the amygdala ${ }^{80}$.

Notably, Pavlovian behaviours were not affected with lesions to the basolateral nucleus of the rat amygdala ${ }^{9599 ; 100}$. In another rat study, it was suggested that the central and medial nuclei of the amygdala may be important parts of neural circuits mediating conditioned responses that constitute conditioned aversive states but that conditioned freezing may be mediated independently ${ }^{101}$.

Extinction is different from forgetting and does not equate to an erasure of the original fear memory. Rather it is an active form of inhibitory learning that competes with excitatory fear conditioning. One form of extinction is a process in which stimuli that elicit fear (excitatory fear conditioning) are then presented in the absence of the aversive stimuli (extinction training). (As a result, the ability of the conditioned stimulus to elicit fear gradually diminishes.) In a NMDA ( $N$ methyl $D$ aspartate) glutamate 
receptor-linked study, Davis, Walker and Myers ${ }^{102}$ found that the neural basis for inhibitory conditioning was probably amygdala- and not hippocampus-based. The amygdala AMPA ( $\alpha$-amino-3-hydroxy-5-methylisoxazole-4-propionic acid) and NMDA receptors have both been implicated in playing a role in fear learning and fear extinction training, and possibly may play a significant role in novel pharmacological approaches to the treatment of clinical anxiety disorders ${ }^{103}$.

In a recent attempt to provide a more unified model of amygdalar associative functions, Gabriel, Burhans and Kashef ${ }^{76}$ tentatively tried to integrate the information from studies of appetitive conditioning with conclusions from studies of other forms of associative learning, including Pavlovian fear conditioning and instrumental conditioning. They speculated that typical aversive and appetitive associations were coded differently in the brain. Everitt et $\mathrm{al}^{104}$ also conducted a review of the literature and concluded that research had consistently demonstrated double dissociations of function between the basolateral area and the central nucleus of the amygdala. In addition, they hypothesized that the basolateral amygdala was required for a conditioned stimulus to gain access to the current affective value of its specific unconditioned stimulus, whereas the central nucleus mediated stimulus-response representations and conditioned motivational influences on behaviour. They argued that emotional behaviour could be seen as a coordinated combination of processing by these amygdaloid subnuclei.

They suggested that the central (CE) nucleus may contribute to discriminative avoidance learning primarily by articulating with areas such as the ventral tegmentum, ventral striatum, and cholinergic basal forebrain nuclei. They postulated the CE nucleus mediated the rapid, early acquisition of Pavlovian conditioned responses, possibly also 
involving indirect CE modulation of the cingulate via the ventral tegmentum. In contrast, the basal and lateral (LA) amygdalar nuclei would appear to articulate primarily with sensory and cinguothalamic areas, to promote the development of early and late discriminative activity. The basolateral (BL) and the LA amygdalar nuclei may also support instrumental avoidance learning, and they may participate in the maintenance of the conditioned stimulus affective value.

Double dissociation of the BL amygdala and the CE nucleus of the amygdala, has been demonstrated in animal studies, with each involved in mediating different types of fearrelated behaviour in a conditioned punishment procedure ${ }^{91}$. It is thought that the central nucleus of the amygdala was involved in forming its own stimulus-value associations, which are provided by the basolateral amygdala ${ }^{94 ; 96}$. Functional magnetic resonance imaging (fMRI) strongly suggests the role of the amygdala in classical fear conditioning in humans as well ${ }^{83}$.

Functional neuroimaging techniques, such as $\mathrm{fMRI}$ and positon emission tomography (PET) provide non-invasive measures to study the human amygdala in vivo. Dolan ${ }^{105}$ summarized functional neuroimaging studies during the perception of fear and fearrelated learning. Dolan concluded that activation of the amygdala did not depend on conscious awareness of a fear-eliciting stimulus. In addition, during fear learning (using classical Pavlovian conditioning), the amygdala's role would seem to be time limited. This may be related to the need for the conditioned stimulus and the aversive event to be in close temporal contiguity. 
The sophistication of animal study models (e.g. macaque monkey and the rat) has revealed much about the complex functioning and connectivity of the amygdala. See Diagrams 4.1. and 4.2.

Diagram 4.1.

Amygdala connections in the macaque monkey

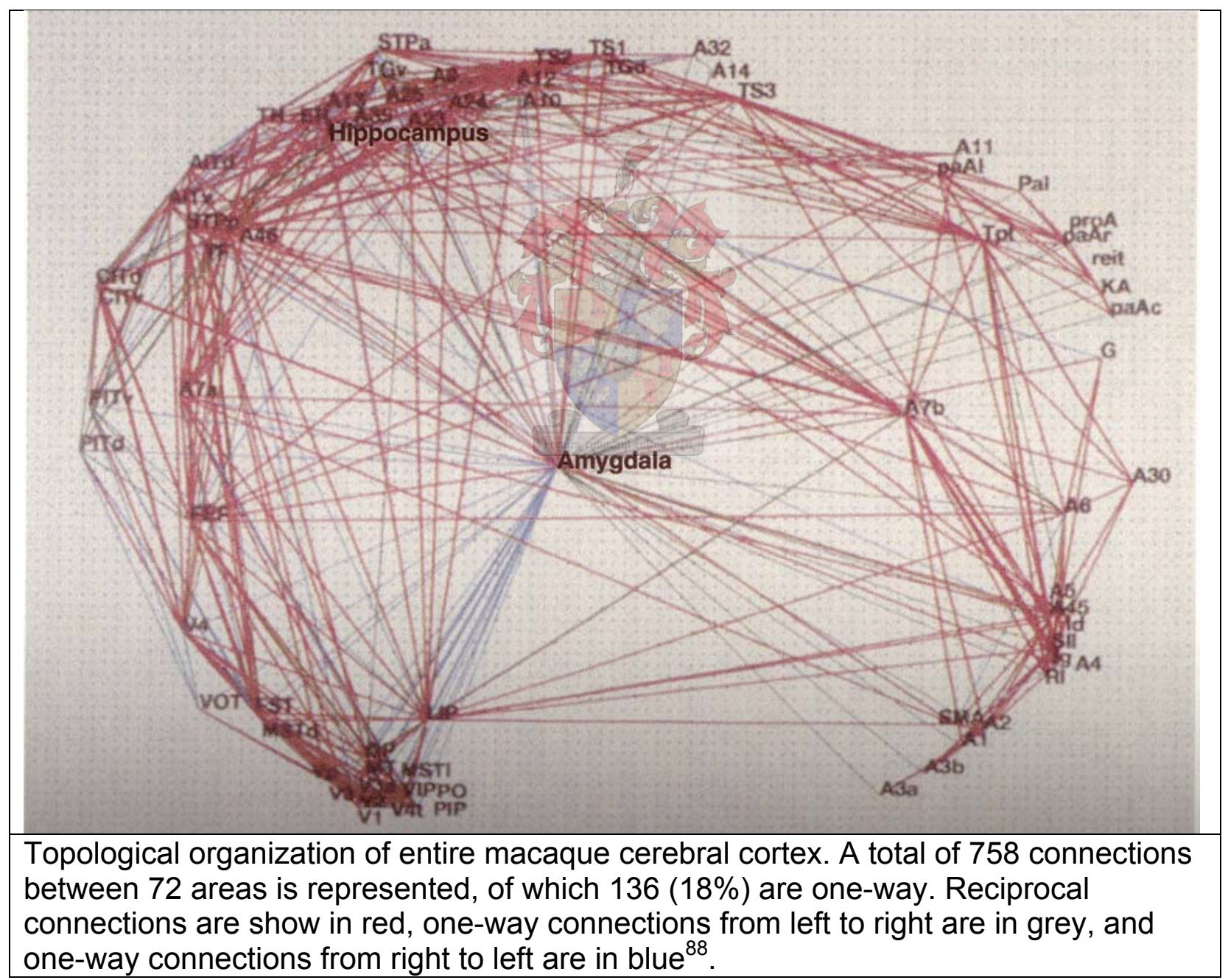


Diagram 4.2.

\section{Amygdala connections in the rat}

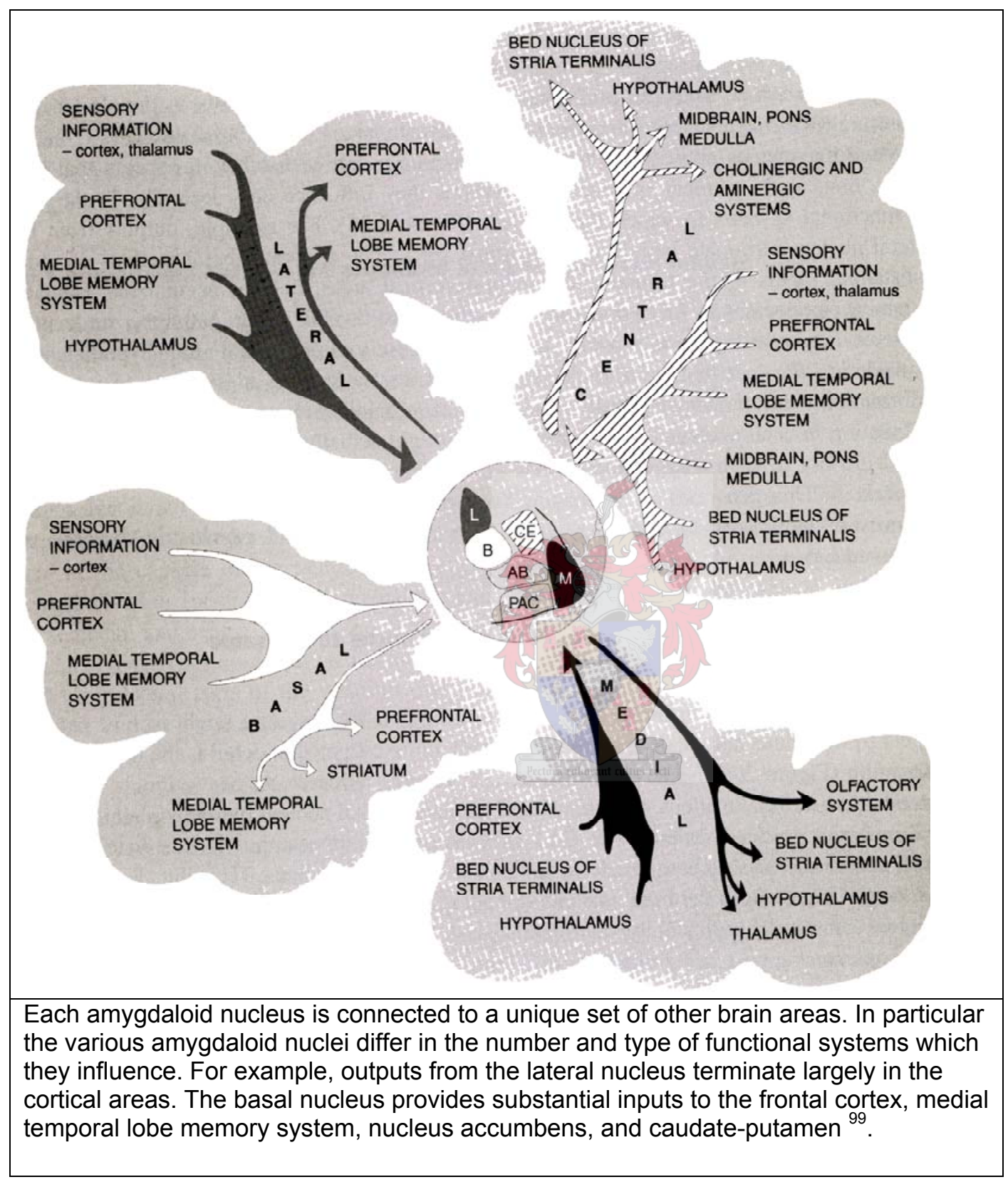




\section{Humans}

There is no doubt that the intricate details revealed by animal studies on the amygdala have greatly helped to shape our understanding of the human amygdala. See Diagram 4.1. Nonetheless, although it was concluded that in monkeys, the primate amygdala was involved in the ability to evaluate social and emotional meaning of visual stimuli, it was by no means evident that bilateral damage to the amygdala in humans would have as severe consequences ${ }^{60}$.

In humans, the amygdala is comprised of a group of almond-shaped nuclei in the heart of telencephalon, associated with emotion, learning, memory, attention and

perception $^{96}$. The amygdala (Latin for "almond", indicating the shape thereof) is involved in our emotions, our decisions we make based on our emotions and our behaviour, and is implicated in the acquisition of emotionally based memory ${ }^{77 ; 100 ; 106-110}$.

There are strong bi-directional projections between the amygdala and the hippocampus. It is important to note that the amygdala receives afferents from the orbitofrontal, cingulate, subcallosal, insular, temporal pole and sensory-specific and higher-order lateral temporal association cortices. Its connections with the autonomic and hypothalamic centres may make the amygdala a modulator of emotions.

There are four functional systems associated with the amygdala ${ }^{78}$ :

1) The Accessory olfactory system and 2) The Main olfactory system 
The anatomical connections reveal important links between the olfactory systems, amygdala and hypothalamus. This may help explain why (especially aversive) smells can influence memory.

\section{3) Autonomic system}

The anatomical connections reveal important links between the autonomic system, central nucleus and brainstem.

\section{4) Frontotemporal system}

The anatomical connections reveal important links between the frontal and temporal cortices with basolateral nuclei and striatum.

The amygdala is thus able to associate converging input from sensory modalities with input from the internal milieu, and to play a role in behaviours involving emotional responses $^{15}$, and in the recognition of the affective or social significance of stimuli, particularly those related to possible danger and threat.

It is now believed that the amygdala plays a strong role in triggering behaviours and knowledge retrieval in response to biologically salient stimuli, especially those related to possible danger and threat ${ }^{21}$. Fear is a hypothetical construct and involves the cluster of behaviours an organism has when facing life-threatening situations ${ }^{106}$. This includes the autonomic reactions (e.g. increased respiration) and simple reflexes (e.g. startle reflex, facial expressions). There is debate as to whether fear is innate or learned or both, but fear conditioning occurs across many species and has been highly conserved across evolution, and has been considered necessary for survival ${ }^{106}$. 
As the amygdala has strong reciprocal connections to the forebrain structures (especially the orbitofrontal region), it is in a unique position to influence neuroendocrine, autonomic and behaviour mechanisms ${ }^{61}$. Using a cross-disconnection design, Baxter et al ${ }^{111}$ showed that the amygdala and the orbital / medial prefrontal cortex must functionally interact to guide choice between objects that yielded different reward outcomes. Another amygdala-prefrontal connection may be the suggestion that people with bilateral amygdala damage can show poor judgment in making personal decisions in the social domain and that they perform poorly on formal tasks that require integration of information about imagined wins (benefits) and losses (risks) in the financial domain ${ }^{96}$. However, these effects are also evident in people with dysexecutive syndrome based on damage to the (ventromedial) prefrontal cortex, and it is possible that the amygdala is involved in evoking the emotional state appropriate to winning or loosing. If such an emotional state is evoked, then it is possible that emotions can guide gambling risk (future predicted wins and losses) ${ }^{112}$. Subjects with bilateral amygdala damage did not show increased skin conductance response on wins or losses on a gambling task ${ }^{113}$.

Perhaps correlating with Klüver and Bucy's research ${ }^{80}$, in humans it is now believed that damage for the amygdala's interconnecting structures (e.g. the posterior septum lying between the hemispheres in front of the anterior comminssure) may be associated with both hypersexuality and diminished aggressive capacity ${ }^{114}$. Bilateral removal of the amygdala is known to have a 'taming effect' and a loss of the ability to make emotionally meaningful discriminations between stimuli. Thus amygdalectomized humans may be apathetic and show little affective expression or spontaneity 2 ;5; $115-119$. 
Damage to the amygdala is thought to contribute to disorders such as Alzheimer's disease, autism ${ }^{120 ; 121}$ and schizophrenia ${ }^{122}$. This is consistent with the hypothesis that the medial temporal lobes may be implicated in the pathogenesis of schizophrenia ${ }^{123-}$ ${ }^{125}$. Fudge et $\mathrm{al}^{123}$ presented a case of chronic psychosis in which postmortem findings revealed lesions in and adjacent to the left amygdala. One theory is that patients with dopamine-compromised illnesses (such as schizophrenia), have difficulties integrating several functions (including emotional and motivational behaviours). The hypothesis is that a dorsal tier of dopamine neurons receive input from the amygdala and the ventral (limbic-related) striatum ${ }^{126}$, and project widely throughout the cortex. Through this and other limbic projections, the limbic system influences dopamine output (and thus can affect the emotional and motivational aspects of a wide range of behaviours). In terms of autism ${ }^{120 ; 121}$, it is suggested that bilateral amygdala damage may impede the ability to make social interpretations of facial expressions.

Seizure activity and experimental stimulation of the amygdala provoke visceral responses associated with fright, and mouth movements involving feeding ${ }^{127}$. It has long been acknowledged that people with epilepsy of temporal origin characteristically experience memory failures to varying degrees ${ }^{128-132}$. With epilepsy surgery, there was an explosion of surgical excisions of the hippocampus along with the amygdala and hippocampal gyrus ${ }^{64}$, and a deluge of literature outlining the neuropsychological consequences of unilateral temporal lobectomies. In epilepsy studies, a correlation between the right amygdala volume and visuospatial memory has been suggested ${ }^{133}$. 


\section{Amygdala functioning in living humans}

The amygdala literature also refers to two non-LiP patients, DR and $\mathrm{SE}^{74}$. Patient DR had bilateral amygdala and extra-amygdala surgery for treatment of severe epilepsy, and Patient SE had suffered a form of herpes simplex viral encephalitis. In both cases there was bilateral damage of, but not circumscribed to, the amygdala. Nonetheless their results were fairly consistent with Patient $\mathrm{SM}^{19 ; 58}$. They found that the two subjects - when shown photographs showing facial expressions of emotion from the Ekman and Friesen series ${ }^{134}$ - had difficulty in recognizing fear. In addition, Patient DR could not differentiate fear from anger, but was able to differentiate happiness from sadness. There is now a great deal of evidence to suggest that the amygdala and its many efferent projections may represent a central fear system involved in fear and anxiety ${ }^{106}$, and the amygdala has been implicated in the processing of fearful expressions ${ }^{74 ; 135}$, but not necessarily other negative facial expressions.

In the study by Blair et al ${ }^{135}, 13$ healthy male subjects were shown static gray-scale images of faces expressing varying degrees of sadness and anger. The subjects were not required to identify or name the facial expressions. With increasing intensity of sad facial expression, so the left amygdala and right temporal pole showed enhanced activity. However, when exposed to increasingly angry facial expressions, there were no signals generated in the amygdala. Instead, there was enhanced activity in the orbitofrontal and anterior cingulate cortex. The authors concluded that there are dissociable but interlocking systems for the processing of distinct categories of negative facial expression. 
Some have suggested that recognition of specific facial expressions depend on distinct systems ${ }^{59}$. Fear and disgust are both seen as 'negative emotions', but it was the perception of facial expressions for fear and anger that caused the amygdala to activate in one study ${ }^{136}$, and the perception of the facial expression of disgust has been suggested to be linked to the interior insular cortex (also involved in responses to offensive tastes $\left.{ }^{137 ; 138}\right)$.

Bechara et $\mathrm{al}^{20}$ compared three subjects with bilateral mesial temporal damage. The first, Patient SM046 was indeed the Patient SM referred to in the research by Adolphs et $\mathrm{al}^{19}$. In this study she was compared to WC1606 who had ischaemia-anoxia and consequent bilateral hippocampal damage, and patient RH1951 who had herpes encephalitis that produced bilateral temporal lobe lesions. All three were exposed to visual slides and later, tones (the conditioned stimuli) as a startling loud sound (the unconditioned stimulus) was delivered. The participants' skin conductance was measured to determine the degree of autonomic response, and the participants were quizzed about what they had seen and heard (learned facts or declarative knowledge). Bechara and colleagues found that Patient SM106 (SM) who had bilateral damage to the amygdala did not acquire conditioned autonomic responses to visual or auditory stimuli, but acquired declarative knowledge. In contrast, the patient with the bilateral hippocampal damage could not acquire the facts but could become conditioned and the last patient with bilateral damage to both the amygdala and hippocampus acquired neither. They concluded that these findings demonstrated a double dissociation of conditioning and declarative knowledge (e.g. list learning) relative to the human amygdala and hippocampus. Thus, the human amygdala is thought to have a crucial role in emotional learning ${ }^{135 ; 139 ; 140}$. 
Patient SM was once again assessed in a task of recognition of facial emotion in nine individuals with bilateral amygdala damage ${ }^{21}$. The other nine subjects had minimal to complete bilateral amygdala damage due to encephalitis or surgery. The subjects DR and $\mathrm{SE}^{74}$ were also included in this study. All the subjects were shown slides of the faces of six different individuals each displaying six different basic emotions (happiness, surprise, fear, anger, disgust, and sadness) and three neutral stimuli. The results showed significant impairment in recognizing fear although individual performances ranged from severely impaired to essentially normal, but that impaired recognition of fear could not be attributed simply to mistaking fear for another emotion. In addition, while most subjects were impaired on several negative emotions in addition to fear, no subject was impaired in recognizing happy expressions. The authors were able to conclude that this research was consistent with the idea that the amygdala plays an important role in triggering knowledge related to threat and danger signaled by facial expressions.

In $2003^{60}$, Patient SM was again involved in another study on the amygdala, to assess if the presence of richer visual stimuli that contained cues in addition to the faces, would still impair recognition of emotions of subjects with bilateral amygdala damage. Patient $\mathrm{SM}$ with bilateral amygdala damage due to LiP, and three other subjects with bilateral amygdala damage due to encephalitis - all three also had damage to "surrounding regions of the brain" and were densely amnesic - were compared to 23 people with unilateral amygdala damage, 22 "brain-damaged controls", and 16 normal individuals ${ }^{60}$. They found that all four patients with bilateral amygdala damage were impaired in recognizing faces shown in isolation, and were disproportionately impaired in 
recognizing certain emotions from complex visual stimuli when subjects utilized information from facial expressions.

It has been strongly put forth that impairments in the recognition of fear ${ }^{19 ; 20 ; 21 ; 76 ; 141-144}$, and possibly disgust ${ }^{145 ; 146}$ follow specific brain lesions. Specifically, lesions to the amygdala and surrounding regions produce deficits both in the recognition of fearful expressions and in fear responses, and lesions to the circuitry of the gustatory insula and the basal nuclei (basal ganglia) lead to impairment in recognizing signals of disgust and disgust-related responses ${ }^{147}$. There have been suggestions that anger too may have its own distinct neural system ${ }^{148}$, but possible systems for happiness, sadness, and surprise have not yet been identified ${ }^{147}$.

\section{Emotional memory}

Gabriel et $\mathrm{al}^{76}$ theorized that the amygdala promoted memory storage in various nonamygdala brain circuits and that this promotion depended on the emotional significance of the events recalled.

Flashbulb Memory (FM) are vivid, stable memories for the reception of arousing, consequential news ${ }^{149}$ and are also thought to involve the amygdala because of their arousing emotional association (e.g. autobiographical recall about where one was when one heard about the death of Robert Kennedy / Princess Diana). In Abrisqueta-Gomez et al's study ${ }^{150}$, they found that unlike controls, Alzheimer subjects did not have enhanced recognition if pictures were emotionally-laden. This is in contrast to studies by Ikeda et al ${ }^{151}$ who found that amnestic patients with Alzheimer's disease (AD) were able 
to remember the Kobe earthquake. Abrisqueta-Gomez et al ${ }^{150}$ postulated that the difference in enhancement of memory could be due to the emotional content being personal and life-threatening (as in the Kobe earthquake), and thus of far greater emotional intensity than pictures that are merely disgusting or enjoyable. Unfortunately, Abrisqueta-Gomez et al did not comment on any differences (or not) between the AD subjects' results based on whether or not the emotional content was positive or negative. This would be interesting because although most current views of amygdala function emphasize its role in negative emotions such as fear, recent evidence supports a role for the amygdala in processing positive emotions as well ${ }^{96}$.

It is now well-established that the amygdala plays a critical role in the acquisition of storage of long-term associative memory, linking sensory information to affective meaning ${ }^{51 ; 117,152}$. In addition, it is thought that the amygdaloid region is a "bottleneck structure that confers an affective flavour to memories" ${ }^{72}$. It would seem possible that if a memory has an emotional overlay, it may enhance a person's long-term storage. Fear-conditioning may be seen as a form of implicit memory ${ }^{153}$, and emotive memories can also be seen in both traumatic stress disorder (PTSD) and phobias. The implications and applications of this possible role are far-reaching. Emotionally laden memory may also encompass recall (or lack of recall) of emotionally traumatic events (e.g. childhood sexual abuse). Much is written on recovered memories and false memories of childhood sexual abuse and incest. Childhood trauma-memory may represent an "unconscious memory" and the theory proposes that these memories can unconsciously affect adult behaviour and return to awareness even after long delays ${ }^{154 ; 155}$. It has been suggested that anxiety disorders may be linked to deficits in the amygdala's inhibitory tone ${ }^{156}$, and it is interesting to note that depression and PTSD 
are approximately twice as high in women as in $\operatorname{men}^{157 ; 158}$ and analysis of amygdala volumes has revealed increased amygdala volumes in women with depression ${ }^{159}$ suggesting there may be sex-related differences in the neurobiology of emotion and memory ${ }^{160}$, Understanding the relationships (if any) between emotional states, emotional memory and their neurobiological underpinnings are to a large degree still in their infancy, but the recurring suggestion of the amygdala playing a pivotal role is increasingly being suggested.

\section{Emotional judgment}

It has been demonstrated that decision-making and guessing involve different neurobiological substrates. If guessing also involves risk-taking (gambling for reward or avoiding loss / punishment) then an emotional component is thought to be employed. Ernst et al $^{161}$ assessed 20 healthy individuals in a risk-taking task during position emission tomography (PET). They found that decision-making activated the orbital and dorsolateral prefrontal cortex, anterior cingulate, insula, inferior parietal cortex and thalamus predominantly on the right side, and cerebellum predominantly on the left side. In contrast, guessing accompanied activation of sensory-motor associative areas, and amygdala on the left side. They found that informed decision-making activated areas that subserve memory (hippocampus, posterior cingulate) and motor control (striatum, cerebellum). The more emotive the decision (or the consequences of the decision), the more theoretically one may assume that the emotional areas of the brain could be involved. Moral dilemmas could be seen as highly evocative emotive decisions. For example ${ }^{162}$ : 
"A runaway trolley is headed for five people who will be killed if it proceeds on its way. The only way to stop it is to hit a switch that will turn the trolley onto an alternate set of tracks where it will kill one person instead of five. Ought you to turn the trolley in order to save five people at the expense of one?" If the only way to save the five people was to push a stranger off a bridge, onto the track below, ought you to save the five people by pushing the stranger to his death?"

Moral dilemmas vary in the extent to which they engage emotional processing and these variations in emotional engagement may influence moral judgment ${ }^{162}$. While the role of reason has traditionally been emphasized in 'moral judgments', there is an increased emphasis on what role is played by emotion. Little is known of the neural correlates associated with reason and emotion in the process of 'moral' decisionmaking, nor about the nature of their interaction or the factors that may influence behaviours.

Emotions play a pivotal role in assigning human values to events, objects and actions. There has been a recent surge in neurosciences to understand the neural organization of moral emotions in the human brain. There is great scope for research involving the role of the amygdala, ranging from emotionally-based cognitions, memories, perceptions and decisions.

Not to undervalue the remarkable contribution of single case reports and small case series in our understanding of the amygdalar complex function, it is so that much of the literature of humans with bilateral amygdala damage describes small case numbers (usually under four subjects, rarely over ten), or individual case presentations. There 
has also been difficulty in standardizing the extent or circumscribedness of the lesions or methodology employed. In addition, sometimes the same patient has been assessed over and over again in different studies or a basis for different papers. It makes definitive conclusions on the role of the amygdala in living humans sometimes difficult to quantify. In LiP, the damage to the amygdala can be relatively circumscribed, bilateral and symmetrical ${ }^{15}$, and thus may allow a rare opportunity for an experimental study of the role of the amygdala in living humans. 


\section{Chapter 5}

\section{Purpose of this study}

Despite the approximately 300 cases of LiP described in the literature and the known prevalence of bilateral symmetrical calcifications of the mesial temporal areas, most of the neuropsychiatric and neuropsychological work to date has been anecdotal rather than systematic. Nonetheless these studies on patients with LiP contributed to our understanding of the role of the amygdala in fear processing and social cognition ${ }^{19-23 ; 51}$.

Previously, the vast bulk of literature has focused on single case reports or small case series $^{6 ; 8 ; 15 ; 19-23 ; 51}$, with only a few recent exceptions ${ }^{12 ; 17}$. Siebert, Markowitsch and Bartel ${ }^{17}$ assessed ten LiP subjects with an extensive neuropsychological battery and Van Hougenhouck-Tulleken et $\mathrm{al}^{12}$ completed a brief neuropsychiatric screen on 11 subjects. To our knowledge, the current study is the largest to date, assessing 37 patients with LiP with standardized neuropsychiatric and neuropsychological measures. In addition, unlike so many of the studies hitherto done, this research offered a matched control group from which to compare the participants' functioning.

The literature suggests depression, increased risk of suicide, disfigurement, paranoia, lower fertility and thus possibly impaired quality of life in affected individuals. In LiP, epilepsy is common. In epilepsy, patients may have the possibility of recurrent seizures, be dealing with adjustment to medication, type, severity and frequency of seizures, 
adverse effects, stigma, lack of independence, consequences for alcohol intake, driving, working and insurance ${ }^{163-165}$. All of these can affect the person's quality of life and self esteem and relationships. Even if the person with LiP does not have seizures, they could have other disabling symptoms - e.g. psychosis. Many have cosmetic symptoms or a husky voice that could possibly label them as different. Assessing the impact of all of these possible LiP presentations on their quality of life is thus an important area to consider $^{166-168}$.

To the author's knowledge, no quality of life (QOL) instrument has yet been given to any of this patient cohort. No published study to date has used structured diagnostic instruments to assess the quality of life, marriage and fertility and employability of LiP individuals. Using standardized measures, this study aimed not only to investigate the neuropsychiatric and neuropsychological presentation in LiP, but also to assess quality of life measures. 


\begin{abstract}
Aim
This study aims to document the neuropsychiatric and neuropsychological functioning of a large cohort of patients with LiP. As LiP has been associated with the amygdala and its role in mediating cognitive and affective functions, this study will investigate the presence of psychosis and mood disorders in this population, and assess the patients' quality of life and neuropsychological performance (including recognition of facial expressions) using recognized neuropsychiatric and neuropsychological measures. This research will assess every person with LiP who can be located in South Africa, and who is willing to be assessed.
\end{abstract}

\title{
Hypotheses
}

$\mathrm{H}_{1}$ : Lipoid Proteinosis is associated with increased psychiatric symptoms when compared to matched controls.

$\mathrm{H}_{1}$ : Lipoid Proteinosis is associated with increased cognitive impairment when compared to matched controls.

$\mathrm{H}_{1}$ : Patients with LiP will find it more difficult to identify fear on facial recognition tasks, when compared to matched controls.

$\mathrm{H}_{1}$ : Patients with LiP will not find it more difficult to identify happiness on facial recognition tasks, when compared to matched controls. 
$\mathrm{H}_{1}$ : Lipoid Proteinosis is associated with decreased quality of life when compared to matched controls. 


\section{Chapter 6}

\section{Subjects and methods}

\section{Subjects and Location}

Ninety people (37 LiP subjects and 53 controls) participated in this study. Of the LiP participants, two were patients (from the Western Cape) attending Tygerberg Hospital, a large state hospital in Cape Town, and five were from the greater Johannesburg / Pretoria area and were seen at the National Health Laboratory Centre in Johannesburg. Thirty came from Namaqualand, an impoverished and rural area in the Northern Cape.

The Northern Cape and Gauteng patients were known to the Genetics Department of the University of the Witwatersrand, and the Molecular Dermatology Department of St Thomas's Hospital in the United Kingdom, who had already genetically confirmed the diagnosis of LiP in 32 of these patients. The others were clinically identified (e.g. biological first-degree relatives of other LiP subjects, hoarse voices since infancy, thickened sublingual frenulum leading to restricted tongue movement, dermatological signs, complex partial seizures). Twenty-five were seen in the community clinics or in their homes, in the small Northern Cape towns of Bulletrap, Concordia, Komaggas, Okiep, Nababeep, and Steinkopf. Two participants had left the Northern Cape for Atlantis and were seen there in their homes or at a local clinical psychologist's office. All 
the controls were seen in community clinics in the Northern Cape, except for one who had also moved to Atlantis.

Thirty LiP people came from the same geographical area (Namaqualand in the Northern Cape in South Africa) and they represented a uniquely homogenized group.

It was felt the greater the number of matched controls, the more valid their mean normative performance would be. It took 120 hours of assessment time to assess matched NC controls. With the time available, it was logistically possible to aim for two matched controls per LiP patient (i.e. 240 hours of assessment time). Fifty-three controls from the Northern Cape (matched for home language, socio-economic status, age, and matched as closely as possible for years of education and gender) completed the same test battery.

Established normative data could not be used on the neuropsychology tests due to education inequalities and they were only compared to the matched controls.

The other seven people came from disparate backgrounds in the Western Cape and Gauteng provinces, and were not compared to a norm group.

These assessments took place in Johannesburg (at the Division of Human Genetics, National Health Laboratory Service and School of Pathology, University of the Witwatersrand) and in Namaqualand in the Northern Cape (at local community clinics) and sometimes in the subjects' homes. 


\section{Ethics}

Before participating in the study, all the participants signed a consent document after reading and understanding the Information Sheet (See Appendix I). They had the right to ask questions at any time and they were all entitled to a signed copy of this document. The consent form was given to the participants in their home language (Afrikaans, and an English copy was also available). The research was conducted according to the Declaration of Helsinki and the guidelines for Good Clinical Practice $(\mathrm{ICH})$. The research ethics committee of the University of Stellenbosch and the Medical Research Council approved the study. All information was confidential, the participants' identities were not made known, and participants were informed the results of the study would be published in professional literature and be made available to the Subcommittee $\mathrm{C}$ of the Research Committee.

Neuropsychological tests were paper and pen exercises and no participant was at risk (e.g. no drugs were administered.). Neuropsychological and neuropsychiatric assessments were provided at no cost to the participants. They were not paid for participation in the study but their travel costs were reimbursed.

As further research was anticipated, subjects also gave consent for possible future participation in tertiary hospital-based research. All anticipated scans (e.g. SPECT, MRI) are of standard acceptable procedures and there are no risks associated with them. All subjects were free to withdraw from participation in this study at any time, for any reason, specified or unspecified, without penalty or loss of benefits to which the subject was otherwise entitled, and with no influence on their future treatment. Although the 
participants may not have immediately benefited from participation in the research, there could be possible future benefits from this study for the participants, their families and other patients with Lip.

All subjects gave informed consent. Fifteen participants (5 with LiP and 10 matched controls) were under 18 years, and they and their guardians gave consent.

All subjects were assessed by Helena Thornton, who acted as Principal Investigator, or qualified Clinical Psychologists trained and supervised by Helena Thornton. Seven clinical psychologists, all of whom who were fluent in Afrikaans - five were Afrikaans home-language speaking - were trained. Four week-long field trips were done. On the first three field trips, one investigator accompanied Helena Thornton, and on the last field trip (to assess NC controls), four investigators accompanied Helena Thornton. Helena Thornton personally neuropsychologically assessed 35 of the 37 LiP patients.

The teams would meet daily to discuss who they had seen, score the results, debate interpretations, and if necessary, organize follow-up. 
The following inclusion and exclusion criteria were applied:

\section{Inclusion criteria (LiP Subjects)}

1. Male or female.

2. Aged between 10 and 65 years (inclusive).

3. An established diagnosis of LiP - either genetically or clinically.

4. Subjects spoke English or Afrikaans.

5. Subject and/or legal guardian has understood and signed the informed consent form, according to the regulations of the ethics committee/s.

6. Subjects resided in South Africa.

\section{Exclusion criteria (LiP subjects)}

Subjects meeting one or more of the following criteria could not be entered:

1. LiP subjects who were psychotic and unable to give consent.

2. LiP subjects who were intoxicated on assessment.

3. Children 16 years or younger participated in the study but for validity reasons, their results were not included in the neuropsychiatric and neuropsychological analyses. For this study, "adults" included participants who were 17 years of age or older, and 65 years or younger. 
4. Some subjects did not complete all of the tests due to validity difficulties (e.g. children under 16 years did not complete the Vocabulary Scale of the WAISIII; people who were illiterate did not complete the phonetic verbal fluency scales).

5. Subjects must be accessible. Two Namaqualand LiP subjects living in Namibia could not be included in the study.

\section{Exclusion criteria (Controls):}

Subjects meeting one or more of the following criteria could not be entered:

1. Subject had had a severe traumatic brain injury or neurological event.

2. Subject not able to be matched to a LiP participant. (Maximum ratio: two control subjects matched via age / gender / education level per participant.)

3. Subjects intoxicated at time of interview / assessment.

\section{Withdrawal criteria}

Subjects were withdrawn from the study if:

1. The subject withdrew his/her consent.

2. The subject was not able to give informed consent (e.g. the subject became psychotic). 


\section{Scales}

The current study is to our knowledge the largest systematic study of psychiatric diagnosis, and neuropsychological measures in LiP. In view of evidence of amygdala pathology, and prior findings of associated neuropsychiatric impairment, it was hypothesized that this population would be characterized by increased rates of mood and anxiety disorders, and impairments in processing of emotional expressions. The scales and tests were designed to elicit these factors.

Subjects were examined by use of standardized neuropsychiatric and neuropsychological measures. The battery was designed to assess neuropsychiatric symptoms and neuropsychological dysfunction previously reported in the literature in association with LiP (e.g. psychosis, depression, problems with emotional recognition, and memory and executive functioning). In addition, quality of life measures were administered. Subjects were assessed in their home-language on the following:

\section{Neuropsychiatric measures:}

- MINI International Neuropsychiatric Interview $(\mathrm{MINI}+)^{169}$

The MINI+ screens for DSMIV Axis I diagnoses.

If on the MINI+ there was a high risk for suicide, then it was arranged that these subjects would be referred to the community sister.

- Positive and Negative Symptoms Scale (PANSS) ${ }^{170,171}$

This scale assesses the positive and negative symptoms associated with schizophrenia.

- Montgomery and Asberg Depression Rating Scale (MADRS) ${ }^{173}$ 
Neuropsychological measures:

Clinician-Administered:

The construct of 'intelligence' as measured by the Wechsler intelligence scales does not necessarily assess individuals' abilities to adapt well to their environment and to function well within in $\mathrm{it}^{172}$. Nonetheless for the purposes of this study the Wechsler instruments were employed as they represent internationally recognized and standardized measures of 'intelligence'.

- Wechsler Abbreviated Scale of Intelligence (WASI) except for the Vocabulary subtest ${ }^{174}$.

This was substituted by the Vocabulary subtest from the Wechsler Adult Intelligence Scale $-3^{\text {rd }}$ Edition (Vocab, WAISIII) scaled score, using the Human Sciences Research Council (HSRC) of South Africa's Afrikaans translation and adaptations for South Africa ${ }^{175}$. Although the WASI has not been standardized in South Africa, the WAISIII has been, and the Vocabulary subtest of the WASI has a correlation coefficient of .88 with the Vocabulary subtest of the WAISIII ${ }^{174}$. "The magnitude of the correlation coefficient is expected and suggests the subtests and IQ scales of the WASI measure constructs similar to those measured by their WAISIII counterparts" ${ }^{\text {"174 }}$.The HSRC has shown that the mean subtest scores on the WAISIII are less than established means from the UK and USA due to different mean education levels of respective populations ${ }^{175}$. This thus is an estimate of intelligence using an established international measure, and like many other 
Neuropsychology tests using Western-norms, the control group is significant in establishing the comparative performance of the LiP group.

Two patients with LiP had already completed the South African Wechsler Intelligence Scale - Revised (SAWAIS-R) ${ }^{176}$ and did not do the WASI.

- Benton Facial Recognition (BFR) (short form) ${ }^{177}$

The respondent must first find the same photograph of a person (out of a choice of six), and in the second phase of the test, identify three photographs of the same person when all the photographs have been taken from different angles and with different lighting.

- Ekman Facial Emotional Recognition (EFER) ${ }^{134}$

Emotional processing can be elicited through a variety of stimuli (facial expressions, emotional scenes, humorous cartoons, prosody, emotional musical passages, and emotional propositional speech). The majority of the studies have however used emotional faces. Facial expressions provide and important behavioral measure for the study of emotion, cognitive processes and social interaction ${ }^{178}$. The Ekman Facial Emotional Recognition test consists of 110 photographs or people displaying either a neutral expression, or one of six emotions (happiness, sadness, fear, anger, surprise or disgust). Subjects must try and match one of the seven options to the expression they see. As the overwhelming majority of the Northern Cape subjects had never worked with computers, the test was administered manually via photographs, rather than by computer. 


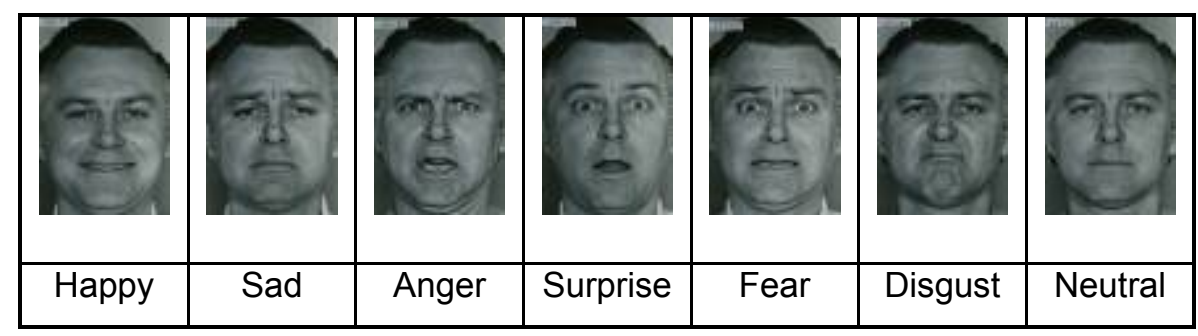

The above basic emotions comprise positive (happy) and negative (angry, disgust, fear, sad) expressions, as well as neutral ones and ambiguous ones (a surprise can be either pleasant or unpleasant). Complex emotional expressions such as embarrassment and envy ${ }^{179}$ were not employed.

- Controlled Oral Word Association Test (COWAT) (administered as per Lezak $^{75}$ ) COWAT (or Words-a-Minute) assesses verbal fluency and verbal initiation. For Afrikaans-home language speakers, the phonetic letters " $\mathrm{V}, \mathrm{A}, \mathrm{S}$ " were used. Each subject had one minute to generate as many words as possible beginning with the given letter. Numbers (e.g. "four"), names of places (e.g. "Steinkopf") and people and the same stem word (e.g. "fish, fishing, fishes, fished") were not acceptable. 
- Rey Auditory Verbal Learning Task (RAVLT) $)^{75}$

The RAVLT is a test of declarative memory (list learning).

Trials I, II, III, IV, V, List B, Recall after distraction (Trial VI), Delayed recall (Trial VII), Recognition. Both True Positives (TP) and False Positives (FP) were scored, and Adjusted Recognition score of True Positives minus False Positives was also obtained. The total number of words learned, the number of error responses and repetitions, and percentages retention after interference and after delayed recall, was also scored. On the RAVLT, the time in delayed recall can vary from 20 minutes to the next day ${ }^{75}$. For this study a delay of one hour was used.

- Wechsler Memory Scale - Revised (WMS-R) ${ }^{181}$ subtests:

o Digit Repetition (DR) - Both Digits Forward (DF) and Digits Backward (DB) were done and calculated as the number of digits correctly recalled in a sequence. Digits Difference (DD) was also obtained by subtracting the score for the reversed sequence from the score for the forward sequence (DF-DB).

o Logical Memory (LM) - Immediate recall (LMI) and delayed recall (LMII) This test assesses paragraph recall or logical memory. Besides the raw score (accumulative total of two stories) for LMI and LMII, the percentage retention (LMII/LMI x 100) was also obtained. LMI and LMII were translated into Afrikaans and the names were changed to local geographical settings - e.g. Okiep instead of Boston. 
o Visual Reproduction (VR) - Immediate recall (VRI) and delayed recall (VRII)

This is a test of forewarned visual recall.

Besides the raw score (accumulative total of the four cards) for VRI and VRII, the percentage retention (VRII/VRI x 100) was also obtained.

- Complex Figure of Rey (RCF) (administered as per Lezak ${ }^{75}$ )

Both the copy (RCF-C), and immediate incidental recall (RCFI) were administered.

The first part of this test assesses executive skills of planning and design, and also visuospatial abilities. RCRI assess immediate incidental recall of complex visual data.

Time permitting; the delayed recall was also administered.

- Draw a Clock (DAC)

This test is assesses planning and visuospatial abiltities ${ }^{75}$.

A simple DAC instrument was used as the population being assessed was not test-wise. Time was to be set for "10 past 11", and the clock was scored out of 10 with the following criteria to be met:

\begin{tabular}{|l|l|c|}
\hline 1 & Circle & 1 point \\
\hline 2 & Twelve numbers & 1 point \\
\hline 3 & Correct numbers & 1 point \\
\hline 4 & Clockwise direction of numbers & 1 point \\
\hline 5 & Three numbers in a quarter & 1 point \\
\hline 6 & Clock in proportion & 1 point \\
\hline 7 & Hands from centre point & 1 point \\
\hline 8 & Two hands & 1 point \\
\hline 9 & Long hand correctly placed & 1 point \\
\hline 10 & Short hand correctly placed & 1 point \\
\hline
\end{tabular}


- Hooper Visual Organization Task (HVOT) ${ }^{182}$

This visuospatial test is predominantly used to assess suspected right hemisphere or parietal lobe involvement.

- Trail Making Tests A \& B (TMT) ${ }^{75}$

Besides visual scanning and hand-motor speed, the trails tests also assess dual sequencing and switching (executive ability).

In addition to the number of seconds taken to complete each trial, scores for the difference in time (in seconds) between the two trials, and the number of errors requiring correction on TMTB, were also obtained.

- Ruff Figural Fluency Test (RFFT) ${ }^{183}$

The RFFT is a measure of nonverbal fluency analogous to the verbal fluency tests, and assesses the capacity for fluid and divergent thinking, flexibility in shifting cognitive set, planning strategies and the executive abilities to coordinate these processes ${ }^{183}$. The test consists of five parts, each consisting of a different stimulus pattern of dots. A respondent must draw as many unique designs as possible within a one-minute time period. If the design is repeated, then this is scored as a perseverative error.

The total unique designs and the number of perseverative errors were calculated - both for the first trial by itself and all five trials together. 
Self-Rated:

- DEX Questionnaire from the Behavioural Assessment of Dysexecutive Syndrome (BADS).

This scale looks at behaviours associated with dysexecutive syndrome (DES) or frontal lobe syndrome (FLS) ${ }^{184}$. It is a 20 -question Likert scale where a person subjectively relates each behaviour from zero (never occurs) to four (the described behaviour occurs very often).

- Cognitive Failures Questionnaire (CFQ).

This 25-question scale measures self-reported failures in perception, memory, and motor function ${ }^{185}$ and is rated on a Likert scale from zero (the cognitive difficulty does not occur) to four (the cognitive difficulty occurs very often).

Quality of Life measures:

- Short Form - 36

This generic scale developed from the RAND 36 -Item Health Survey ${ }^{165 ; 168 ; 186-}$ ${ }^{188}$ and is a 36-item quality of life (QOL) measure. 
- Impact of Epilepsy Scale (IES) ${ }^{165 ; 167}$ (with permission from Professor Gus Baker, adapted by Helena Thornton to the Impact of LiP Scale).

This is an epilepsy-specific QOL scale but was adapted in this research, to assess the impact of LiP rather than epilepsy.

\section{$\underline{\text { Semi-structured }}$}

- Demographic details

- Genetic history of LiP and surnames (asking patients if there was a known family history of LiP or the surname Cloete, and if there had been cosanguineous partnerships)

- Family Medical and Psychiatric History

- Personal Medical and Psychiatric History

Answers were noted on a standardized form.

After understanding and completing the informed consent document (Appendix I), each participant was seen for two two-hour assessment sessions. 
Assessment one:

- Informed consent

- Semi Structured interview

- $\mathrm{MINI}+$

- PANSS

- MADRS

- SF-36

- IES

- DEX, BADS

- $\mathrm{CFQ}$

- WASI Similarities and WAISIII Woordeskat (Vocabulary) tests 
Assessment two:

- COWAT

- $\quad \mathrm{R}, \mathrm{WMS}-\mathrm{R}$

- RAVLT

- LM, WMS-R

- VR, WMS-R

- RCFI \& RCFII

- HVOT

- DAC

- RCF-C

- Matrices, WASI

- $\mathrm{BD}, \mathrm{WASI}$

- RFFT

- TMT

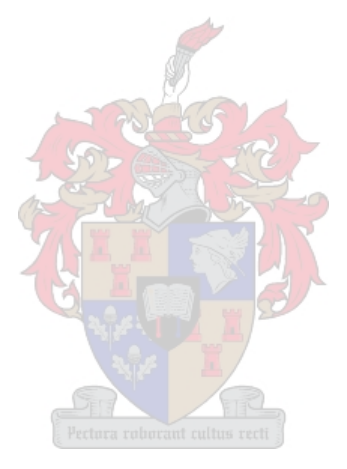

- Benton Facial Recognition

- Ekman Facial Expression Recognition

Controls did not complete the SF-36, DEX or CFQ. 
Statistical Analysis:

Statistical analysis was performed with the help of a specialized computer software package Statistica version 6 and 7 (Statsoft, Inc.). Professor Daan Nel, of the Centre for Statistical Consultation, University of Stellenbosch, performed all the analyses together with Helena Thornton.

Descriptive statistics were used to describe the LiP population. For correlations between pairs of numeric variables, either Pearson product moment correlation coefficient (parametric), or the Spearman rank order correlation coefficient (non-parametric) was used. All sets regression was used with the following criteria:

- Maximizing the Multiple $\mathrm{R}^{2}$

- Maximizing the Adjusted $\mathrm{R}^{2}$

- Minimizing the Mallow's CP

As discussed in the literature on amygdala studies of LiP patients ${ }^{15 ; 21 ; 74}$, lack of recognition for fearful expressions is common. Thus further statistical analysis was done on the recognition of fear results (best subtests regression).

In addition a number of graphs (histograms, scattergrams, and box-whisker plots) were provided to highlight findings set out in the tables and the body of the chapter. 
Data from the Northern Cape LiP subjects and controls were compared as follows:

- When continuous variables were compared between the two groups, ANOVA (or equivalently the t-test) was used. If residuals proved to be non-normally distributed, the analysis was repeated non-parametrically, with the Mann-Whitney or Bootstrap tests.

- When ordinal variables were compared between the two groups, the Mann-Whitney test was also used.

- When nominal variables were compared between the two groups, the likelihood-ratio chi-square test was used.

In all analyses a significance level of $5 \%$ was used, i.e. if the $p$-value of the particular test was $<0.05$, the difference between the two groups was considered significant. On the graphs, $p<0.05={ }^{*}$ and $p<0.01={ }^{* *}$. 


\section{Chapter 7}

\section{Results: General}

\section{Subjects:}

Forty-six patients with LiP were potentially identified for this study. Of this total, three people from previous studies who were known to have LiP, had died. Three were untraceable with no forwarding contact details, two were residing in Namibia, and one woman from the Pretoria area refused to participate in the research.

Thus there were thirty-seven patients with LiP involved in this study, representing more than $10 \%$ of the known world population of patients with LiP. There were 20 males (54.05\%) and 17 females (45.95\%), with ages ranging from 10-63 years (mean=34.27, $s d=14.61)$. All spoke Afrikaans as their home-language, $31(83.7 \%)$ were of mixed race (i.e. mixed Nama and Caucasian ancestry), and 6 (16.21\%) were Caucasian.

Subjects from Namaqualand (Northern Cape) $(n=30)$ were compared to matched controls $(n=53)$. An attempt was made to find two matched controls for every Northern Cape subject, and the control group was seven short of this ideal. Of the 53 controls taken from the same areas (same ethnicity / language / culture / language), all but four were also matched for age, education and gender. Three were matched for age and education but not gender, and one was matched for age and gender but not education. Two controls were intoxicated at the time of their follow-up sessions and therefore only 
limited batteries were completed. In these cases the $\mathrm{MINI}+$ could not be completed in the time available.

For the $30 \mathrm{LiP}$ subjects from the Northern Cape (NC) there were 15 males $(50 \%)$ and 15 females (50\%). The controls had 26 males (49\%) and 27 females (51\%). For the NC LiP group, the mean age was 34.43 years ( $s d=15.24$, range $=10-63$ years). For the 53 controls, the mean age was 33.79 years ( $s d=15.42$, range $=10-65$ years). For both groups $100 \%$ of participants were Afrikaans-speaking and were in the racial population previously known as 'Coloured'. For the NC LiP group, levels of education ranged from 2-13 years (mean=8.07 years, $s d=3.24)$ and for the controls, years of education ranged from 0-14 years (mean=8.57, sd=3.04). There was no statistical difference between the two groups for gender, age or education. (See Graphs 7.1, Graph 7.2 and Graph 7.3). 


\section{Graph 7.1.}

\section{Histogram of gender: Northern Cape LiP subjects versus Controls}

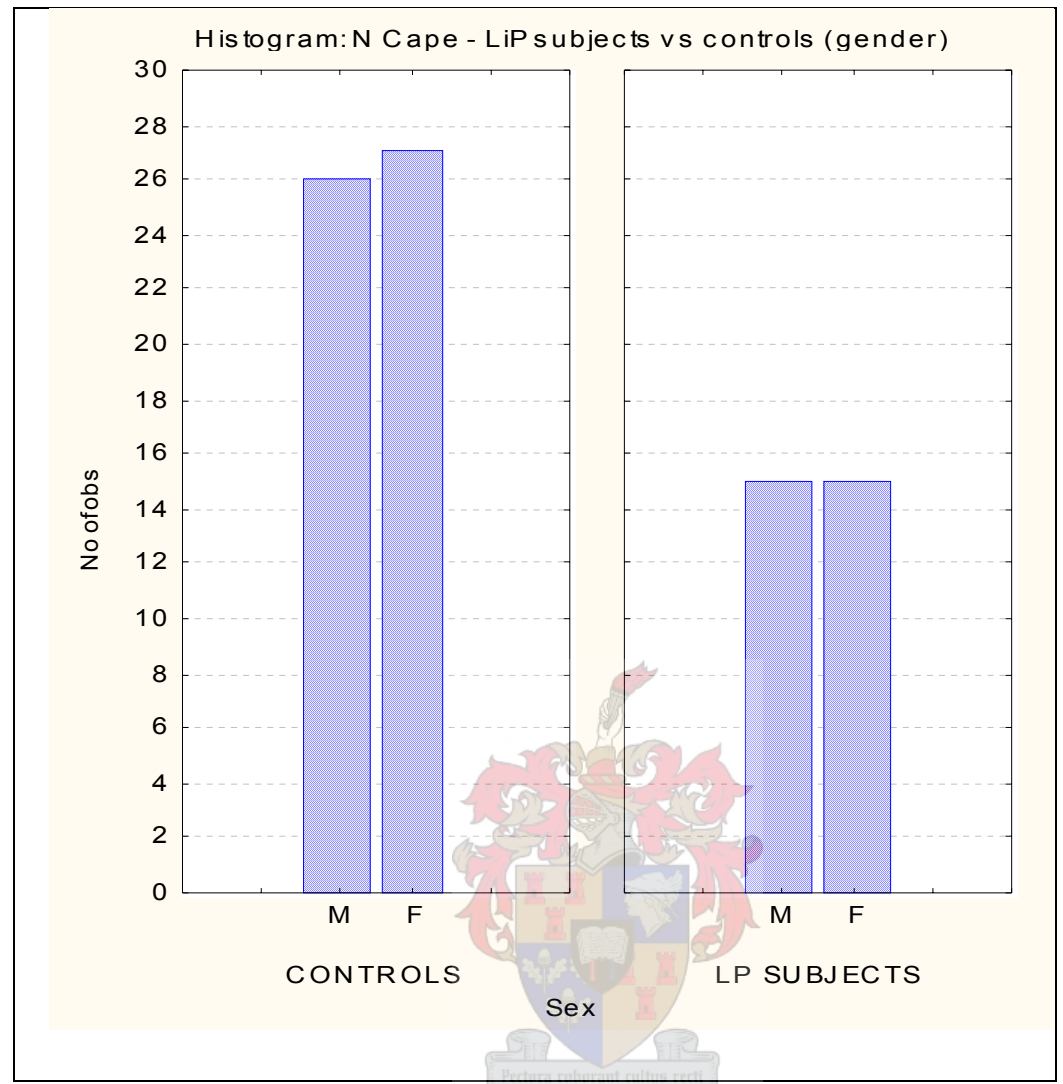




\section{Graph 7.2.}

\section{Age: Northern Cape LiP subjects versus Controls}

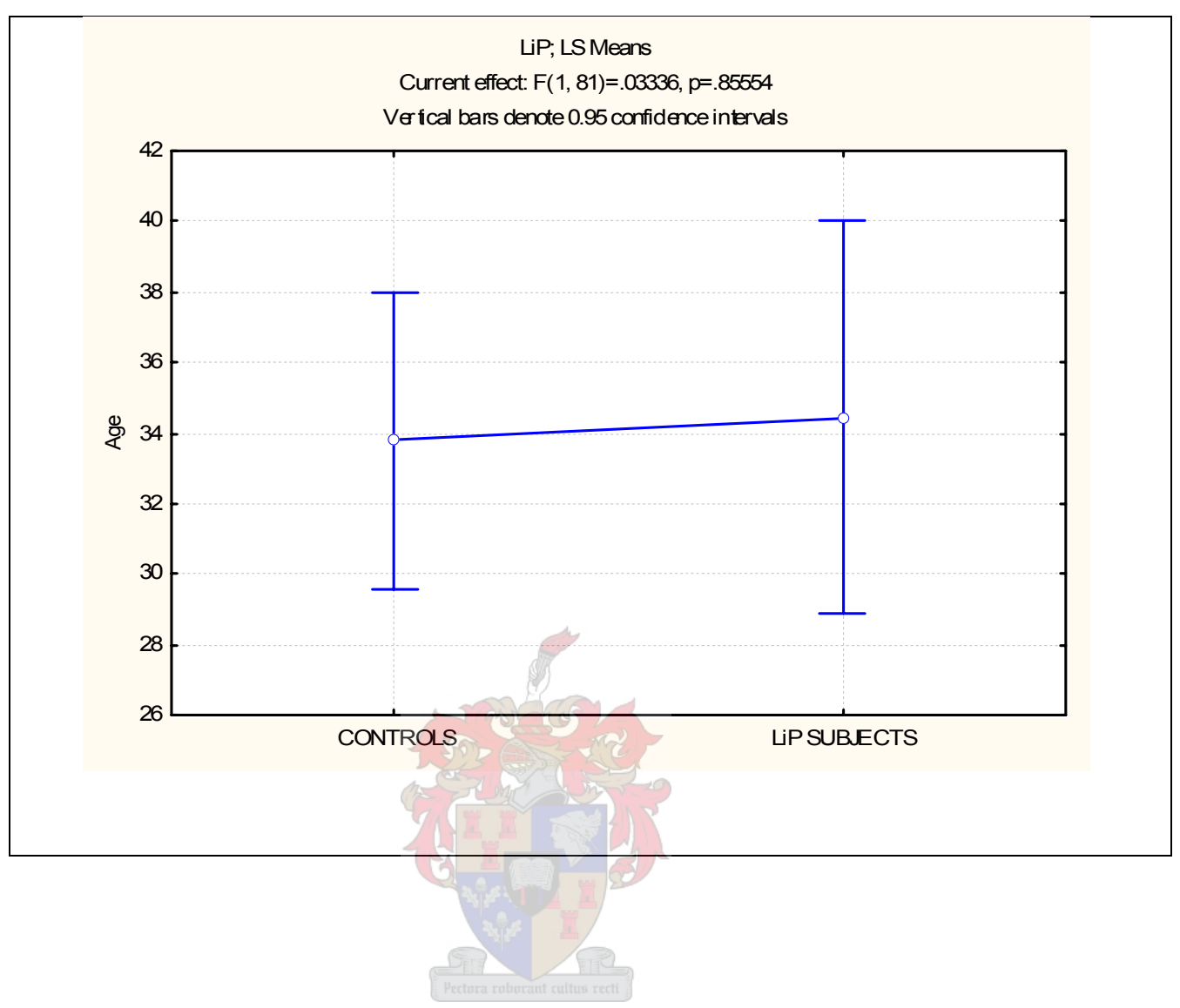




\section{Graph 7.3.}

\section{Education: Northern Cape LiP subjects versus Controls}

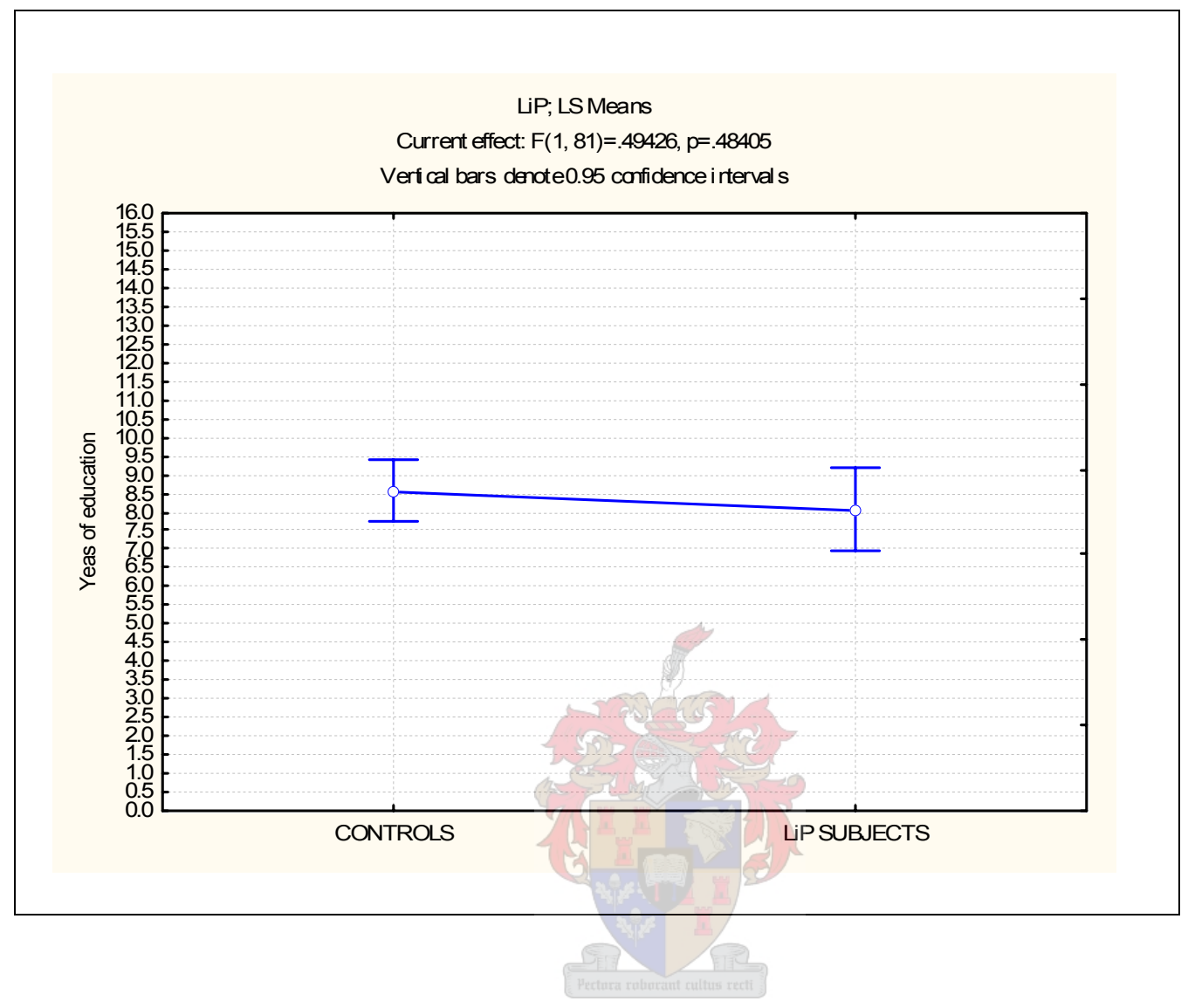


Eighteen NC LiP people (60\%) had the surname or had a direct ancestor with the surname 'Cloete', and for the control group it was 24 people (49\%) - not a statistically significant difference. On average, the NC LiP group had 0.83 children $(s d=1.580)$ and $19(63.33 \%)$ had no children. It was statistically more likely that patients with LiP would have no children, than matched controls. For the controls the mean number of children was $1.44(\mathrm{~s}=1.92)$ and six $(11.32 \%)$ had no children. Two of the NC LiP subjects had had tracheotomies $(6.67 \%)$ and none of the controls had had tracheotomies.

Patients with LiP were significantly more likely to report a history of epilepsy and psychosis, and were statistically more likely to have a diagnosis of schizophrenia $(p<0.01)$. Nine $(30 \%)$ of the NC LiP subjects reported a history of epilepsy - none of the controls reported having had a seizure. Six of the NC LiP population $(20 \%)$ reported a history of psychosis - none of the controls. Four of the NC LiP population (13.33\%) had a diagnosis of Schizophrenia - none of the controls. Unlooked for, the two NC groups were also matched for alcohol abuse ( $p=0.47$; no statistically significant difference).

In summary, the two Northern Cape groups were matched for gender, age (Current effect: $F(1,81)=.03336, p=.85554$ ), years of education (Current effect: $F(1,81)=.49426$, $p=.48405)$ and alcohol abuse $(p=0.47)$. They came from the same area, spoke the same language and were from the same racial and cultural group. 


\section{Exclusion of children}

For the neuropsychiatric and neuropsychological measures, the three children (aged 10, 12 and 15 years) were excluded from the neuropsychiatric and neuropsychological analysis. All of these children were male and from the Northern Cape. The Northern Cape control group was reduced from 53 participants to 47 (i.e. removing the six children matched in age to the LiP child subjects). The remaining adults involved in the study were in the age range of 17-63 (NC LiP subjects) and 17-65 years (NC controls).

Of the remaining thirty-four adults living with LiP there were 17 males (50\%) and 17 females. Age ranged from 17-63 (mean=36.21 years, $s d=13.60)$. All spoke Afrikaans as their home-language, $28(82.36 \%)$ were of mixed race, and $6(17.65 \%)$ were Caucasian. Levels of education ranged from 2-16 years (mean=9.32, sd=3.61) and one subject was illiterate. Two subjects had tracheotomies. Thirteen (38.24\%) reported having seizure disorder. The subjects were divided into those living in or out of the Northern Cape (NC) community.

In the NC adult LiP group ( $\mathrm{n}=27)$, there were 12 males $(44.4 \%)$ and 15 females $(55.6 \%)$. The mean age was 36.89 years ( $(d=14)$, and the mean education was 8.37 years (sd=3.2). The NC control group had 20 males (42.6\%) and 27 females (57.4\%), with a mean age of 36.51 years $(s d=14.2)$, and a mean education of 8.94 years ( $s d=2.93)$. In comparison, the non NC LiP group $(n=7)$, were comprised of 5 males $(71.4 \%)$ and 2 females $(28.6 \%)$. Their mean age was 33.57 years $(s d=12.51)$ and their mean education was 13 years ( $\mathrm{sd}=2.71$ ) (See Table 1 for demographic details). 
Table 7.1.

Demographics

\begin{tabular}{|c|c|c|c|c|c|c|c|c|}
\hline \multirow{2}{*}{\begin{tabular}{|l} 
Subjects \\
Male \\
\end{tabular}} & \multicolumn{2}{|c|}{$\begin{array}{l}\text { NC LiP subjects } \\
(n=27)\end{array}$} & \multicolumn{2}{|c|}{$\begin{array}{l}\text { NC Controls } \\
(n=47)\end{array}$} & \multirow[b]{2}{*}{$p=0.44$} & \multicolumn{3}{|c|}{$\begin{array}{l}\text { Non-NC LiP subjects } \\
(n=7)\end{array}$} \\
\hline & 12 & $44.4 \%$ & 20 & $42.6 \%$ & & Male & 5 & $71.4 \%$ \\
\hline \multirow[t]{2}{*}{ Female } & 15 & $55.6 \%$ & 27 & $57.4 \%$ & $p=0.56$ & Female & 2 & 28.6 \\
\hline & mean & Sd & mean & sd & & & Mean & sd \\
\hline Age & 36.89 & 14.00 & 36.51 & 14.20 & No significant & Age & 33.57 & 12.51 \\
\hline Education & 8.37 & 3.20 & 8.94 & 2.93 & differences & Education & 13.0 & 2.71 \\
\hline
\end{tabular}

\section{Exclusion of non-NC patients}

The NC subjects differed significantly from the non-NC LiP patients on a number of

demographic parameters (i.e. gender, epilepsy, years of education, level of

employment). (See Table 7.1.) The two subjects from Tygerberg Hospital had only

completed limited batteries, and there were often very low numbers for the non-NC LiP

patients. Thus non-NC LiP patients were also excluded from further neuropsychiatric

and neuropsychological analyses (chapters 10 and 11). However if there were points of

interest in their results then these were commented on at the end of each chapter. 


\section{Chapter 8}

\section{Results: Psychosocial}

Although the mean age (mid-thirties) was consistent between the Northern Cape groups and the non-NC LiP group, full-time employment between the two LiP groups differed markedly. This difference in employment was not between the NC LiP group and the NC controls, but between the people from the Northern Cape versus those not from the Northern Cape.

In the Northern Cape, only three people (less than 12\%) of the LiP population were in full-time employment (of which one was self-employed, and one worked for a family member). For the non-Northern Cape group, more than half (57.1\%) were in full time employment (see Table 8.1).

Table 8.1.

Employment details

\begin{tabular}{|c|c|c|c|c|c|c|c|c|c|}
\hline \multirow[b]{2}{*}{$p=0.78$} & \multirow{2}{*}{\begin{tabular}{|l} 
Subjects \\
Full time employ
\end{tabular}} & \multicolumn{3}{|c|}{$\begin{array}{l}\text { NC LiP subjects } \\
(n=27)\end{array}$} & \multicolumn{2}{|c|}{$\begin{array}{l}\text { NC Controls } \\
(n=47)\end{array}$} & \multicolumn{3}{|c|}{$\begin{array}{l}\text { Non-NC LiP subjects } \\
(n=7)\end{array}$} \\
\hline & & 3 & $11.1 \%$ & & 5 & $10.6 \%$ & Full time employ & 4 & $57.1 \%$ \\
\hline$p=0.81$ & Part time employ & 2 & $7.4 \%$ & & 4 & $8.5 \%$ & Part time employ & 1 & $14.3 \%$ \\
\hline$p=0.89$ & $\begin{array}{l}\text { Full or part time } \\
\text { employ }\end{array}$ & 5 & 18.5 & & 9 & $19.2 \%$ & $\begin{array}{l}\text { Full of part time } \\
\text { employ }\end{array}$ & 5 & $71.4 \%$ \\
\hline
\end{tabular}


To understand why this difference existed, and what the role of LiP could be in terms of employability, further scrutiny between the two LiP groups was needed.

One difference was in terms of race. One hundred percent of the NC LiP group was of mixed descent and in the population group known in South Africa as 'Coloured'. Of the 7 participants not from the Northern Cape, six of them (85\%) were Caucasian.

Historically due to Apartheid and generational fallout of Bantu education, Caucasian South Africans have usually had access to better quality and increased quantity of education, and access to job opportunities. In the adult NC LiP group $(n=27)$, the mean education was 8.37 years $(s d=3.2)$ and for the non NC LiP group $(n=7)$, the mean education of 13 years $(s d=2.71)$. In addition, the Northern Cape is generally an impoverished area and five of the non-Northern Cape LiP subjects came from the economically more powerful region of Johannesburg Pretoria Vereeniging, providing more infrastructure, resources and job opportunities.

Thus although the Northern Cape LiP group had such a low incidence of employability, it was not significantly different to employability of the Northern Cape control group. In all likelihood, education and socioeconomic factors confound any LiP-related explanation. However there are several factors where LiP could be playing a determinant role in terms of employability, especially in terms of associated neurological and neuropsychiatric and neuropsychological symptomatology. Employment and morbidity may affect an individual's quality of life.

In terms of other measures (e.g. relationship with adult partners or fertility), the following was evident: 
In the adult NC LiP group ( $\mathrm{n}=27)$, six people (22\%) were married, one was divorced and twenty $(74 \%)$ were single (Graph 8.1$)$. Eighteen people $(67 \%)$ lived with their parents, five $(19 \%)$ lived with partners, one stayed with a niece and three adults $(11 \%)$ with LiP lived alone. On average, they had 0.89 children ( 17 or $63 \%$ had no children, four people (15\%) had one child only, three had two children, one had three children, one had four children and one person with LiP had seven children). Seventeen (63\%) of the NC LiP respondents had a known family history of LiP and ten (37\%) did not. Thirteen subjects answered the question regarding forensic history, and only one person admitted to being arrested or convicted. Six or 33\% $(n=18)$ felt they had difficulties controlling their temper. 


\section{Graph 8.1.}

\section{Categorized Histogram: NC: Marital Status}

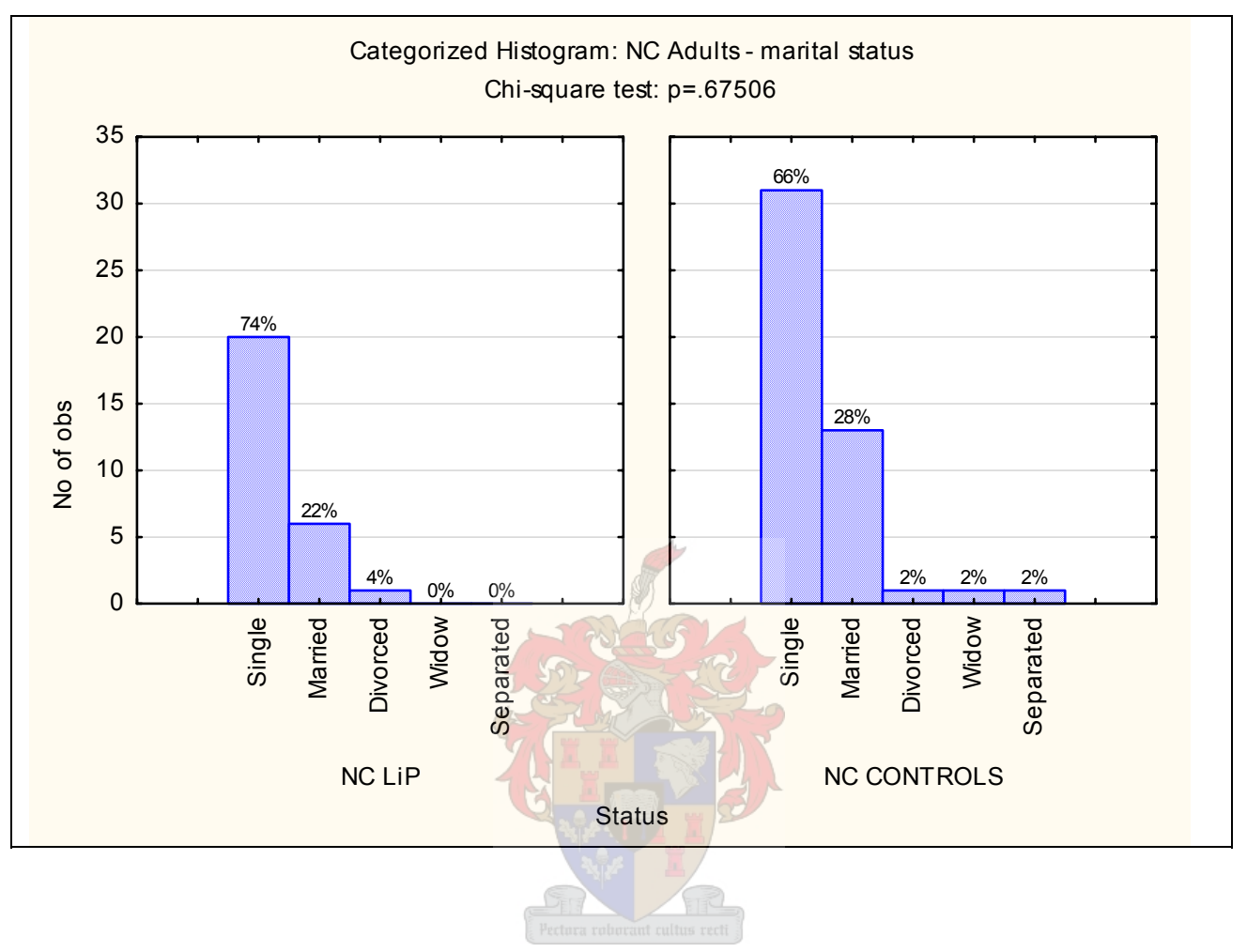


The adult NC control group $(n=47)$ answered the same questions. Thirteen $(28 \%)$ were married, one divorced, one separated, one widowed, and thirty-one (66\%) single. Seventeen people (36\%) lived with their parents, $14(30 \%)$ lived with partners, four with their grandparents, three with their children, four with siblings and one person did not answer the question (see Graph 8.2). On average, the NC controls had 1.63 children $17(36 \%)$ had no children, seven (15\%) had one child only, six had two children, six had three children, one had four children, three had five children, two had six children and person had seven children (see Graph 8.3 and 11.4). Four (9\%) of the control group knew there was a family history of LiP and $43(91 \%)$ denied any known LiP in their family. Seven admitted to a forensic history, and four felt they had difficulty controlling their temper. 


\section{Graph 8.2.}

\section{Categorized Histogram: NC adults - who they live with}

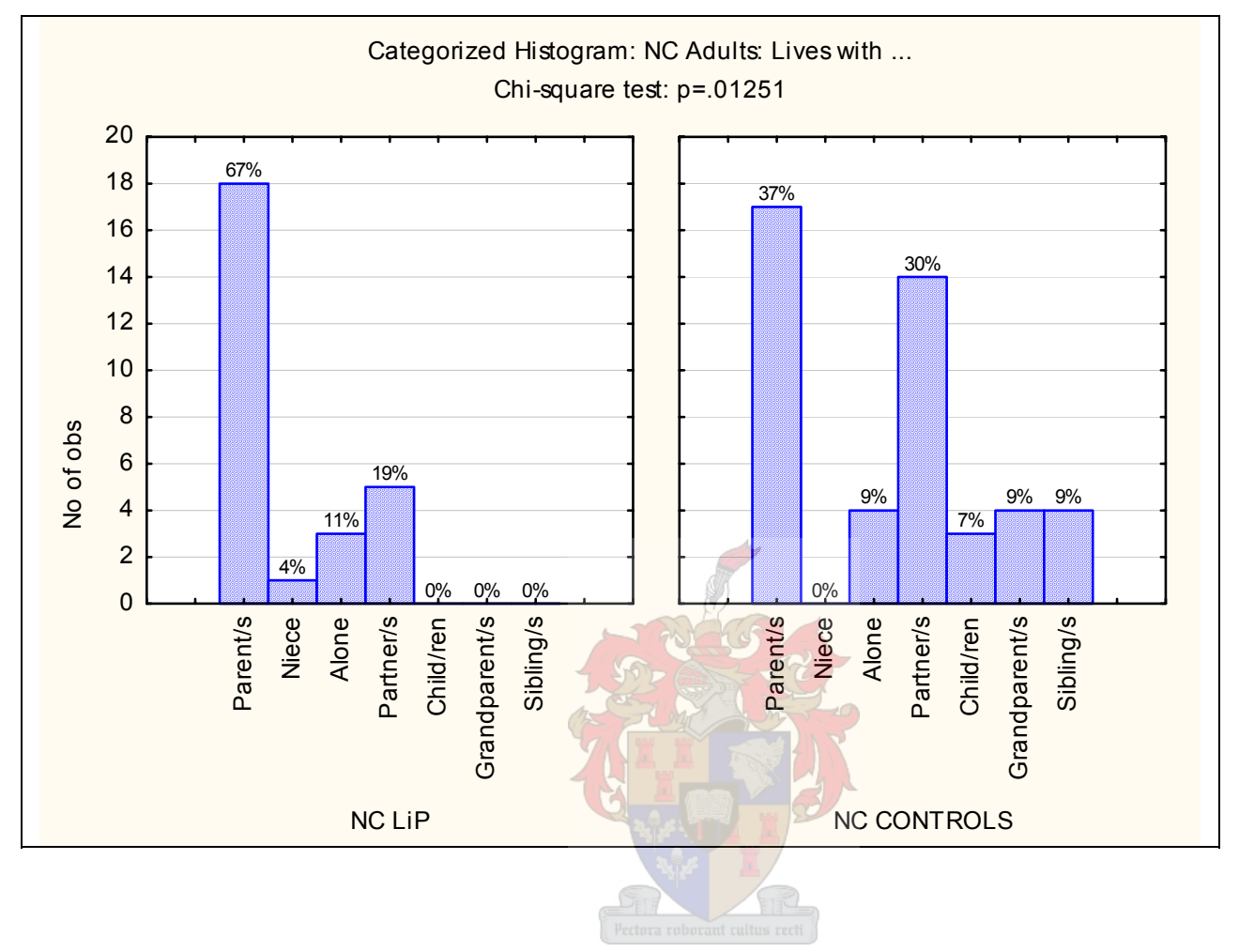




\section{Graph 8.3.}

\section{Categorized Histogram: NC: Number of Children}

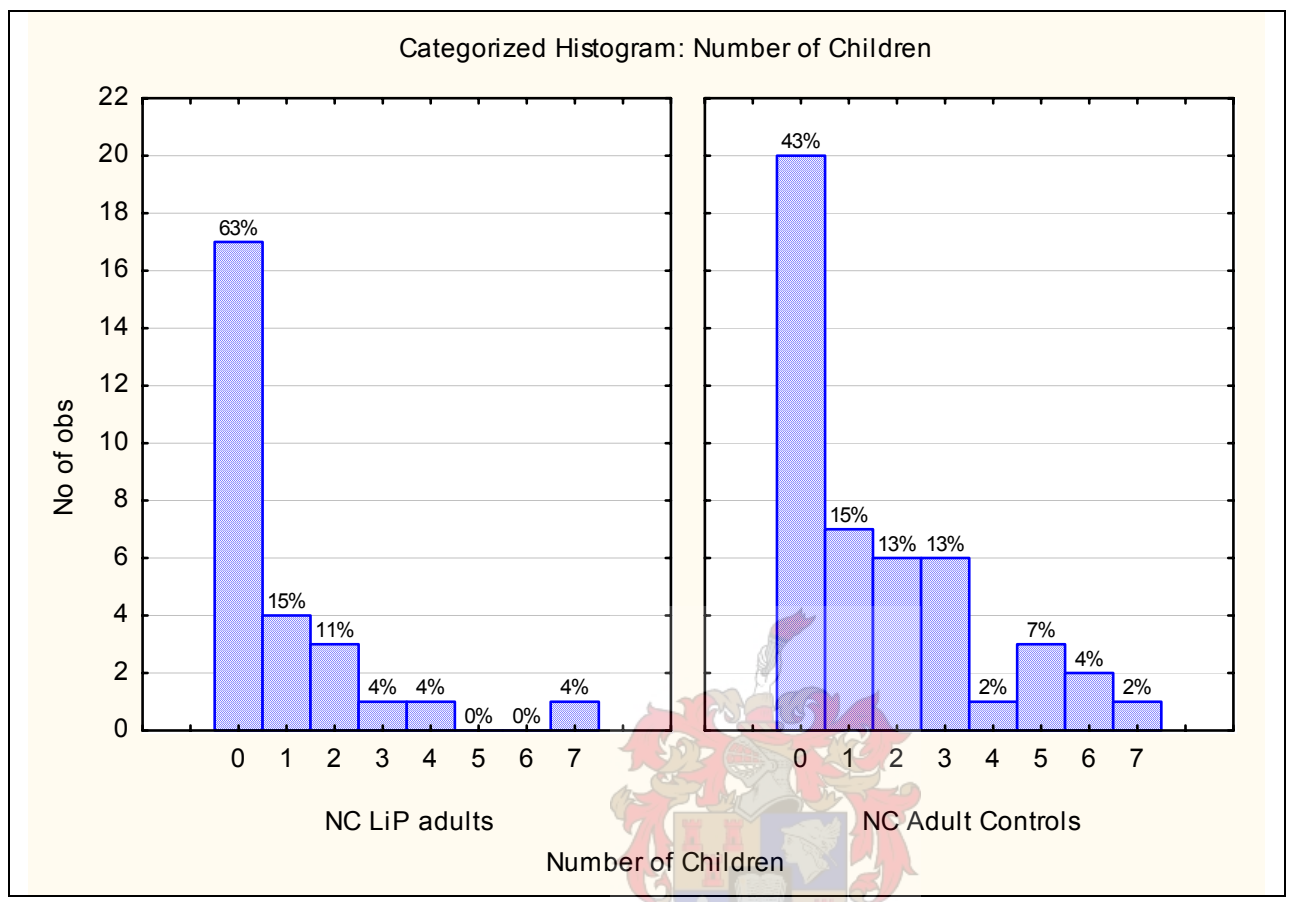


Graph 8.4.

Boxplot by Group: NC adults: Number of Children

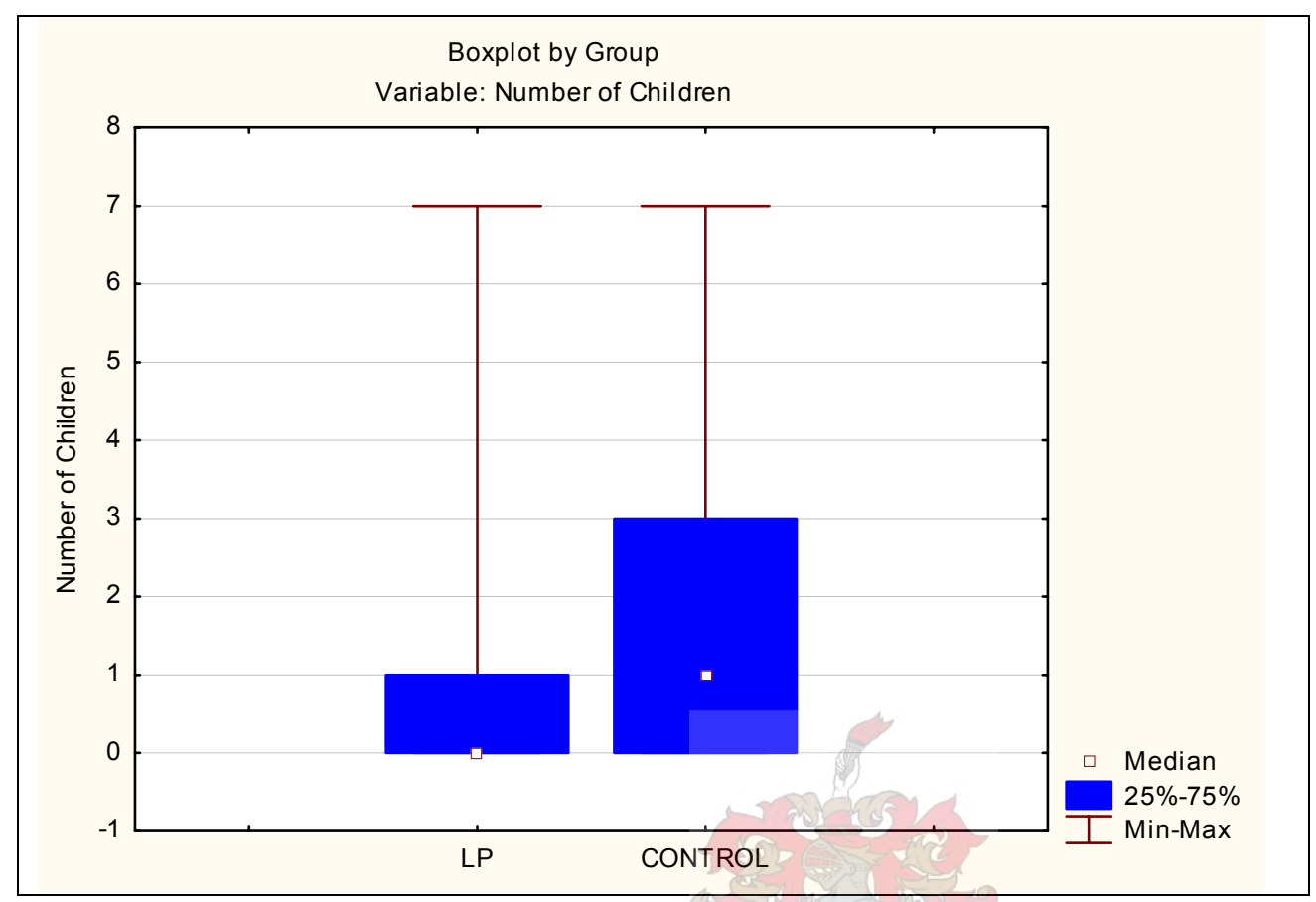


In the Quality of Life (QOL) Short Form - 36 scale (SF36), subjects were asked how they would rate their QOL during the last four weeks, or to say how things have gone for them. It was rated on a five point scale, with No. 1 being "Very well - it could not be going better" to No. 5 ("Very bad. It could not be worse.").

In the Northern Cape, there was no significant difference in results between patients with LiP (mean $=2.19, \mathrm{sd}=1.17)$ and the NC controls (mean $=2.21, \mathrm{sd}=0.89)$. Overall (all patients with LiP) the mean was $2.06(s d=1.14)$. That is, the mean for all the groups, irrespective or controls or subjects, was that "things were going relatively well". Only four people from the Johannesburg area answered the question and their mean was 1.5 $(s d=0.58)$.

In a second quality of life measure (rated from 0 to 10 , with zero being the worst possible quality of life and ten being the best possible quality of life, and five being "things equally good and bad"). Ninety-four percent $(n=30)$ of the LiP respondents rated themselves a five, or above. Only two respondents rated their quality of life on the negative side. (See Graph 8.5.) 
Graph 8.5.

Histogram (All LiP): Quality of Life measures

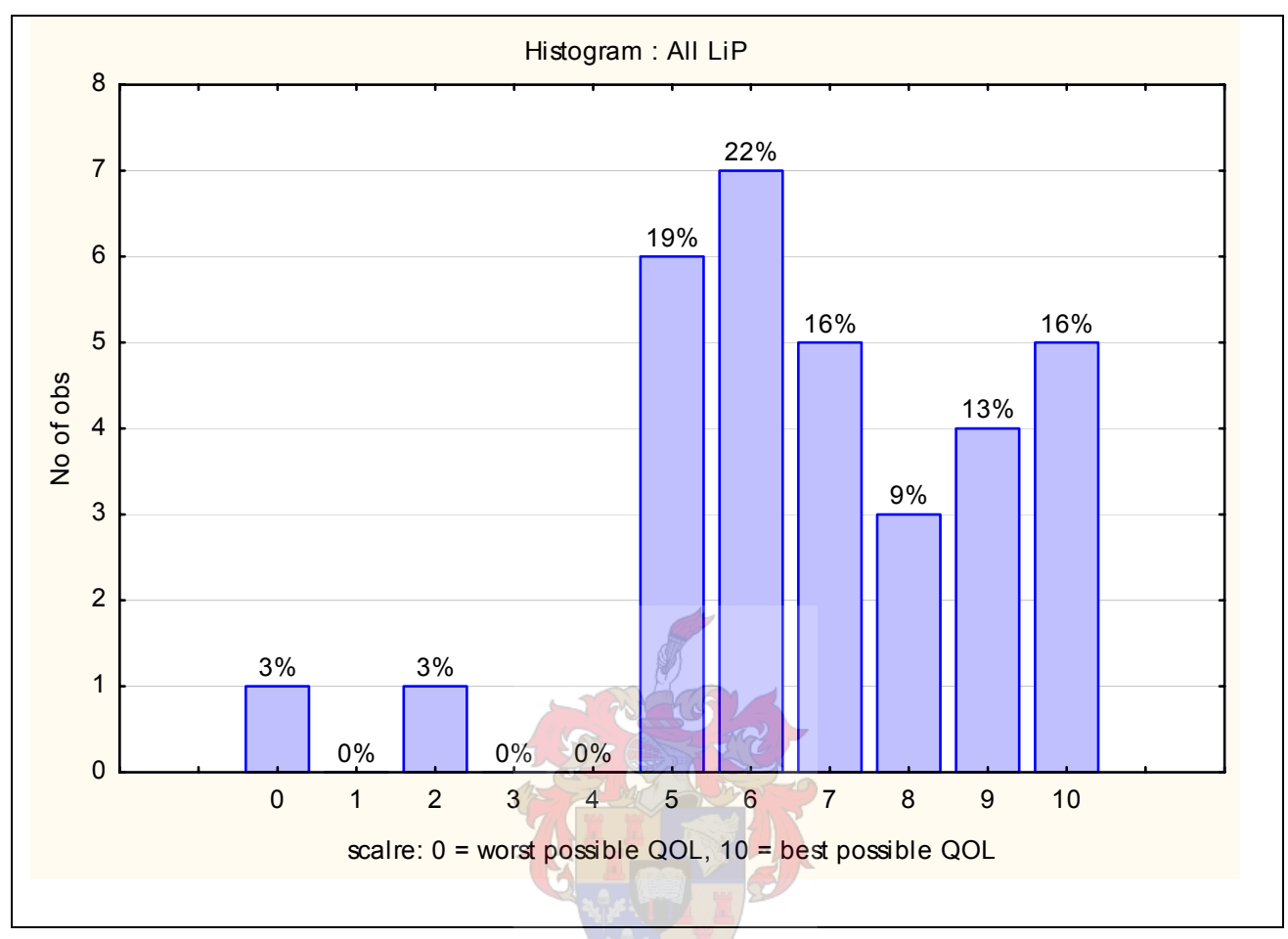

\section{Conclusion}

The research hypothesis that LiP is associated with decreased quality of life when compared to matched controls, was not conclusively confirmed. Lowered fertility in LiP was suggested. Patients with LiP were statistically significantly less likely to live with a partner and were statistically significantly less likely to have children, than matched controls. 


\section{Chapter 9}

\section{Results: 'Intelligence'}

\section{'Intelligence'}

All the subjects (adults and children), completed the WASI Performance Intelligence

measures. The estimated mean PIQ for the whole group $(n=36)$ was $81.4(s d=17.22)$. As the three children did not complete the WAISIII Vocabulary scale, only 31 subjects completed the subscale. The estimated mean VIQ $(n=33$, including the two subjects who completed the SAWAIS) was 81.3 , and the mean estimated FSIQ was 79.5. Once again there was marked variability with the FSIQ ranging from the mentally retarded to the superior ranges. (See Table 9.1 and Graph 9.1). 
Table 9.1.

Intelligence test results (All LiP subjects)

\begin{tabular}{|l|l|l|l|l|l|l|l|}
\hline All LiP subjects & $\mathbf{n}$ & mean & Median & mode & minimum & maximum & sd \\
\hline WAISIII Vocabulary & 31 & 5.90 & 5 & 3 & 3 & 14 & 2.65 \\
\hline WASI Similarities & 36 & 5.99 & 6 & 6 & 1 & 13 & 3.18 \\
\hline$\approx$ VIQ & 33 & 81.3 & 80 & multiple & 63 & 119 & 13.61 \\
\hline WASI Matrices & 34 & 5.15 & 4 & multiple & 1 & 13 & 3.59 \\
\hline WASI Block Design & 36 & 7.22 & 6.5 & multiple & 1 & 15 & 3.17 \\
\hline$\approx$ PIQ & 36 & 81.4 & 77 & 77 & 61 & 130 & 17.22 \\
\hline$\approx$ FSIQ & 33 & 79.5 & 75 & 66 & 60 & 121 & 15.88 \\
\hline
\end{tabular}




\section{Graph 9.1.}

Histogram of Intelligence Categorizations ( $\mathrm{N}=33$ LiP subjects)

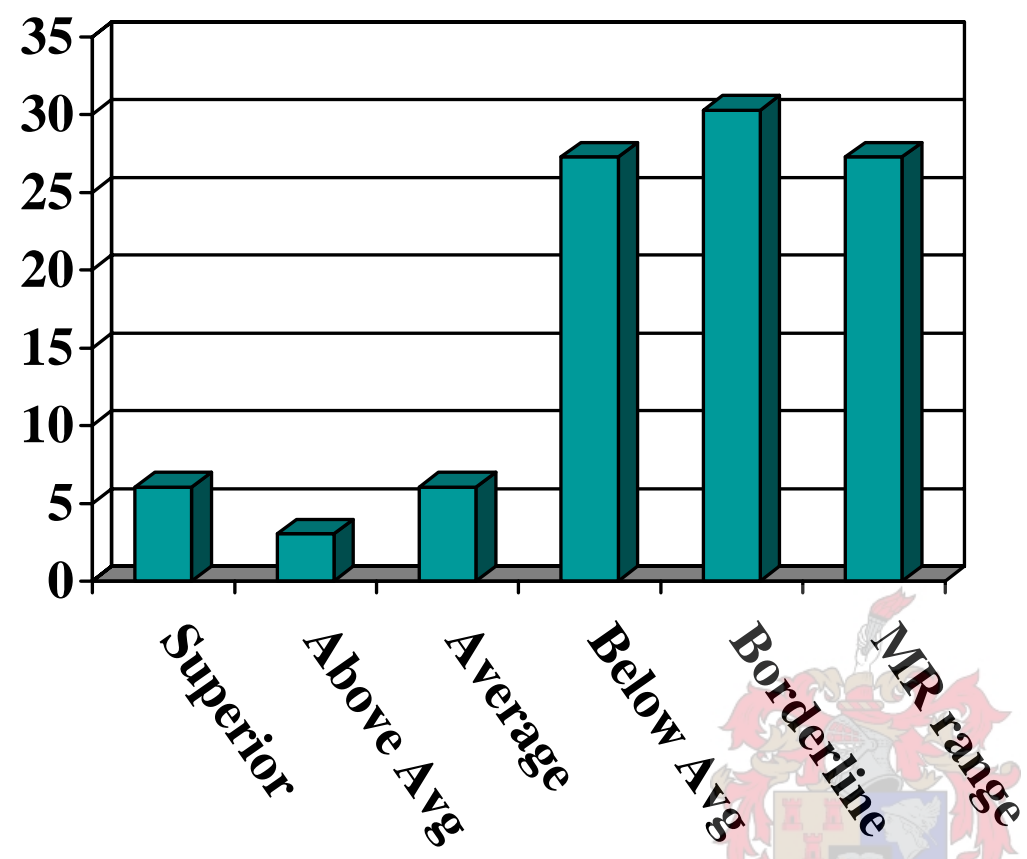


Not surprisingly, there was a strong positive, and significant correlation between 'intelligence' and years of education $(p=<0.001)$; the more the numbers of years of education, the higher the performance on the FSIQ. Every person with an average or above level of intelligence as assessed by the WASI had a Grade 10 or higher level of education. (See Graph 9.2).

\section{Graph 9.2.}

Correlation between 'intelligence' and years of education

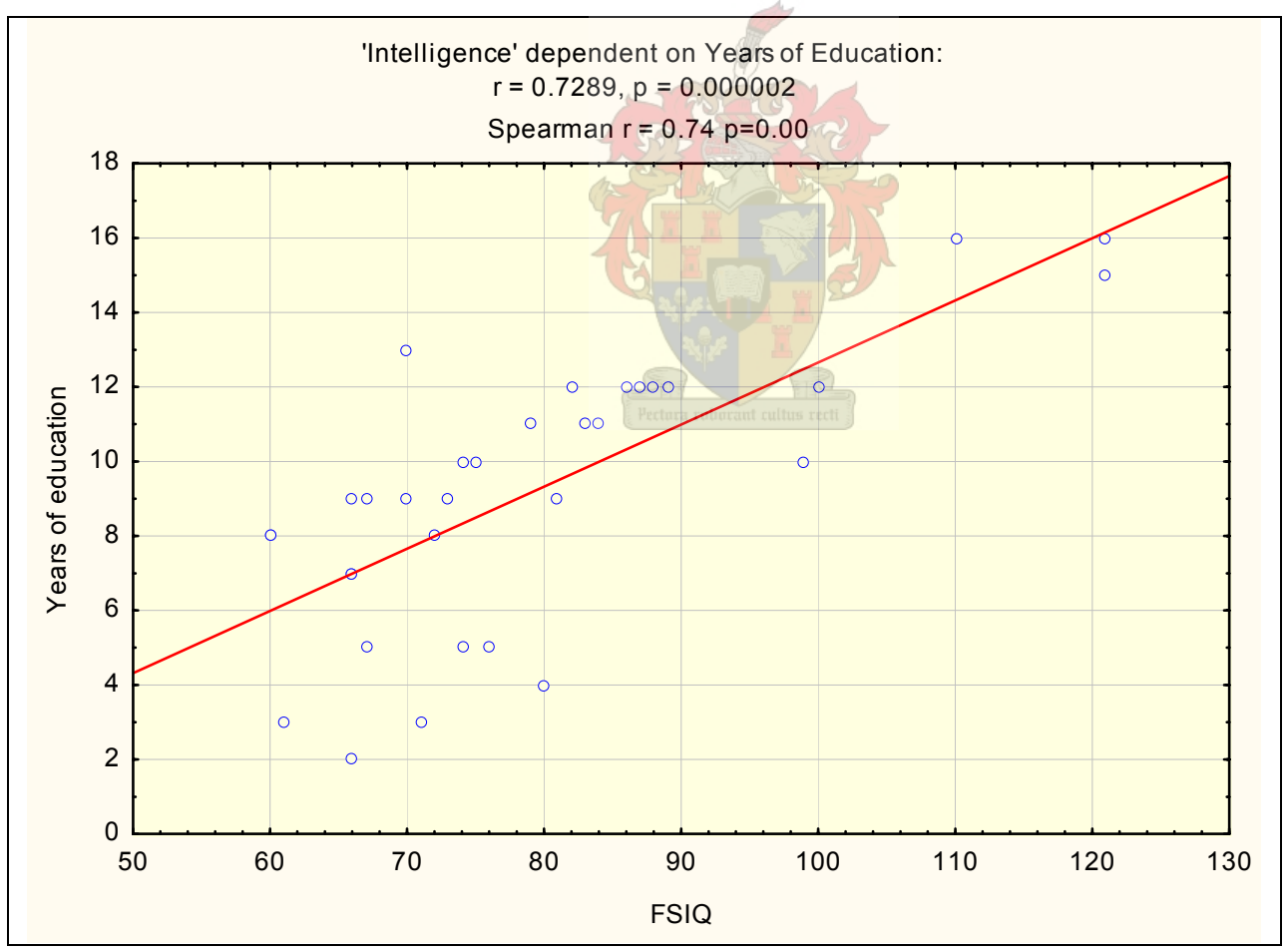


If taking all adult LiP subjects into consideration, both intelligence and years of education had significant correlations with subjects' abilities to recognize emotional expressions. (See Graph 9.3. for the relationship between 'intelligence' and recognition of fear).

\section{Graph 9.3.}

Scatterplot (All LiP adults' intelligence compared with recognition of fear)

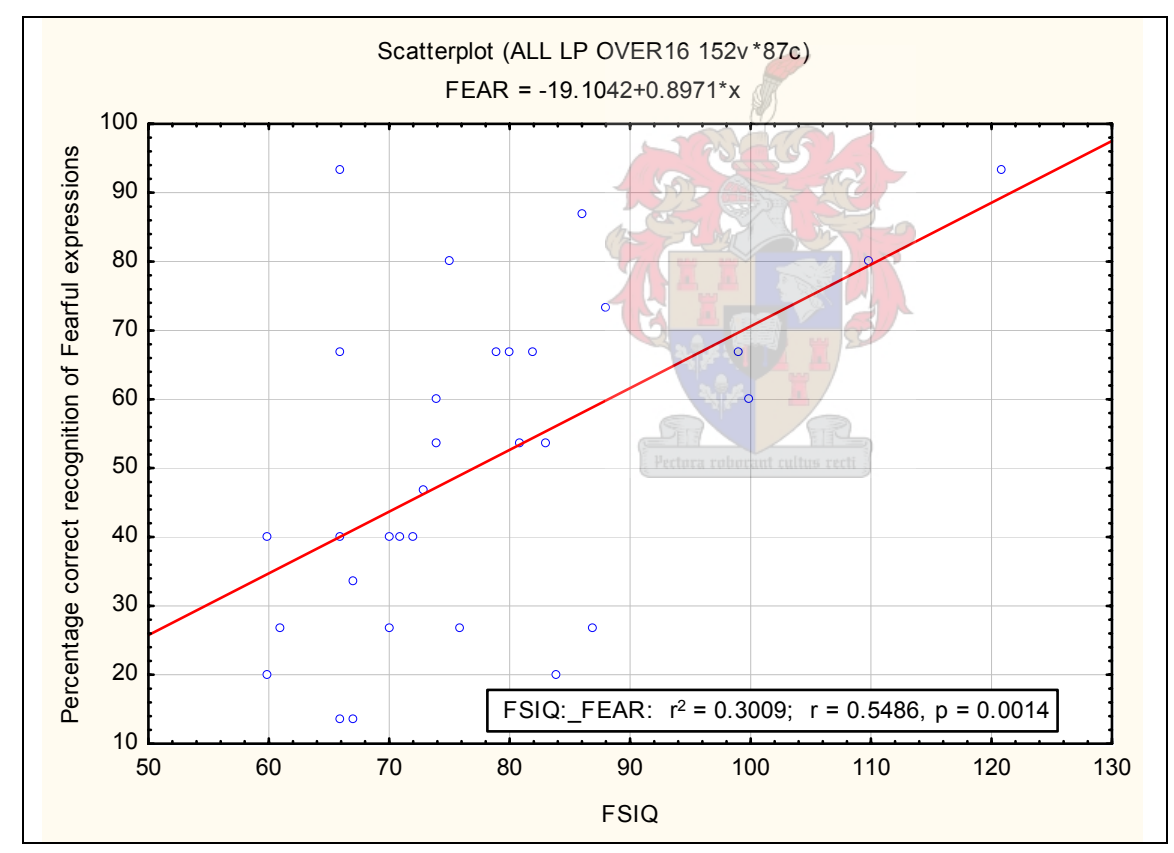


When only considering the Northern Cape subjects (including many educationally deprived participants) the mean IQ for both the NC LiP subjects and the Northern Cape controls was markedly poorer than established norms (See Table 9.2).

When comparing the LiP patients to the control subjects the following was evident; of the three WASI tests and Vocabulary test from the WAISIII, only Similarities was significantly different between the two groups (controls significantly better than LiP subjects). However this was sufficient to make the LiP NC population's WASI Verbal IQ measure and the WASI Full Scale IQ (FSIQ) measure significantly poorer than the controls.

Table 9.2.

Intelligence: Northern Cape: LiP versus Controls

\begin{tabular}{|c|c|c|c|c|c|c|c|c|c|c|c|c|c|}
\hline & \multicolumn{5}{|c|}{ LiP subjects } & \multicolumn{5}{|c|}{ Controls } & \multirow[b]{2}{*}{$p$} & \multirow[b]{2}{*}{\begin{tabular}{|l} 
Effect \\
size
\end{tabular}} & \multirow[b]{2}{*}{\begin{tabular}{|l} 
Normal \\
Distribution?
\end{tabular}} \\
\hline Test & mean & sd & $\min$ & $\max$ & $\mathbf{n}$ & mean & sd & $\min$ & $\max$ & $\mathrm{n}$ & & & \\
\hline VIQ & 76.81 & 9.73 & 63.00 & 98.00 & 26 & 82.39 & 8.00 & 69.00 & 100.00 & 41 & 0.0129 & 0.641 & yes \\
\hline PIQ & 76.23 & 10.85 & 61.00 & 99.00 & 26 & 79.63 & 10.90 & 63.00 & 101.00 & 38 & 0.2178 & 0.313 & no \\
\hline FSIQ & 74.38 & 9.82 & 60.00 & 99.00 & 26 & 79.86 & 8.99 & 68.00 & 101.00 & 35 & 0.0254 & 0.586 & no \\
\hline
\end{tabular}




\section{Comment on the performance of the non-NC LiP patients}

As a mean performance ('intelligence'), those patients with LiP who did not come from the Northern Cape performed better than those without LiP who lived in the Northern Cape.

As a group the non-NC group were better educated and had higher mean intelligence scores, but with a considerable variance in performance. When considering these LiP subjects $(n=7)$ the mean FSIQ was $98.57(s d=20.12$, range=70-121), VIQ was 97.86 (sd=13.66, range=79-119) and PIQ was 99.86 (sd=26.74, range=64-130). (See Table 9.3.) Two participants with superior intelligence quotients (FSIQ $\geq 120$ ) tended to skew the results - with their exclusion the mean intelligence fell by ten quotients $(F S I Q=89.6$, $n=5)$.

Table 9.3.

Intelligence: Non-Northern Cape

\begin{tabular}{|l|l|l|}
\hline \multicolumn{3}{|l|}{ Non NC LiP subjects $(\mathbf{n = 7})$} \\
\hline Test & mean & sd \\
\hline VIQ & 97.86 & 13.66 \\
\hline PIQ & 99.86 & 26.74 \\
\hline FSIQ & 98.57 & 20.12 \\
\hline
\end{tabular}




\section{Chapter 10}

\section{Results: Neuropsychological}

Only the neuropsychology results from the adult NC patients were included in the analysis. One adult LiP patient did not complete any of the neuropsychology tests as he was psychotic at the time of the assessment and was unable to provide informed consent. Twenty-six NC LiP patients and 47 controls thus completed the following neuropsychology tests:

\section{Language tests}

In terms of the two Northern Cape groups, there were no significant differences across NC LiP subjects and controls for the two tests of language (COWAT and Vocabulary, WAISIII). The mean COWAT score was $25.78(s d=11.29)$ and the mean scaled WAISIII Vocabulary score (Afrikaans translation) was $5.38(s=2.23)$. 
Attention and concentration tests

When the Northern Cape LiP subjects were compared to matched controls, both DF and DB were of significance (Controls performing significantly better than LiP participants). (See Table.10.1.)

Table 10.1.

NC Li versus Controls (Concentration tests)

\begin{tabular}{|c|c|c|c|c|c|c|c|c|c|c|c|}
\hline \multirow{2}{*}{$\begin{array}{l}\text { Northern Cape } \\
\text { Test } \\
\end{array}$} & \multicolumn{4}{|c|}{ LiP } & & \multicolumn{5}{|c|}{ Controls } & \multirow[b]{2}{*}{$\mathbf{p}$} \\
\hline & mean & sd & $\min$ & $\max$ & $\mathrm{n}$ & mean & sd & $\min$ & $\max$ & $\mathrm{n}$ & \\
\hline DF & \begin{tabular}{|l|}
5.00 \\
\end{tabular} & 0.94 & 4 & 7 & 26 & 5.64 & 0.93 & 4 & 8 & & $0.0113^{x}$ \\
\hline DB & 3.42 & 0.90 & 2 & & 26 & 4.06 & 0.97 & 2 & 6 & & $0.0122^{\prime}$ \\
\hline
\end{tabular}




\section{Memory tests}

LiP patients' auditory memory was assessed on the RAVLT and LM, WMS-R. On average, NC patients recalled a mean of 5.46 words on their immediate recall $(s d=1.9)$, learned 4.81 new words over the five trials ( $s d=1.7$ ), and after a distraction task, retained $76.29 \%$ of the words they had learned $(s d=21.25)$, to produce 8.08 words $(s d=3.21)$ on the recall trial (RAVLT Trial VI). After a delay of one hour ${ }^{75}$, subjects recalled a mean of 7.77 words ( $s d=3.61$ ), correctly recognized a mean of 13.19 words $(s d=2.42)$ and incorrectly identified 5.81 words $(s d=6.16)$ from the 35 distracters. (See Table 10.2)

However the NC LiP group scored significantly worse than controls on several tests of memory, including auditory new learning on RAVLT, retention after distraction, the recognition task, the number of repetitions in new learning, on both immediate and delayed paragraph recall, as well as the percentage of the story that was retained, and on delayed recall of the visual reproductions designs (see Table 10.2). There were no significant differences in either forewarned or incidental immediate recall tasks.

Visual recall was assessed by the VR, WMS-R. The mean immediate recall (VRI) was 30.16 ( $\mathrm{sd}=7.02$ ), delayed Visual Reproduction (VRII) fell to a mean of 23.32 (sd=9.61), with a mean retention of $74.2 \%(s d=22.3)(V R I I / V R I ~ * 100)$. Twelve NC LiP patients completed the immediate incidental recall of the Complex Figure of Rey (RCFI) and recalled a mean of $14.17 / 36(s d=5.06)$. 
Table 10. 2.

NC LiP patients versus Controls (Memory tests)

\begin{tabular}{|c|c|c|c|c|c|c|c|c|c|c|c|c|c|}
\hline \multirow{2}{*}{\begin{tabular}{|l} 
Northern Cape \\
Test \\
\end{tabular}} & \multicolumn{5}{|c|}{ LiP (17-63 years) } & \multicolumn{5}{|c|}{ Controls (17-65 years) } & \multirow[b]{2}{*}{$\mathbf{p}$} & \multirow{2}{*}{$\begin{array}{l}\text { Effect } \\
\text { size }\end{array}$} & \multirow{2}{*}{\begin{tabular}{|l|} 
Normal \\
Distribu \\
tion?
\end{tabular}} \\
\hline & mean & sd & $\min$ & $\max$ & $\mathbf{n}$ & mean & sd & $\min$ & $\max$ & n & & & \\
\hline RAVLT I & 5.46 & \begin{tabular}{|l|l|}
1.90 \\
\end{tabular} & 1 & 9 & 26 & 6.68 & \begin{tabular}{|l|}
2.21 \\
\end{tabular} & 2 & 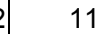 & 41 & $0.0232^{*}$ & .582 & yes \\
\hline RAVLT II & 7.81 & 1.96 & 5 & 11 & 26 & 9.22 & 2.32 & 4 & 13 & 41 & $0.0123^{*}$ & .645 & yes \\
\hline RAVLT III & 9.31 & 2.57 & 4 & 13 & 26 & 10.32 & 2.36 & 4 & 15 & 41 & 0.1044 & .413 & yes \\
\hline RAVLT IV & 9.62 & 2.87 & 4 & 14 & 26 & 11.29 & 2.40 & 4 & 15 & 41 & $0.0181^{*}$ & .644 & no \\
\hline RAVLT V & 10.27 & 2.41 & 4 & 13 & 26 & 11.46 & 2.45 & 3 & 15 & 41 & $0.0285^{\star}$ & .489 & no \\
\hline RAVLT VI (Recall after Interference) & 8.08 & 3.21 & 1 & 13 & 26 & 10.49 & 2.93 & 3 & 15 & 41 & $0.0024^{\star *}$ & .793 & yes \\
\hline RAVLT VII (Delayed Recall) & 7.77 & 3.61 & 0 & 14 & 26 & 9.76 & 2.93 & 3 & 15 & 41 & $0.0408^{*}$ & .620 & no \\
\hline RAVLT B (Interference trial) & 5.12 & 2.29 & 1 & 9 & 26 & 6.07 & 2.45 & 2 & 11 & 41 & 0.1149 & .397 & yes \\
\hline RAVLT total (Trials I to V) & 42.42 & 10.56 & 23 & 59 & 26 & 48.98 & 10.48 & 19 & 67 & 41 & $0.0155^{*}$ & .624 & yes \\
\hline RAVLT V-VI & 2.19 & 1.88 & -1 & 7 & 26 & 0.98 & 1.29 & -3 & 4 & 41 & $0.0025^{\star *}$ & & yes \\
\hline RAVLT V-VII & 2.50 & 2.14 & -1 & 7 & 26 & 1.71 & 1.58 & -1 & 6 & 41 & 0.1638 & & no \\
\hline RAVLT VI-VII & 0.31 & 1.54 & -2 & 4 & 26 & 0.73 & 1.55 & -2 & 5 & 41 & 0.2783 & & yes \\
\hline RAVLT V-I & 4.81 & 1.70 & 0 & 8 & 26 & 4.78 & 2.14 & -1 & 9 & 41 & 0.9565 & & yes \\
\hline RAVLT VI/V \% retention & 76.29 & 21.25 & \begin{tabular}{|l|l|}
5.00 \\
\end{tabular} & 109.09 & 26 & 90.72 & 12.19 & 60.00 & 125.00 & 41 & $0.0020^{\star *}$ & .886 & no \\
\hline RAVLT VII/V \% retention & 72.17 & 26.65 & 0 & 107.69 & 26 & 84.57 & 13.90 & 54.55 & 107.69 & 41 & 0.0627 & .626 & no \\
\hline RAVLT VII/VI \% retention & 92.76 & 30.10 & 0 & 133.33 & 26 & 93.80 & 13.65 & 61.54 & 122.22 & 41 & 0.3534 & .048 & no \\
\hline RAVLT Recognition True positives (TP) & 13.19 & 2.42 & 6 & 15 & 26 & 14.02 & 1.31 & 8 & 315 & 41 & 0.2966 & .456 & no \\
\hline RAVLT Recognition False Positives (FP) & 5.81 & 6.16 & 0 & 24 & 26 & 2.88 & 3.98 & 0 & 19 & 41 & $0.0348^{*}$ & 1.055 & no \\
\hline RAVLT Adjusted Recognition (TP-FP) & 7.38 & 6.20 & -9 & 15 & 26 & 11.15 & 3.98 & -4 & 15 & 41 & $0.0073^{\star *}$ & 1.334 & no \\
\hline RAVLT Recognition total $(/ 50)$ & 42.38 & 6.20 & 26 & 50 & 26 & 46.15 & 3.98 & 31 & 50 & 41 & $0.0073^{* *}$ & & no \\
\hline RAVLT Errors (Trials I to V) & 1.12 & 1.90 & 0 & 6 & 26 & 0.61 & 1.30 & 0 & 7 & 41 & 0.4020 & .327 & no \\
\hline RAVLT Repetitions (Trials I to V) & 6.77 & 4.89 & 0 & 19 & 26 & 4.54 & 4.05 & 0 & 19 & 41 & $0.0336^{*}$ & .508 & no \\
\hline LMI WMS-R & 17.85 & 6.55 & 5 & 34 & 26 & 26.56 & 7.69 & 3 & 40 & 43 & $0.0000^{* *}$ & 1.195 & yes \\
\hline LMII WMS-R & 13.54 & 6.20 & 0 & 28 & 26 & 23.60 & 7.33 & 8 & \begin{tabular}{|l|l|}
30 \\
\end{tabular} & 42 & $0.0000^{* *}$ & 1.452 & yes \\
\hline LMII/LMI \% retention & 72.87 & 20.64 & 0 & 100 & 26 & 86.29 & \begin{tabular}{|l|}
11.53 \\
\end{tabular} & 60.00 & 105.88 & 42 & $0.0024^{\star *}$ & & no \\
\hline VRI WMS-R & 30.16 & 7.02 & 13 & 39 & 25 & 33.29 & 5.46 & 13.00 & 39.00 & 38 & 0.0686 & .511 & no \\
\hline VRII WMS-R & 23.32 & 9.61 & 3 & 37 & 25 & 28.00 & 8.47 & 2.00 & 39.00 & 38 & $0.0292^{*}$ & .524 & no \\
\hline VRII/VRI WMS-R \% retention & 74.20 & 22.30 & 18.75 & 100.00 & 25 & 82.27 & 20.08 & 15.38 & 104.00 & 38 & 0.0731 & & no \\
\hline RCFI (/36) (Immediate incidental recall) & 14.17 & 5.08 & 8.50 & 25.00 & 12 & 17.66 & 7.28 & 2.00 & 33.00 & 45 & 0.1070 & .506 & no \\
\hline
\end{tabular}




\section{Executive tests}

Executive tasks ranged from planning (DAC, RCF Copy, HVOT, Matrices WASI and BD WASI) to initiation, inhibition and switching (COWAT, RFFT, TMTB, RAVLT) and abstract thinking (Similarities, WASI).

The LiP patients performed as follows on tests of planning. Copying of a complex figure was intact $(\mathrm{RCF}$ mean $=32.04$ with more than half the subjects achieving the mode of 34/36). Their design of a Clock was intact $(x=9.4 / 10, s d=1$, and more than half achieving a mode of 10/10). The mean out of 30 on the HVOT was $16.81(\mathrm{sd}=4.75)$, and on the WASI Performance tasks, LiP patients' scaled scores were $4.5(\mathrm{sd}=2.96, \mathrm{n}=26)$ for Matrices and $6.15(\mathrm{sd}=2.36, \mathrm{n}=26)$ for Block Design (BD). When compared to the control group, there were no significant differences on tests of planning (DAC, copy of Complex Figure, WASI Matrices or Block Design) in the NC LiP group - although the NC LiP group did significantly worse on visual organization (HVOT). (See Table 10.3.)

For the adult NC LiP group, verbal initiation produced a mean of 25.78 words $(s d=11.29)$ for the combined total of three phonetic categories. On Part A of the Ruff Figural Fluency Test (RFFT) the mean number of designs generated in one minute was $8.92(s d=3.51, n=25)$ with a mean of 0.68 perseverative errors $(s d=0.85)$. For the entire RFFT (all five parts) the mean was 47.61 designs being generated ( $s d=18.2)$ with a mean of 5.39 perseverative errors $(s d=6.35)$. On the Trails tasks, the mean time in seconds to complete TMTA was 50.28 seconds $(s d=24.95)$ and 121.05 seconds to complete TMTB ( $(\mathrm{d}=65.61)$. The mean difference in time (TMTB-TMTA) was over a minute $(x=76.68$ seconds longer to complete TMTB, $s d=55.14)$ and the mean number of errors requiring correction on TMTB was 1.09 ( $(s d=1.41)$. When compared to matched 
controls, there were a number of significant differences in these executive tasks. In the Northern Cape, the control group performed significantly better than the NC group on the RFFT, TMTB, and Similarities tests (see Table 10.3).

Abstract thinking as measured by the WASI Similarities task gave a mean scaled score of $4.88(\mathrm{sd}=2.64, \mathrm{n}=26)$. Once again, when comparing the NC LiP group to the matched controls, there were differences. The control group performed significantly better than the LiP group $(p=0.0091)$.

Thus controls performed significantly better than NC LiP subjects on memory and specific executive abilities (design initiation, switching, visual organization and abstract thinking), but language tasks and other executive skills (planning) appeared unaffected by LiP. 
Table 10.3.

NC LiP patients versus Controls (Executive tests)

\begin{tabular}{|c|c|c|c|c|c|c|c|c|c|c|c|c|c|}
\hline \multirow{2}{*}{$\begin{array}{l}\text { Northern Cape } \\
\text { Test }\end{array}$} & \multicolumn{5}{|l|}{ LiP } & \multicolumn{5}{|c|}{ Controls } & \multirow[b]{2}{*}{ p } & \multirow[b]{2}{*}{$\begin{array}{l}\text { Effect } \\
\text { Size }\end{array}$} & \multirow[b]{2}{*}{$\begin{array}{l}\text { Normal } \\
\text { Distribution? }\end{array}$} \\
\hline & mean & sd & $\min$ & $\max$ & n & mean & sd & $\min$ & $\max$ & n & & & \\
\hline HVOT & 16.81 & 4.75 & 6.50 & 23.50 & 26 & 20.67 & 4.69 & 10.00 & 28.00 & & $30.0028^{* *}$ & .818 & yes \\
\hline $\mathrm{DAC}(/ 10)$ & 9.40 & 1.00 & 7.00 & 10.00 & 25 & 9.81 & 0.48 & 8.00 & 10.00 & 3 & 10.2441 & .543 & no \\
\hline RCF Copy (/36) & 32.04 & 4.93 & 15.50 & 36.00 & 25 & 32.77 & 5.33 & 10.00 & 36.00 & & 60.2623 & .141 & no \\
\hline Matrices, WASI & 4.50 & 2.96 & 1.00 & 10.00 & 26 & 5.23 & 3.03 & 1.00 & 12.00 & & 40.3314 & .243 & yes \\
\hline BD WASI & 6.15 & 2.36 & 1.00 & 10.00 & 26 & 6.58 & 2.21 & 1.00 & 11.00 & 3 & 80.4654 & .189 & yes \\
\hline RFFT 1 Unique designs & 8.92 & 3.51 & 4.00 & 18.00 & 25 & 12.02 & 4.07 & 5.00 & 21.00 & & $50.0021^{* *}$ & .799 & yes \\
\hline RFFT 1 Perseverations & 0.68 & 0.85 & 0.00 & 3.00 & 25 & 1.23 & 1.67 & 0.00 & 6.00 & & 30.4039 & .384 & no \\
\hline RFFT Total designs & 47.61 & 18.20 & 22.00 & 79.00 & 23 & 63.61 & 18.49 & 31.00 & 107.00 & & $30.0050^{* *}$ & .872 & yes \\
\hline RFFT Total errors & 5.39 & 6.35 & 0.00 & 26.00 & 23 & 7.57 & 7.37 & 0.00 & 31.00 & & 30.1546 & .317 & no \\
\hline RFFT Total err ratio & 0.11 & 0.10 & 0.00 & 0.33 & 22 & 0.12 & 0.11 & 0.00 & 0.47 & & 30.8485 & .095 & no \\
\hline TMTA (seconds) & 50.28 & 24.95 & 21.00 & 138.00 & 25 & 34.29 & 11.93 & 16.00 & 73.00 & & $80.0007^{* *}$ & .879 & no \\
\hline TMTB (seconds) & 121.05 & 65.61 & 44.00 & 261.00 & 22 & 72.95 & 28.38 & 342.00 & 170.00 & & $90.0010^{* *}$ & 1.062 & no \\
\hline TMTA-B (seconds) & 76.68 & 55.14 & 17.00 & 194.00 & 22 & 39.34 & 25.82 & 7.00 & 134.00 & & $80.0071^{* *}$ & & no \\
\hline TMTB (errors) & 1.09 & 1.41 & 0.00 & 4.00 & 22 & 0.49 & 1.07 & 0.00 & 5.00 & & 90.0570 & & no \\
\hline Similarities WASI & 4.88 & 2.64 & 1.00 & 9.00 & 26 & 6.54 & 2.32 & 2.00 & 11.00 & & $10.0091^{* *}$ & .677 & yes \\
\hline
\end{tabular}




\section{Conclusion}

The research hypothesis that LiP is associated with increased cognitive impairment when compared to matched controls was confirmed.

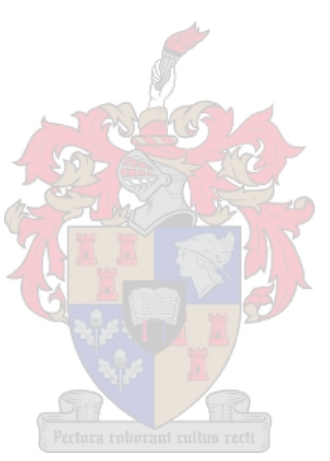




\section{Chapter 11}

\section{Results: Neuropsychiatric}

There were 27 adult NC LiP patients and 47 adult NC controls. All of the following results refer to these groups:

Twenty-seven percent of the NC LiP group reported epilepsy. It is possible there was under-reporting in the NC group (six patients were unsure). Amongst the NC patients, 9 (33\%) reported anxiety disorders, $9(33 \%)$ reported mood disorders, $6(22 \%)$ reported psychotic disorders and 4 (15\%) had a diagnosis of schizophrenia. (See Table 11.1. for breakdown of categories.)

Neuropsychiatric diagnoses were compared between NC LiP patients and the controls $(n=53)$. NC LiP had significantly more anxiety disorders $(n=9,33 \%, p<0.01)$, mood disorders $(n=9,33 \% p<0.01)$, psychosis $(n=6,20 \%, p<0.01)$ and schizophrenia $(n=4$, $13 \%, p<0.01)$.

A breakdown of the MINI+ diagnoses (adult NC LiP adults) was as follows: 
Table 11.1.

MINI+ diagnoses (Adult NC LiP patients)

\begin{tabular}{|c|c|c|}
\hline \multicolumn{2}{|c|}{ Adult NC LiP patients $(n=27)$} & \multirow{2}{*}{\begin{tabular}{|l|}
$\mathrm{NC}$ \\
$\mathrm{LiP}$ \\
3
\end{tabular}} \\
\hline \multirow{3}{*}{$\begin{array}{l}\text { Psychosis } \\
(n=6)\end{array}$} & Schizophrenia & \\
\hline & Psychotic Disorder NOS (lifetime) & 1 \\
\hline & Brief Psychotic Disorder (lifetime) & 1 \\
\hline \multirow{10}{*}{$\begin{array}{l}\text { Anxiety } \\
(n=9)\end{array}$} & Generalized Anxiety Disorder & 2 \\
\hline & Anxiety Disorder with panic attacks & 1 \\
\hline & Panic Disorder & 1 \\
\hline & Agoraphobia & 2 \\
\hline & Social phobia & 6 \\
\hline & ${ }^{*}$ History of Social phobia & 1 \\
\hline & $\begin{array}{l}\text { Specific phobia (blood) } \\
\text { Specific phobia (insects) } \\
\text { Specific phobia (heights) }\end{array}$ & $\begin{array}{l}1 \\
1\end{array}$ \\
\hline & Hypochondriasis & 1 \\
\hline & Somatization Disorder & 1 \\
\hline & Body Dysmorphic Disorder & 1 \\
\hline \multirow{8}{*}{$\begin{array}{l}\text { Mood } \\
(n=9)\end{array}$} & Bipolar Affective Disorder & 2 \\
\hline & Major Depressive Episode (recurrent) & 4 \\
\hline & Major Depressive Episode (current) & 1 \\
\hline & Major Depressive Episode (current, with melancholic features) & 1 \\
\hline & "History of clinical depression & 1 \\
\hline & Dysthymia & 1 \\
\hline & Premenstrual Dysphoric Disorder & 3 \\
\hline & $\begin{array}{l}{ }^{\delta} \text { Suicidality (low) } \\
\text { Suicidality (medium) } \\
\text { Suicidality (high) - All referred on to the community clinic }\end{array}$ & $\begin{array}{l}6 \\
3 \\
1\end{array}$ \\
\hline \multirow{3}{*}{$\begin{array}{l}\text { Substance } \\
(\mathrm{n}=7)\end{array}$} & Alcohol abuse (past 12 months) & 4 \\
\hline & Alcohol abuse (lifetime) & 4 \\
\hline & Alcohol dependence (lifetime) & 1 \\
\hline
\end{tabular}

* denotes MINI+ criteria that have been met for the disorder, but were not present in the last twelve months.

$\delta$ denotes a criteria not used in the 'Depression' category 
The following clinical diagnoses were met: one NC LiP subject had schizophrenia and was always too psychotic at the time of interview to be assessed on the MINI+ (unable to give informed consent and refused to be interviewed). Diagnosis was met via interviews with family and clinic folder notes. The subject, who had been psychotic for several months, was referred by the research team to a regional hospital for admission and treatment, as a psychiatrist only visited the community clinic once a year.

Table 11.2.

MINI+ diagnoses (controls)

\begin{tabular}{|l|l|l|}
\hline CONTROLS: & \\
\hline $\begin{array}{l}\text { Anxiety } \\
(\mathrm{n}=1)\end{array}$ & Specific phobia (heights) & 1 \\
\hline $\begin{array}{l}\text { Mood } \\
(\mathrm{n}=4)\end{array}$ & *History of clinical depression & 4 \\
\cline { 2 - 3 } $\begin{array}{l}\text { Substance } \\
(\mathrm{n}=12)\end{array}$ & Alcohol abuse (past 12 months) & 8 \\
\cline { 2 - 3 } & Alcohol abuse (lifetime) & 5 \\
\cline { 2 - 3 } & Alcohol dependence (past 12 months) & 1 \\
\cline { 2 - 3 } & Alcohol dependence (lifetime) & 4 \\
\cline { 2 - 3 } & $\begin{array}{l}\text { Substance dependence (lifetime) (cannabis, mandrax, crack) } \\
\text { Substance dependence (lifetime) (mandrax) }\end{array}$ & 7 \\
\hline & Substance dependence (lifetime) (cannabis) & 1 \\
\hline
\end{tabular}

* denotes MINI+ criteria that have been met for the disorder, but were not present in the last twelve months.

$\delta$ denotes a criterion not used in the 'Depression' category 
One control who did not complete the MINI+ due to intoxication, probably met the criteria for alcohol abuse or alcohol dependence. One person who decided not to be in the study was significantly clinically depressed, and was referred to other services via the Community Clinic.

The NC LiP group was significantly more likely to have higher scores on the MADRS and on the negative symptoms scale of the PANSS. Self-reports of risk for suicide were significantly higher in the LiP group $(p=0.03)$. There was no significant difference between the two groups for alcohol abuse ( $26 \%$ in both) $(p=0.47)$. Only male subjects abused alcohol and when looking at the proportionate amount of male adult participants with alcohol abuse (current or in their life time), the number rose to $58 \%$ of the LiP men and $60 \%$ of the controls $(p=0.54)$. See Graph 11.1 . 
Graph 11.1.

Histogram: Alcohol abuse: Northern Cape LiP subjects versus Controls

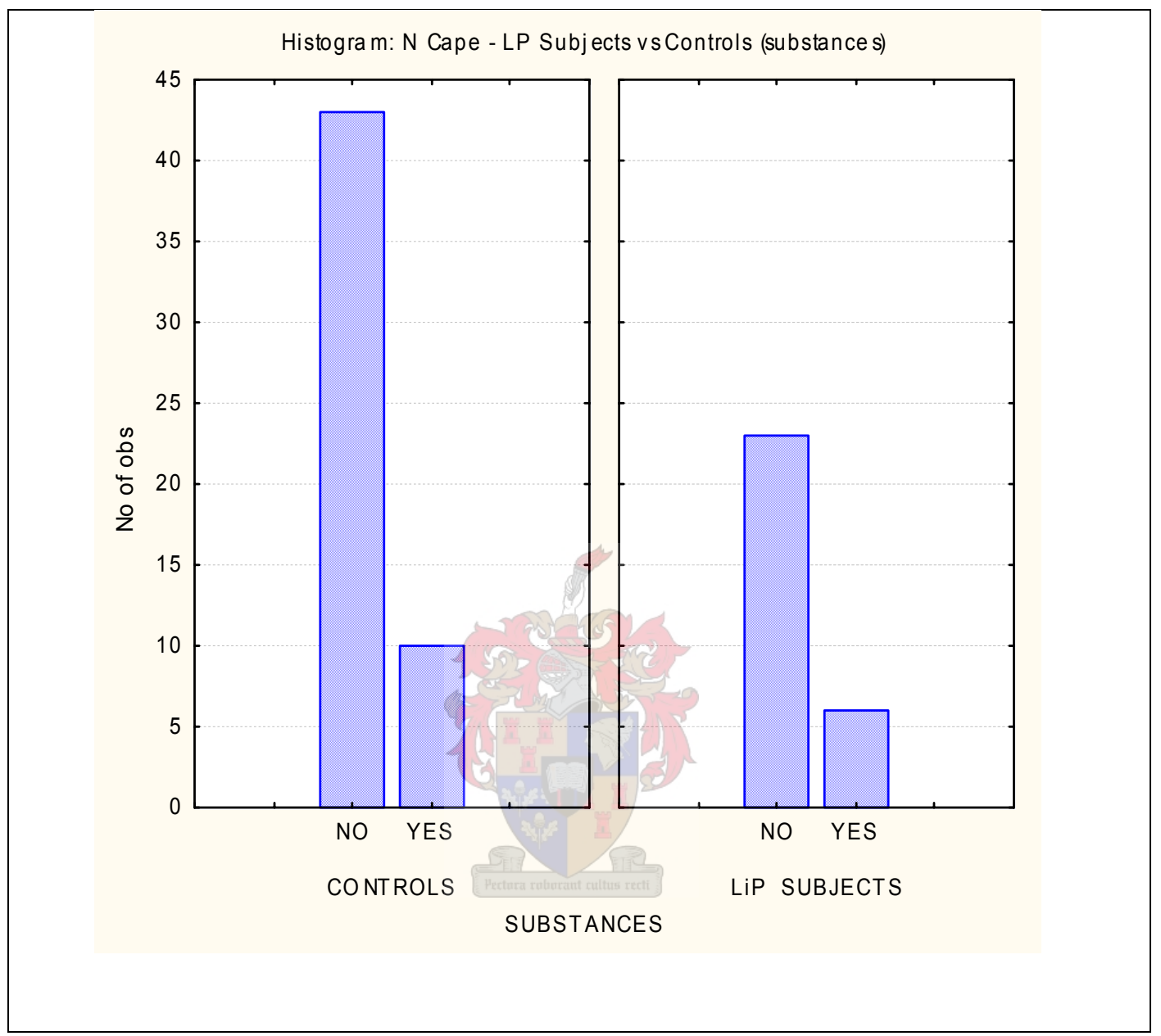


There was a significant difference $(p=0.02)$ in subjective reports of temper difficulties (patients with LiP significantly more likely to report these). However in terms of forensic convictions, more controls than LiP subjects reported being arrested or convicted, but this was not significant $(p=0.44)$. See Graph 11.2.

\section{Graph 11.2.}

Categorized Histogram: Subjective reports of temper difficulties

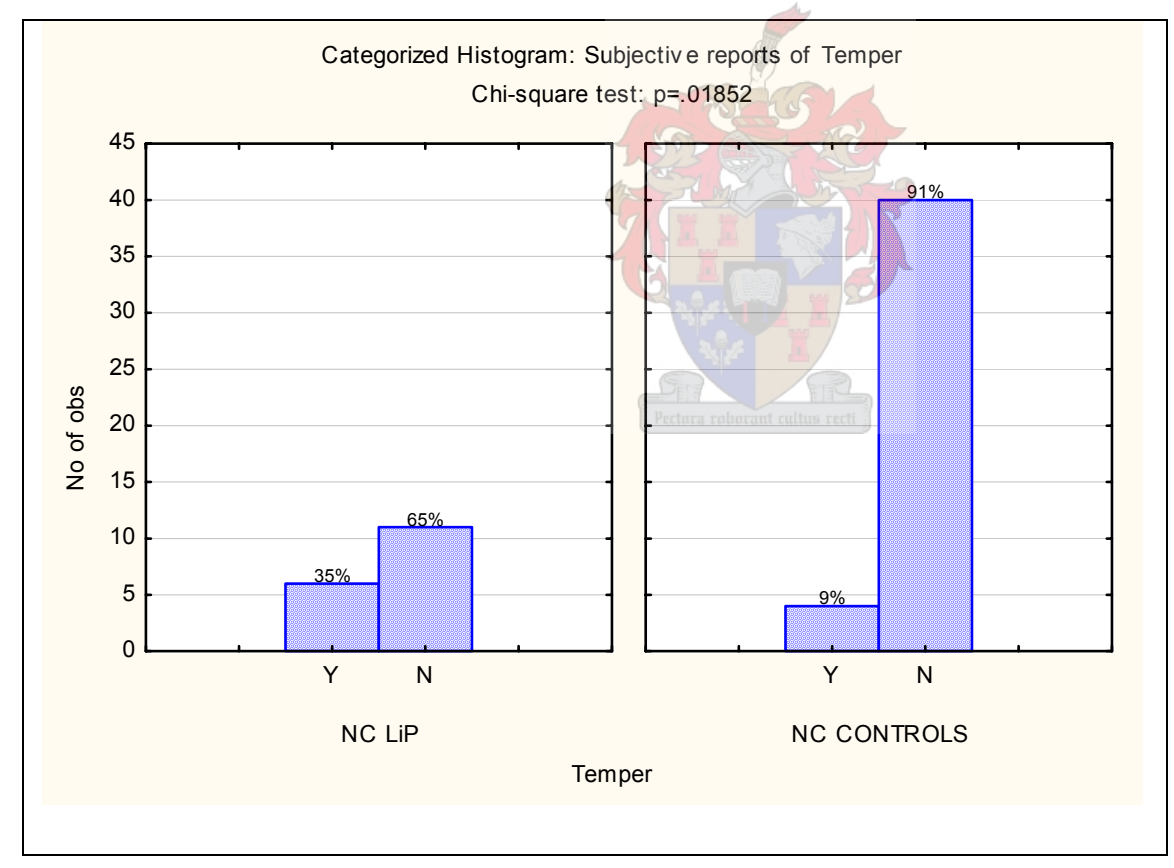


All subjects completed the Ekman facial expression recognition tests. See Photograph 11.1.

Photograph 11.1.

Ekman photo of a fearful expression

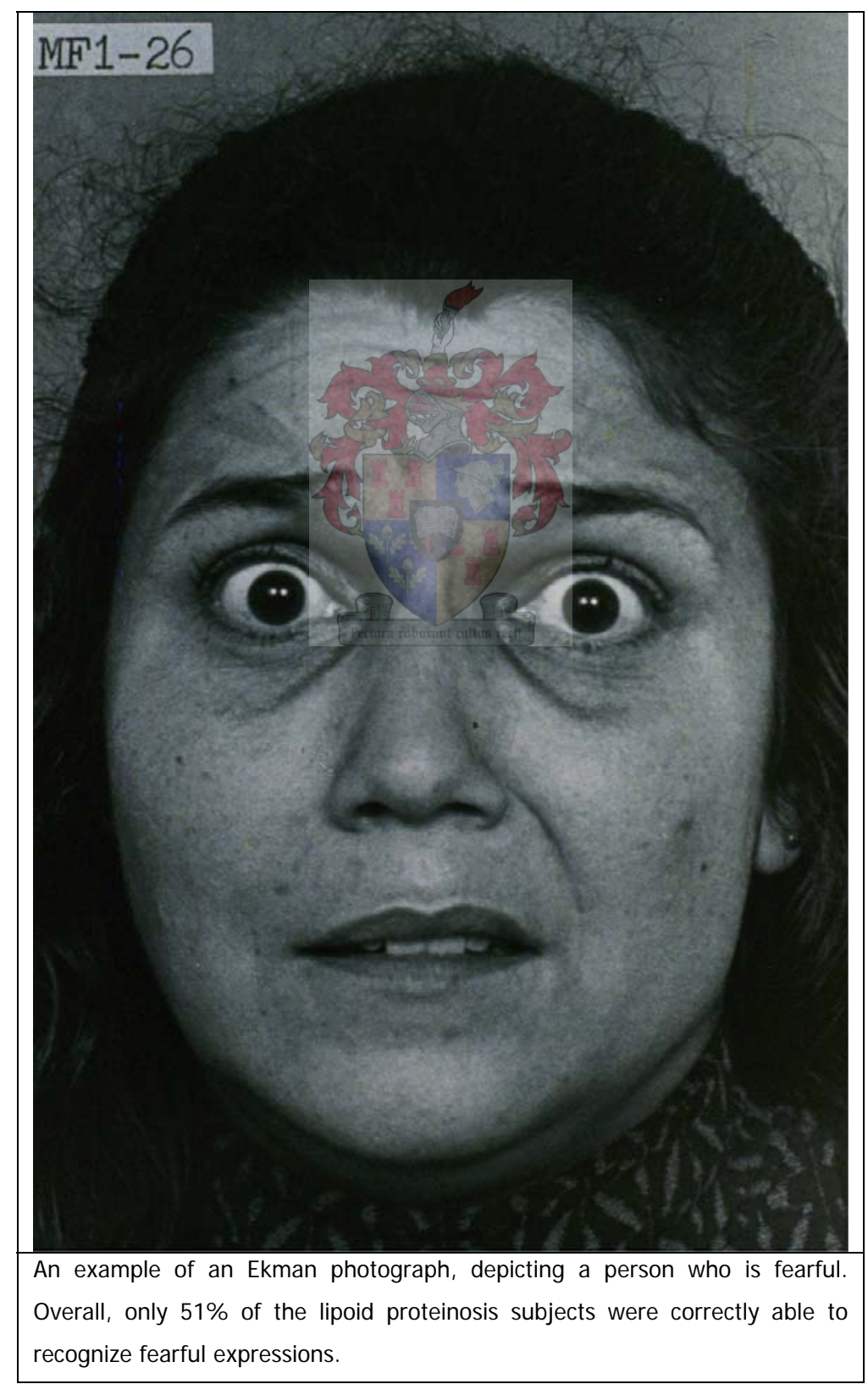


When looking at the NC participants, NC LiP subjects were significantly less likely to recognize emotions - including the negative (e.g. fear), positive (e.g. happiness) and neutral expressions. (See Tables 8.2. and 8.4. and Graphs 8.3., 8.4., 8.4. and 8.6.) Although happiness was the best recognized, the control group's performance was still significantly better in recognition of happy expressions than when compared to the NC LiP group $(p=0.0349)$.

Table 11.3.

Recognition of faces and emotional expressions: Northern Cape lipoid proteinosis subjects versus controls.

\begin{tabular}{|c|c|c|c|c|c|c|}
\hline $\begin{array}{l}\text { Northern } \\
\text { Cape }\end{array}$ & $\begin{array}{l}\text { LiP subjects } \\
(\text { mean edu }= \\
(n=24-26)\end{array}$ & years) & $\begin{array}{l}\text { Controls } \\
(\text { mean edu }= \\
(n=47)\end{array}$ & $=8.94$ years $)$ & & \\
\hline Test & mean & $\mathrm{sd}$ & mean & B & p & $\begin{array}{c}\text { Effect } \\
\text { size }\end{array}$ \\
\hline Total Fear & 47.44 & 22.89 & 61.28 & 23.62 & $0.0179 *$ & 0.592 \\
\hline Total Disgust & 49.76 & 28.09 & 74.34 & 23.14 & $0.0001^{* *}$ & 0.983 \\
\hline Total Surprise & 54.67 & 35.05 & 75.84 & 19.51 & $0.0251^{*}$ & 0.812 \\
\hline Total Sad & 56.25 & 22.64 & 69.15 & 20.91 & $0.0167^{*}$ & 0.599 \\
\hline Total Angry & 59.95 & 24.96 & 77.60 & 18.01 & $0.0021^{* *}$ & 0.852 \\
\hline Total Neutral & 62.36 & 36.95 & 82.67 & 20.08 & $0.0329^{*}$ & 0.746 \\
\hline Total Happy & 87.18 & 13.31 & 93.85 & 6.47 & $0.0349^{*}$ & 0.705 \\
\hline Total Emotion & 59.30 & 18.08 & 75.67 & 12.97 & $0.0001^{* *}$ & 1.094 \\
\hline
\end{tabular}


As a mean performance (recognition of fearful expressions), the patients with LiP from outside of the NC, performed better than controls from the NC - however only five people not from the Northern Cape completed the test.

\section{Graph 11.3.}

Boxplot by Group: Northern Cape: LiP subjects versus controls for recognition of fear

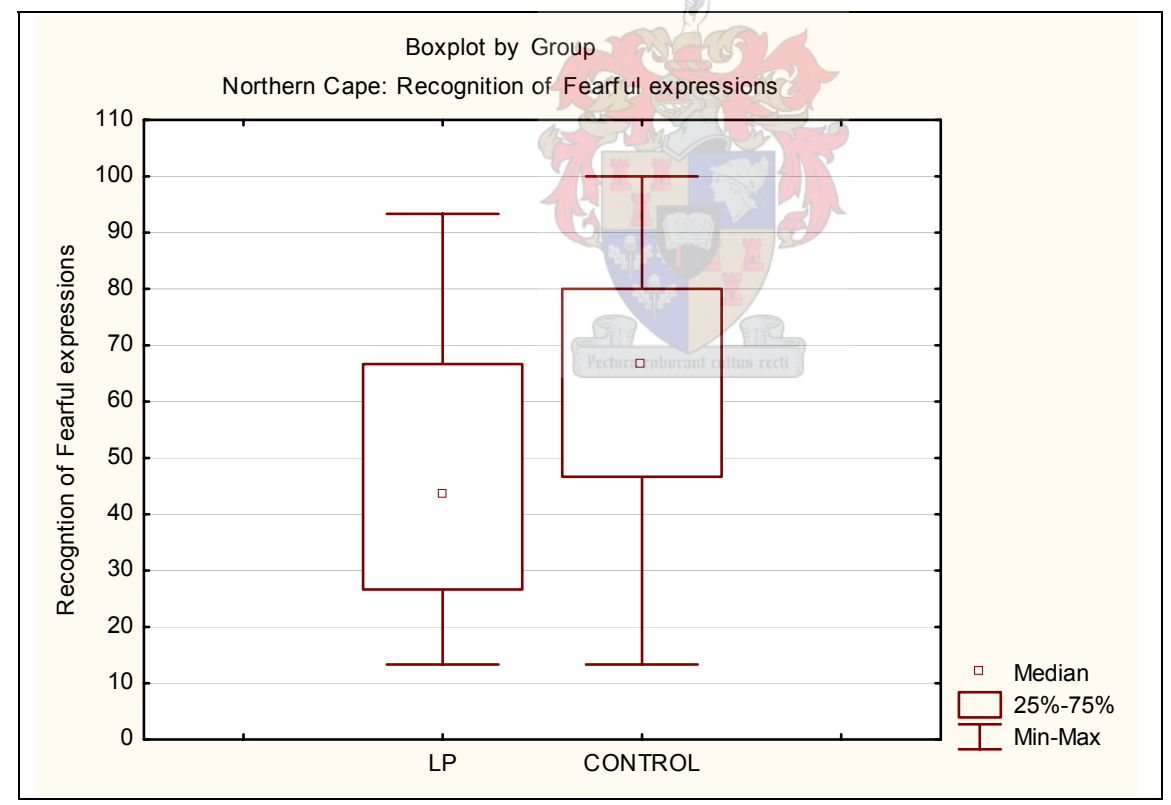




\section{Graph 11.4.}

NC: Significant differences in the recognition of happiness

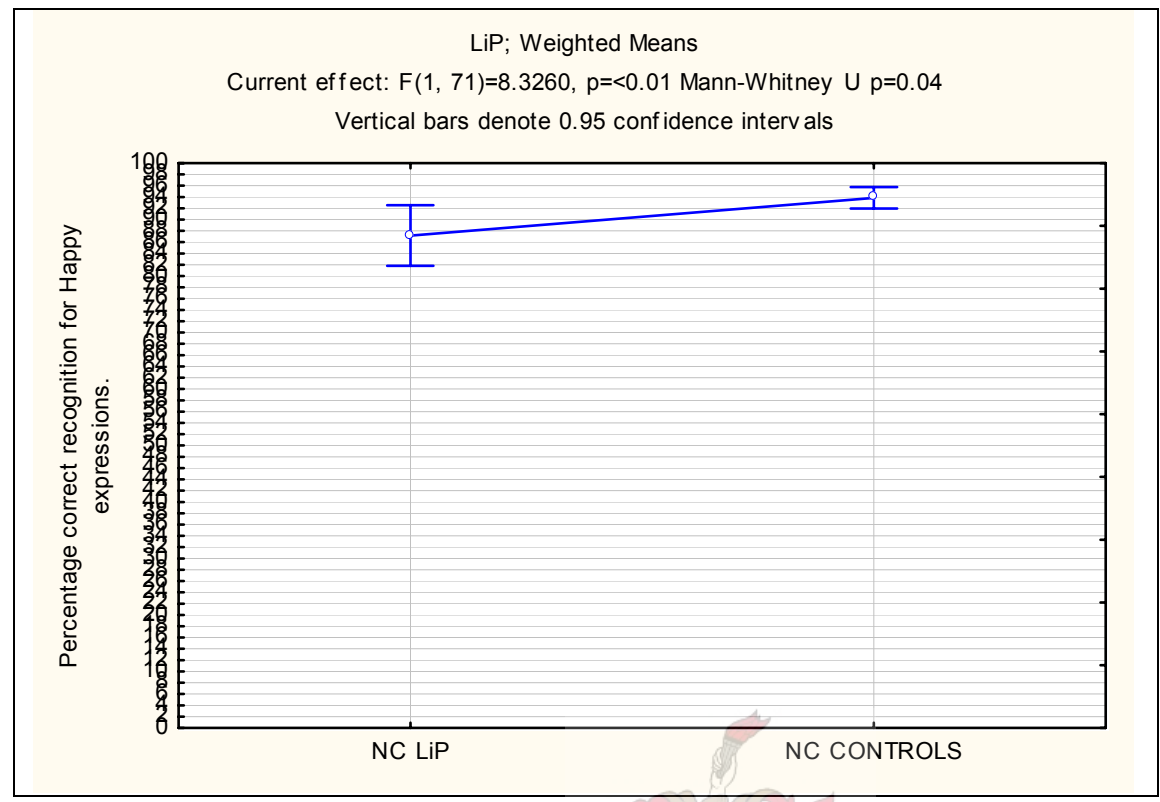

\section{Graph 11.5.}

\section{NC: Significant differences in the recognition of surprise}

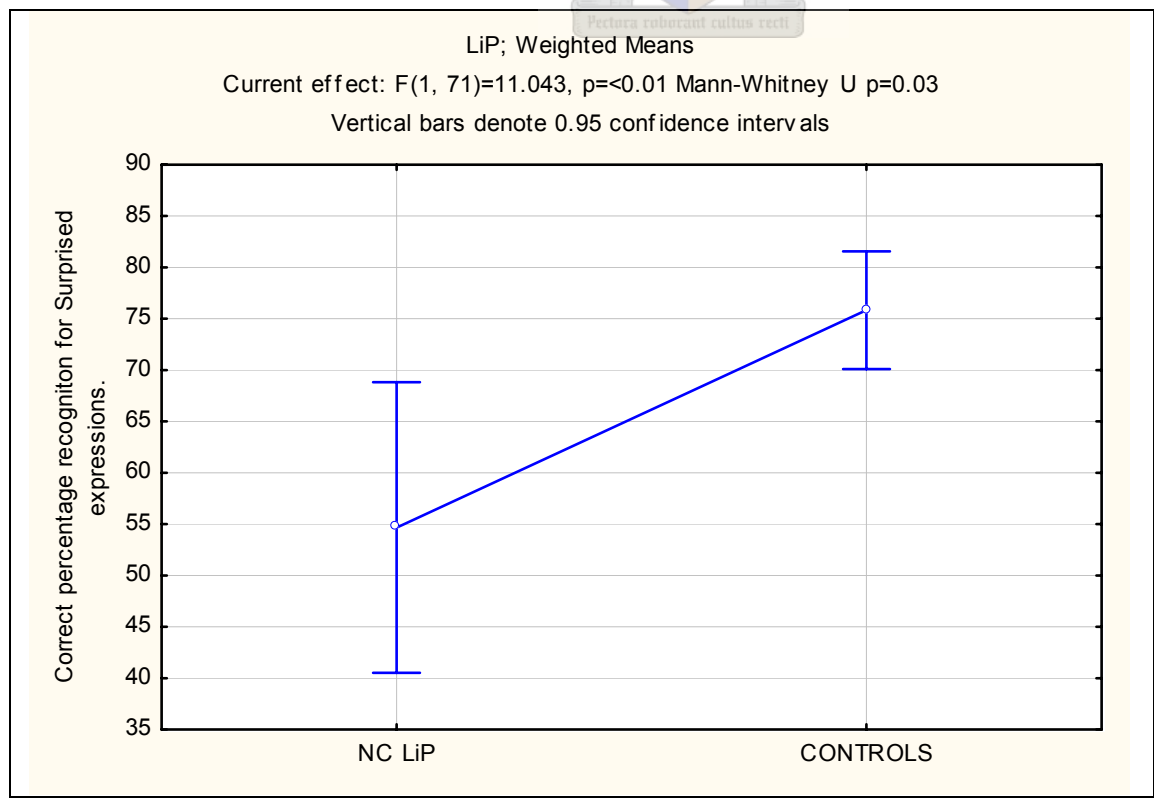


Graph 11.6.

NC: Significant differences in the recognition of disgust

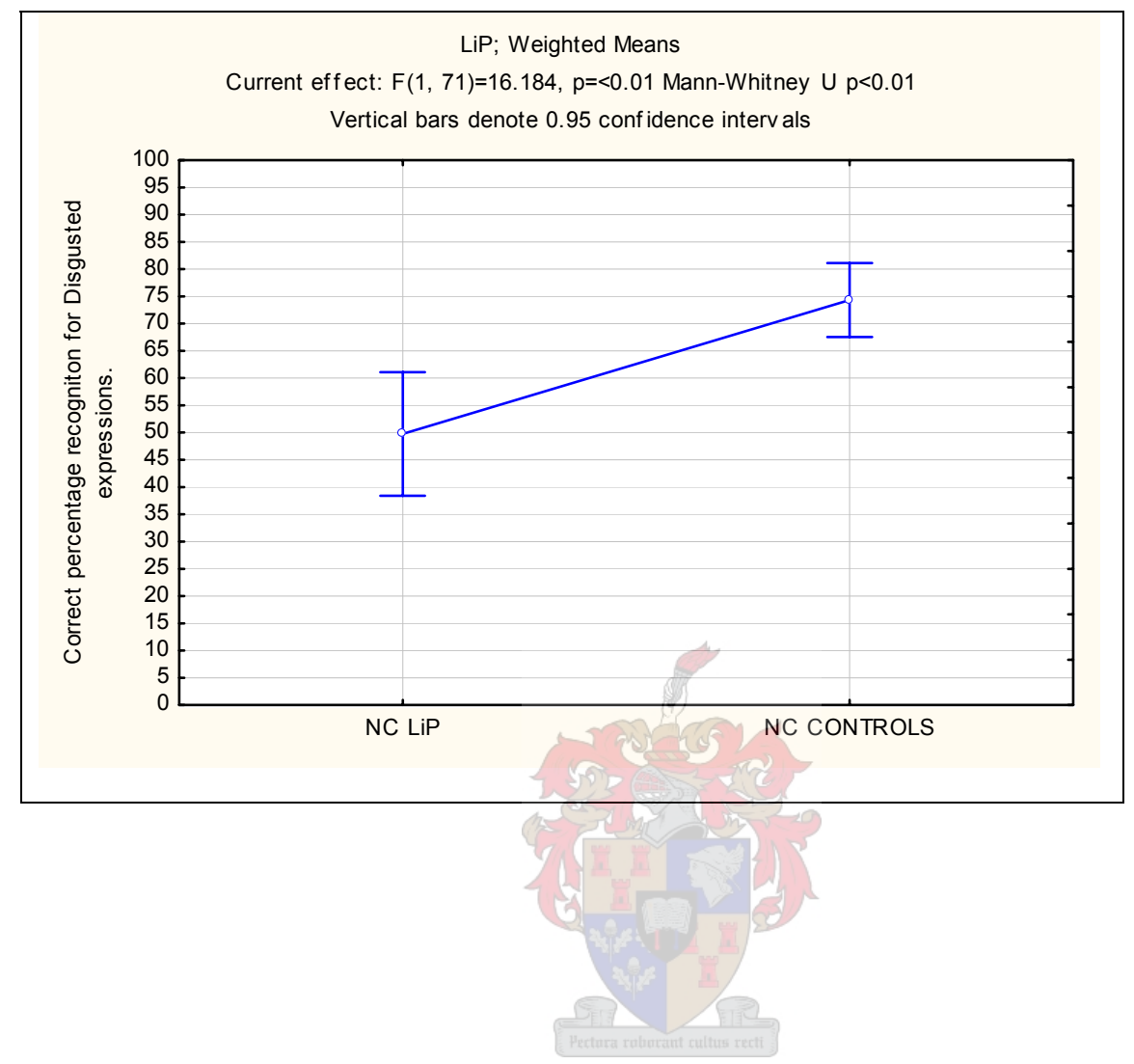


On basic face recognition, there were no significant differences on the first section of the Benton photographs. However on the second part of the Benton test, when faces were presented with less lighting or from a different angle, the NC controls performed significantly better than the LiP group.

When one analyzed the Northern Cape adults as a whole, and looked at the impact of a $\mathrm{MINI}+$ diagnosis of anxiety, there was a significant effect on the ability to recognize all the emotions except for neutrality $(p=0.95)$ and surprise $(p=0.11)$ (Graph 11.7$)$. Only one Northern Cape control subject qualified for a MINI+ diagnosis of anxiety. Depression on the MINI+ however, has no such effect on recognition of emotions. 


\section{Graph 11.7.}

NC: How Anxiety on MINI+ influences recognition of emotions; Weighted Means

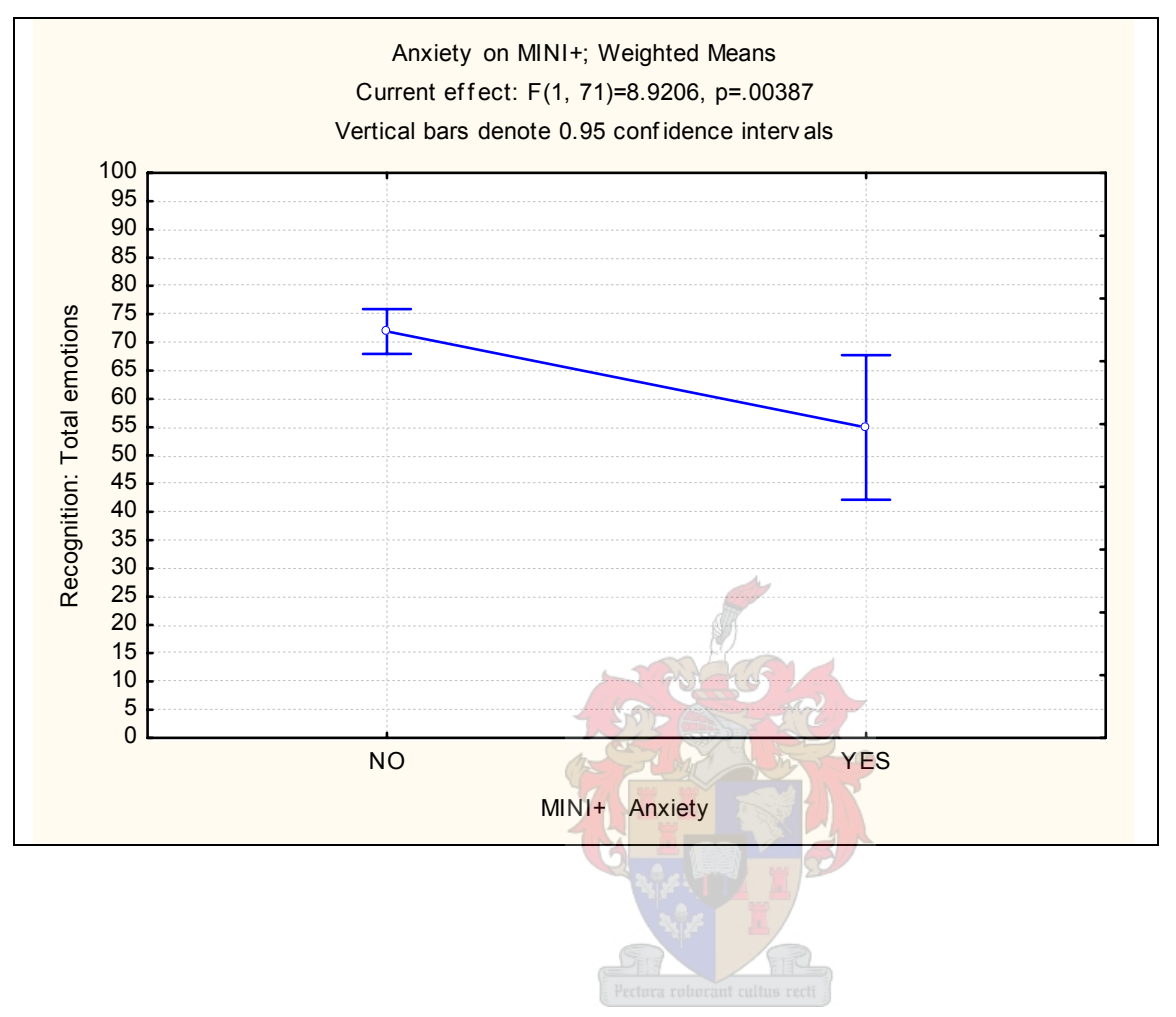


In the LiP adult population, a diagnosis of depression on the MINI+ was not significantly associated with any of the facial expressions.

A best subtests regression analysis was done on the following factors, to see their effect on LiP subjects' abilities to recognize the facial expression of fear. Looking at the factors of age, years of education, intelligence, having seizures or not, and having had psychotic, mood, anxiety or substance abuse disorders, it was evident that the estimated full scale intelligence measure on the WASI together with the presence or not of a mood disorder, were the two best predictive measures, but the correlation coefficient remained low (adjusted $r^{2}=0.34$ ). Other subsets were investigated (e.g. gender) (Graph 11.8 and 11.9). However these were not of particular significance $(p=0.41)$. 
Graph 11.8.

NC: LiP and Gender; Weighted Means

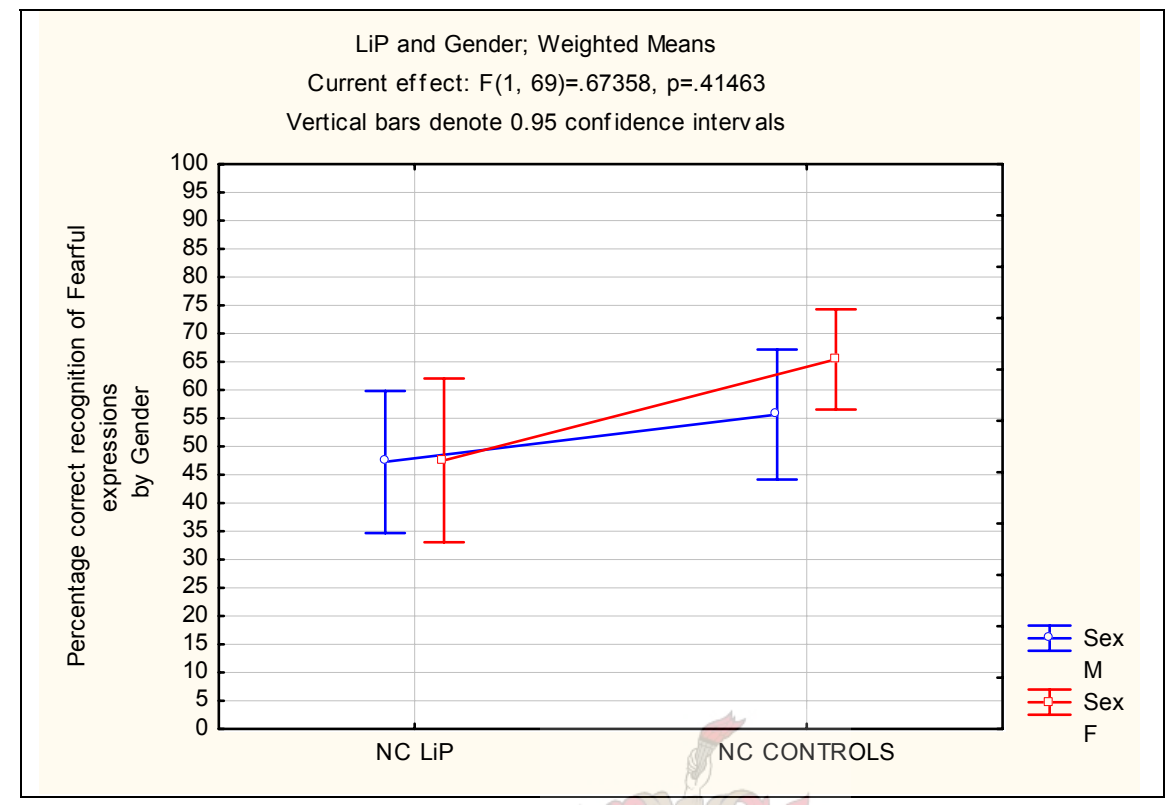

Graph 11.9.

Bootstrap: NC: LiP and Gender; Weighted Means

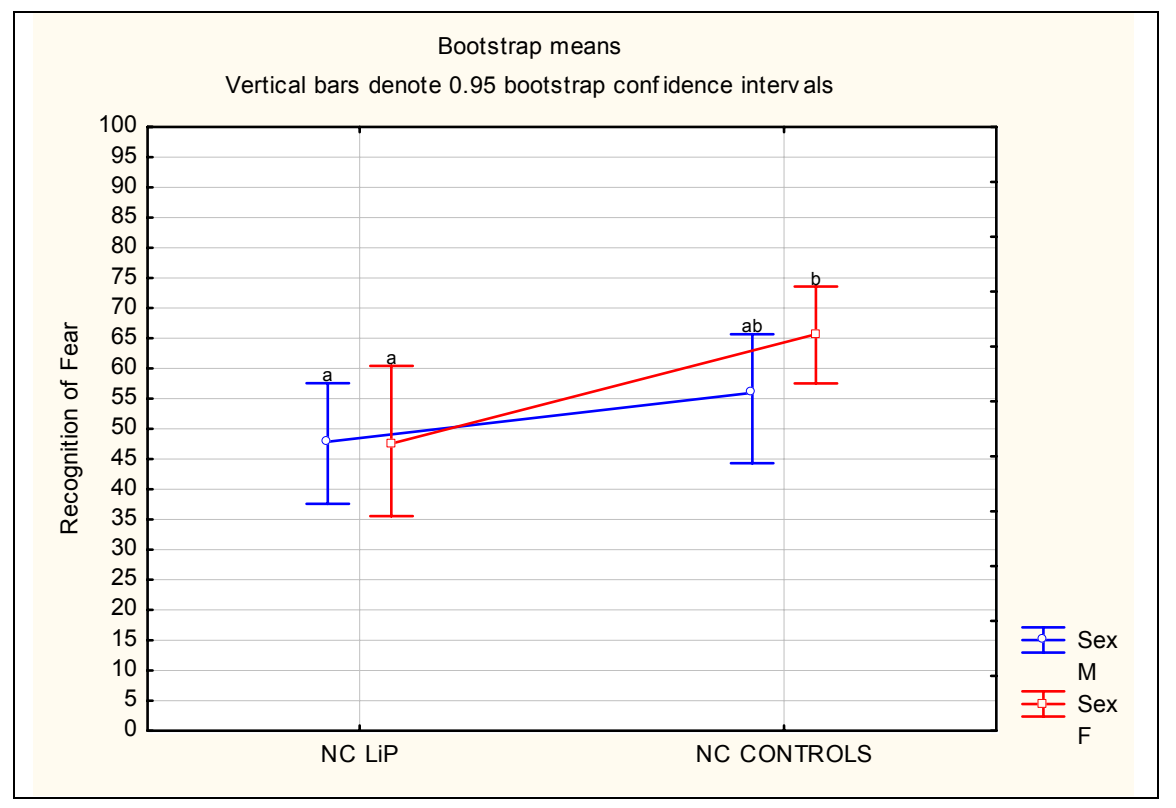


Sub-syndromes could not easily be identified. Depression, anxiety, seizures and gender did not produce statistically significant differences in the recognition of emotions (Table 11.4). Intelligence seems one of the main indicators for emotional recognition, but it is also linked to years of education. Vignettes were included to highlight the disparities between some of the LiP subjects. NC controls did not have seizure disorders and the incidence of depression and anxiety were too low for statistical analysis. 
Table 11.4.

Vignettes

\begin{tabular}{|c|c|c|c|c|c|c|c|c|c|c|}
\hline$\stackrel{0}{\mathscr{g}}$ & $\begin{array}{l}\bar{d} \\
\text { ¿ } \\
\bar{\Xi} \\
0\end{array}$ & $\frac{\pi}{\stackrel{2}{\alpha}}$ & 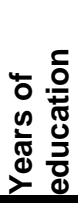 & 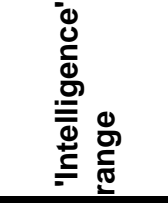 & 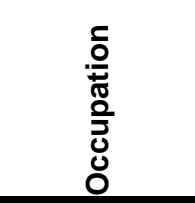 & 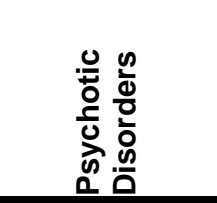 & 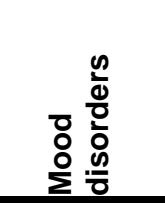 & 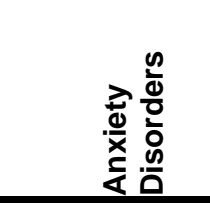 & 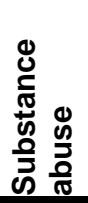 & $\begin{array}{l}\frac{\overrightarrow{0}}{\frac{0}{0}} \\
\frac{0}{\overline{0}}\end{array}$ \\
\hline $52^{1}$ & $\mathrm{~F}$ & $\mathrm{NC}$ & 3 & $\begin{array}{l}\text { Mental } \\
\text { retardation }\end{array}$ & Unemployed & No & Bipolar & $\begin{array}{l}\text { GAD } \\
\text { Panic attacks }\end{array}$ & No & Yes \\
\hline 28 & M & $\mathrm{NC}$ & 7 & $\begin{array}{l}\text { Mental } \\
\text { retardation }\end{array}$ & Unemployed & No & No & Social phobia & Yes & Yes \\
\hline 19 & $\mathrm{~F}$ & J'burg & 9 & Borderline & Temp & No & Dysthymia & Panic attacks & No & No \\
\hline 25 & $\mathrm{M}$ & $\mathrm{NC}$ & 9 & $\begin{array}{l}\text { Below } \\
\text { average }\end{array}$ & Unemployed & No & No & $\begin{array}{l}\text { Agoraphobia } \\
\text { Social phobia }\end{array}$ & No & No \\
\hline 17 & $\mathrm{~F}$ & NC & 10 & Average & Scholar & No & No & No & No & No \\
\hline 49 & $\mathrm{M}$ & J'burg & 10 & Borderline & Clerical & No & No & No & No & Yes \\
\hline 32 & $\mathrm{M}$ & $\mathrm{NC}$ & 12 & $\begin{array}{l}\text { Below } \\
\text { average }\end{array}$ & Unemployed & Schizophrenia & No & No & Yes & Yes \\
\hline 27 & $\mathrm{M}$ & WC & 12 & $\begin{array}{l}\text { Below } \\
\text { Average }\end{array}$ & Unemployed & & No & No & No & Yes \\
\hline 22 & $\mathrm{~F}$ & $\mathrm{NC}$ & 13 & Borderline & Unemployed & No & No & Social phobia & No & No \\
\hline $35^{2}$ & M & J'burg & 16 & $\begin{array}{l}\text { Above } \\
\text { average }\end{array}$ & Professional & No & No & No & No & Yes \\
\hline
\end{tabular}

J'burg: Johannesburg, WC: Western Cape

\begin{tabular}{|c|c|}
\hline & $\begin{array}{l}\text { D-C was a left-handed 52-year-old single woman from a small village in the Northern Cape. } \\
\text { She was a single teen mother (her daughter is now 33) and later married but was divorced } \\
\text { due to domestic violence. At the time of the interview she was raising her ten-year-old } \\
\text { granddaughter. Her mother, older sister and brother had lipoid proteinosis. (Her mother and } \\
\text { sister were deceased.) She passed Std } 1 \text { (Grade 3) and had been unemployed her whole life. } \\
\text { She has epilepsy but was unsure when the seizures began. She complained of anxiety and } \\
\text { suffered from depression (once tried to hang herself) and hypomania. She met the MINI+ } \\
\text { criteria for Bipolar Affective Disorder (BPAD), a Generalized Anxiety Disorder (GAD) and panic } \\
\text { attacks. She had been admitted on at least one occasion to a psychiatric hospital where she } \\
\text { had stayed for three months and received ECT treatment. D-C was vague about the details. }\end{array}$ \\
\hline 2 & $\begin{array}{l}\text { A-F was a right-handed 35-year-old married man, and father of a toddler. He lived in the } \\
\text { greater J ohannesburg area. He has no family history of lipoid proteinosis. After completing } \\
\text { high school, he went to college where he completed a four-year professional qualification, } \\
\text { and has been in full-time employ for the last } 11 \text { years. He had febrile convulsions and was } \\
\text { diagnosed with "temporal lobe" epilepsy at the age of } 24 \text {. He had about fifty seizures a year } \\
\text { but was not on any anti-epileptic medication. He denied any psychiatric or substance abuse } \\
\text { history. He was self-conscious at times of having LiP (his skin looking as if it was burned and } \\
\text { people putting the phone down on him as he "whispers") and did not like to meet new } \\
\text { people. }\end{array}$ \\
\hline
\end{tabular}




\section{Comment on the performance of the non-NC LiP patients}

Seventy-one percent of the non-NC group reported epilepsy. One (non-NC) LiP subject met the criteria for a history of the DSM-IV Impulse Control Disorder. Although Axis I diagnoses were concentrated on, it was apparent that one non-NC LiP subject met the DSM-IV criteria for Borderline Personality Disorder.

Non-NC LiP subjects $(n=7)$ had a higher mean of education ( $x=13$ years), and had a better recognition of facial expressions than those LiP subjects from the Northern Cape. Nonetheless, even in this group with a higher education mean, the negative emotions of sadness, disgust and fear were less well recognized, and neutrality and happiness were the best recognized. (See Table 11.5.) 
Table 11.5.

LiP subjects from areas other than the Northern Cape, and all LiP subjects: Mean recognition of facial emotional expressions

\begin{tabular}{|l|l|l|}
\hline & \multicolumn{2}{|l|}{$\begin{array}{l}\text { Other parts of SA } \\
\text { (mean edu }=13 \text { years) }(\mathrm{n}=5)\end{array}$} \\
\hline & & \\
Test & mean & sd \\
\hline Total Fear & 68.00 & 20.22 \\
\hline Total Disgust & 63.75 & 24.37 \\
\hline Total Surprise & 82.86 & 17.93 \\
\hline Total Sad & 62.5 & 8.84 \\
\hline Total Angry & 80.00 & 15.89 \\
\hline Total Neutral & 95.71 & 6.39 \\
\hline Total Happy & 93.33 & 4.65 \\
\hline Total Emotion & $\mathbf{7 6 . 9 1}$ & 9.06 \\
\hline
\end{tabular}




\section{Comment on the performance of the children}

One child had five MINI+ diagnoses (Bipolar Affective Disorder (BPAD), Conduct Disorder, Attention Deficit Disorder with Hyperactivity (ADD-H), Anxiety Disorder with Panic Attacks and a rating of "High risk" on suicidality). Although there were many common symptoms between the diagnoses, all five were independently given after consultation with a specialist child psychiatrist. No other child participant (with LiP nor control) met the criteria for a MINI+ diagnosis.

When the nine NC children - three with LiP and six controls - were included in the Ekman test analyses, then there were no significant differences in the recognition of happiness. It was only with their exclusion that recognition of happiness became significant. 


\section{Conclusion}

The research hypothesis that LiP is associated with significantly increased psychiatric symptoms when compared to matched controls, was confirmed. In addition, the research hypothesis that patients with LiP will find it more difficult to recognize fear on emotional recognition tasks, when compared to matched controls was also confirmed, but the research hypothesis that happiness would not be significantly different, was disconfirmed. In the Northern Cape sample, the control population's ability to recognize all the facial expressions tested, was significantly better than the performance of LiP patients. 


\section{Chapter 12}

\section{Discussion and Limitations of this Study}

This research aimed to document the neuropsychiatric and neuropsychological functioning of patients with LiP. It investigated the presence of psychosis and mood disorders in this population, and assessed the patients' quality of life and neuropsychological performance using recognized neuropsychiatric and neuropsychological measures. These findings represent the largest report to date of neuropsychiatric and neuropsychological data in patients with LiP.

The main findings were:

1) Lipoid Proteinosis is associated with significantly increased psychiatric symptoms when compared to matched controls.

2) Lipoid Proteinosis is associated with significantly increased cognitive impairment when compared to matched controls.

3) Patients with LiP find it significantly more difficult to identify fear on facial recognition tasks, when compared to matched controls. 
4) Besides fear, patients with LiP find it significantly more difficult to identify happiness, neutrality, sadness, surprise, disgust and anger on facial recognition tasks, when compared to matched controls.

5) Factors such as intelligence probably play a mediating role in the ability to identify facial expressions. Gender, having seizures or not, and substance abuse or not, did not play a significant role.

6) Lipoid Proteinosis is not associated with a decreased quality of life or employability or marital status when compared to matched controls. However patients with LiP are significantly less likely to live with partners or have children and significantly more likely to be depressed or score for suicidal risk on the $\mathrm{MINI+}$

Compared with controls, patients with LiP had significantly increased mood, anxiety and psychotic symptoms, and significantly decreased ability to identify emotional expressions, and had significant memory and executive (specifically design fluency, switching and abstract thinking) difficulties. However within the LiP groups there was significant variability in neuropsychiatric and neuropsychological function. 


\section{Education and 'Intelligence'}

It is well-acknowledged that application of tests of cognitive ability (including intelligence tests) from one ethnic group to another without appropriate standardization is highly problematic $^{65 ; 147 ; 189-191}$. South African-based research has clearly demonstrated an association between race and access to quality education ${ }^{192-195}$ and lack of Westernized test sophistication has found significant levels of influence even in so-called 'culturefree' tests. The community from the Northern Cape represents a different 'cultural group' from any established norms and this is most evident in the often depressed normative data that was generated from this population. Most tests have only been standardized in Western settings, with the majority of people having received at least 12 years of education, and often relatively a higher standard of education than that people in the Northern Cape from 'Coloured' communities have received. In this study, often patients with LiP from more affluent areas (e.g. Johannesburg) performed more highly than the Northern Cape controls who did not have LiP.

Socio-cultural influences include variables such as language usage, reading ability, level and quality of education, socio-economic status, home and schooling experiences $^{194 ; 196-198}$. These variables are closely inter-related and are difficult to separate. In the Northern Cape, all the subjects had been exposed to rural educational systems, in the medium of Afrikaans, and all came from relatively poor circumstances with a mean of $11 \%$ of the entire adult Northern Cape sample being in full-time employ. Official statistics for unemployment in the Northern Cape (2003 statistics) was $27.5 \%{ }^{199}$. The participants (both patients with LiP and the controls) can generally be viewed as economically deprived with all the concomitant psychosocial sequelea. 
A low educational level may be both a result of poor functioning, and a contributing cause for falloff in functioning. Certainly in this study, where there was sometimes a critical paucity of education, there was a significant correlation between years of education and ability to recognize the facial expressions. As hypothesized by Siebert et al ${ }^{17}$, LiP subjects with high school education or university degrees may have generated cognitive strategies to compensate their deficits in recognizing facial prototypical expressions or were performing the task of emotional processing by using intact structures apart from the amygdala. However, when education was factored in (matching education levels), there were still significant differences in emotional recognition, and education by itself was not sufficient to explain the differences.

Although one might argue that the level of education one can achieve is dependent on one's 'intelligence', the lack of education will directly impinge on what one can achieve on a standardized measure of intelligence. Once again, there was a strong correlation between 'intelligence' and years of education, with intelligence being viewed in this case, as dependent on years of education. (It was the extreme paucity of education that confounded intelligence variables as so many of the questions (e.g. Vocabulary subscale) are dependent upon access to education.)

Shuttleworth-Edwards et $\mathrm{al}^{194}$ emphasizes that not only the level, but also the quality of education must be considered. There is now growing acceptance that the quality of education should be viewed as a moderating variable in psychometric performance ${ }^{175 ; 200 ; 201}$. 


\section{Neuropsychiatric involvement}

Quirk and Gehlert ${ }^{156}$ hypothesized that deficient inhibitory tone in the amygdala could lead to over-expression of conditioned responses, producing pathological states such as anxiety disorders and drug-seeking behaviour. In this study, there was a high incidence of drug taking (e.g. $26 \%$ of the Northern Cape adults - or 58 to $60 \%$ of the Northern Cape adult men - abusing alcohol) but it was not increased when compared to matched controls. However the higher prevalence of anxiety, mood and psychotic disorders than in controls, suggested that LiP may be playing an aetiological role in the manifestation of these conditions - e.g. the four subjects comorbidly diagnosed with schizophrenia may have been misdiagnosed and should rather be considered to have psychosis due to a general medical condition (lipoid proteinosis). The same may also apply to the anxiety and mood disorders.

\section{Anatomical underpinnings}

It is also known that not everyone with LiP has calcifications in the amygdala, and some patients have calcifications in other areas of the anterior temporal lobes $8 ; 16 ; 51$, or there may be differing degrees of severity of calcification, or there may be patients with no cortical calcifications ${ }^{10}$. In addition, there can be multiple brain calcifications. Newton et $\mathrm{al}^{8}$ found that there were two prominent areas of calcification within each hemisphere a superiorly located area in the caudate nucleus and globus pallidus, and an inferiorly located area in the amygdaloid nucleus. Newton et al also suggested that the common presence of recent memory deficits would suggest hippocampal dysfunction even if not radiologically evident. Several neurotransmitters or transmitter-related substances have been found to influence neuronal activity of the hippocampus and amygdala ${ }^{110 ; 202 ; 203}$. Epinephrine, norepinephrine, opioid and gabaergic active substances have been found 
to effect learning and memory processes in the amygdaloid region ${ }^{109 ; 110}$. Histamine, present in both the hippocampus and the amygdala, has been implicated in the memory mechanisms of the rat, and research suggests that there is a functional interaction between histamine-sensitive neurons of the amygdala and hippocampus during the learning process ${ }^{77}$.

Most LiP neuropsychological literature refers to the intracranial calcification as being bilateral and symmetrical. However Ghika-Schmid et $\mathrm{al}^{51}$, described an elderly gentleman who was thought to have LiP, who had hippocampal heamorrhage which was more extensive on the left, and it was associated with a leukoencephalopathy. Although his diagnosis of LiP was not confirmed, it does suggest that in some cases the temporal damage may not always be entirely circumscribed or symmetrical.

A further complication is the possibility that intracranial lesions in LiP may develop only in adolescence or adulthood. The age of onset of these lesions may affect the cognitiveaffective consequences of the lesions, as amygdala lesions early in development may have different effects on social behaviour than lesions produced in adulthood ${ }^{82}$.

In this study, results on selective declarative memory tests including learning of lists (often associated with left hippocampal function) and visuospatial recall tasks (sometimes linked to left amygdala function) ${ }^{133}$ were significantly poorer on subjects with LiP when compared to controls. There were also highly significant impaired results on the Hooper Visual Organization Test, normally done to assess for right parietal damage. However studies have shown that there is controversy as to whether results imply global or lateralized or regional functionality. In one fMRI study of the Hooper 
Visual Organization Test, bilateral fMRI responses were found predominantly in the posterior brain, in regions of superior parietal lobules, ventral temporal-occipital cortex, and posterior visual association areas, and to a lesser extent, the frontal eye fields bilaterally, and left dorsolateral prefrontal cortex ${ }^{204}$. It suggests that a possible general brain network is involved when a person completes a single test, and there are interpretive limitations in inferring anatomical localization or in adapting neuropsychological tests to fMRI analysis. On the TMTB there was a large standard deviation - large TMTB variances are not uncommon ${ }^{75}$ - and this may have reflected the different ages, genders, education and neuroanatomical calcification within the NC LiP group.

It is possible that a person can perform poorly on emotional faces not because they have emotional processing difficulties, but because they had impaired visuospatial processing. Face recognition must include abilities in special attention, feature binding and memory recall ${ }^{205}$. However, on most visuo-spatially loaded tests (including the designing of the clock, the copy of the complex figure, the Matrices and completing block designs), there were no significant differences in performance when the LiP subjects were compared to the controls. Interestingly on the Benton faces - although able to recognize the same photograph of a person without difficulty - LiP subjects had significantly more problems with facial recognition when the photographs were produced from different angles or lighting. Possibly a photograph of a person surrounded in shadow may produce an emotional content.

Thus while one must be cautious in localizing and interpreting function, there does seem to be consistency that medial temporal involvement and the amygdala are 
involved in emotional processing. The complex function of the brain in processing information during cognitive actions can be visualized as an interrelated chain of neural components involving the hippocampus and amygdala ${ }^{73,109,160}$.

\section{Complex interplay of factors}

Cognitive abnormalities have been well documented in depression and loss of cortical gray matter in medial temporal structures may be associated with chronicity of depression ${ }^{206}$. Anti-epileptic drugs can have significant effects on psychometric testing ${ }^{207}$. The interplay between LiP, mood disorders, cognitive difficulties and seizures are complex, as all can affect each other ${ }^{208}$. 


\section{Multiple Emotions Systems}

With the advances in neuroimaging techniques, there had been a renewed interest in the relationship between the brain, and emotion, cognition, and behaviour, and how they relate to attention, memory and reasoning ${ }^{153}$.

Over the last few decades there have been numerous theories and models to explain the structure-function relationship of emotion ${ }^{147}$. The limbic system theory ${ }^{209 ; 210}$ remains popular, but has been questioned both anatomically ${ }^{107 ; 108 ; 211}$ and theoretically ${ }^{212}$. While many continue to employ the concept of the limbic system (including the amygdaloid nuclei, the cingulate cortex, the anterior cingulate and the hypothalamus) as a "convenience for communication" ${ }^{213}$, it should not be seen as the only relevant structure involved in emotions, and the concept of emotion itself, needs to be broadened to include aspects of behaviours and experiences.

One of the earliest models of lateralization, the right-hemisphere hypothesis highlighted its role in all aspects of emotion processing ${ }^{214}$. While it has been suggested that the left side of the face expresses emotions more intensely ${ }^{215}$, others suggest the right hemisphere plays an important role in acquired deficit of emotional expression and comprehension $^{216-220}$, and that damage to the right hemisphere has been demonstrated to impair recognition of emotional expression ${ }^{221}$. It is possible that the right hemisphere may be involved in the perception and recognition of emotion, but not necessarily specifically in the experience of emotion, and that the posterior regions may be more involved in the latter ${ }^{59 ; 222-224}$. 
Dual emotional systems tend to explore psychological divisions - e.g., valence (positive or negative emotions), pleasure (pleasant or unpleasant emotions), and arousal (excited or calm) ${ }^{225-232}$. Some emphasize the importance of looking at both goal-directed emotions (e.g. curiosity, fear), as well postgoal-achievement emotions (e.g. satiation, guilt) ${ }^{233 ; 234}$. In contrast, affect programmes examine neural mechanisms which may store patterns for and trigger complex emotional responses.

Many theorists have suggested that instead of an integrated neural system for all emotions, individual neural systems code distinct dimensions of emotion (i.e. different affect programs) ${ }^{147}$, giving rise to numerous dual- and multi-system models $227 ; 232 ; 235-241$.

In a study of a LiP patient with bilateral hippocampal structural damage, amygdala involvement was spared ${ }^{51}$. There were the anticipated memory difficulties, but also impairment of the vocal perception of fear. This implies that the hippocampus and not only the amygdala may also play a critical role in the auditory perception of fear. It possibly suggests that there may be dissociation between severely impaired auditory recognition of fear and preserved recognition of fear in facial emotion, and that there are multiple emotion systems.

Some researchers were adamant about the selective involvement of the amygdala in some but not all emotions, and have emphasized that the amygdala was not involved with the processing of positive emotions such as happiness, or negative emotions such as disgust ${ }^{19 ; 58 ; 213}$. In partial contradiction of this, in a 2003 meta-analysis of, functional neuroanatomy of emotions ${ }^{147}$, the authors concluded there was partial 
support for asymmetry accounts in that greater left-sided activity was observed for approach emotions, whereas negative or withdrawal emotions were associated with symmetrical neural activity. They also reported that the activation distributions associated with fear, disgust and anger, were most consistently associated with the regions of the amygdala, the insula and globus pallidus, and the lateral orbitofrontal cortex, respectively. The distributions for happiness and sadness did not differ.

In this study, it can clearly be shown that all emotions are less well recognized, but in the absence of neuroimaging, the underlying anatomical structures cannot be concluded. With this study, the high incidence of reported seizures, and the high incidence of neuropsychiatric and neuropsychological signs suggest significant dysfunctional brain involvement in this population, consistent with Newton et al's hypothesis ${ }^{8}$ that at least three quarters of LiP subjects will show the bilateral temporal calcifications.

These findings are consistent with current understanding of the amygdala and its role in mediating psychopathology. Consistent with previous reports ${ }^{17 ; 21 ; 74}$, there was a high prevalence of mood, anxiety, and psychotic symptoms in LiP, and significant problems in emotional recognition, memory and verbal intelligence.

Inconsistent with previous reports by Adolphs et $\mathrm{al}^{21}$ and Calder and Young ${ }^{74}$, recognition of happiness was not preserved. It supports Baxter and Murray ${ }^{96}$ who concluded there was evidence to support the role for the amygdala in the processing of both negative and positive emotions, and Dolan's reporting ${ }^{153}$ that there is enhanced amygdala activity to both positive and negative stimuli. It also is consistent with the 
findings by Siebert, Markowitsch and Bartel ${ }^{17}$ who assessed ten LiP subjects, of whom more than half had bilateral amygdaloid damage, thus suggesting that the human amygdala influences both negative and positive emotional processing.

It was interesting to note that when the few children with LiP were included there were no significant differences in the recognition of happiness. It was only with the exclusion of the children that recognition of happiness became significant. This possibly suggests that brain involvement in LiP may not be evident until late teenagehood or may be progressive - consistent with the suggestions by Aroni et al ${ }^{3}$ and Van Rooy, Swart and Pietrzak ${ }^{16}$. The numbers are as yet too small for definitive comment on this.

It has long been suggested that people who are skilled in interpreting expressive behaviour in others are perceived as more socially skilled ${ }^{242}$. A possibility suggested by Canli et $\mathrm{al}^{243}$ is that amygdala activation in response specifically to happiness is varied, and may reflect individual differences in personality trait of extraversion. This process may be engaged variably across people, as a function of extraversion, in response to happy expressions. In Canli et al's study, the function was left-lateralized, consistent they felt with the hemisphere associated with positive emotions and approach-related behaviour and consistent with the sociable interactive style of extraverts. Limited spatial resolution limited the researchers' determination regarding whether these processes could be differentially localized among the amygdaloid subnuclei or adjacent regions.

In this study, the LiP subjects' recognition of emotive expressions was impaired. In addition, the LiP subjects had significantly more anxiety and depressive disorders, and 
performed more poorly on neuropsychological measures of attention, memory and most executive abilities (including abstract thinking). On some measures of language, planning and Performance Intelligence there were no statistical differences. 


\section{Limitations}

There are several limitations that immediately come to mind in this study:

1. Firstly, as this has been field work, there has been no neuroimaging which would have afforded insights as to the mesial temporal involvements, especially the amygdala. It is hoped this can be addressed in future research.

2. Many of the neuropsychology tests are based on Westernized norms and in settings dealing with rural and often semi-literate populations, there is relevance in questioning the applicability of using such tests. However in South Africa, it has been found that the acculturation process sometimes has shown the absence of clinically significant cultural effects on frequently employed, standard test material ${ }^{193}$. This was certainly evident in some tests (e.g. RAVLT, RCF) where the normative group from the NC performed relatively consistently with established Western norms. However in other tests (e.g. WASI) there was a marked difference. In these cases, the importance of using the normative data as opposed to interpreting the data to other established norms, was emphasized.

3. Amygdala tests were not done on everyone. Only five of the 37 subjects completed them, as they were only introduced to the study more than half-way into the data collection. Although all the controls have done the amygdala tests and normative data is available, future research will still need to address this discrepancy. 
4. In addition at the time of this research, other established 'amygdala tests' were not available - so it was not possible to generate comparative test results in comparison with other research (e.g. moral decisions, fear tests, skin-conduction tests, or the use of loud noises to elicit startle responses). Many of these tests require tertiary-level testing conditions.

5. It should be noted that only six of the LiP sample were Caucasian, and yet all the Ekman photographs are of Caucasian people. It is possible that this may have influenced how subjects were able to complete the test.

6. The matched sample aimed for 2:1 ratio of all the subjects, but fell seven people short.

7. Several important and relevant areas of information were not consistently obtained and this would need to be improved. Firstly the medication and medication history of the subjects. Some knew they took "the little white pill" but did not necessarily know why. More information regarding Axis II pathology or lack of it would be useful.

8. Neuropsychiatric and neuropsychological tests were conducted in what could often be considered to be field-work conditions. In one instance, a young mother with LiP came for the sessions with a breast-feeding infant who stayed with her and was nursed by her during the session. On a few occasions in the clinics, nurses would sometimes need to enter to the room to get notes or tools. In 
Komaggas where three patients with LiP were seen, the community clinic building (one room) shared offices with the electricity and rates centre. Thus one clinical psychologist saw participants in the reception area / hallway, and another sat outside with two chairs, to see the other participants. Notes were taken if validity of the results was felt compromised and during the evening sessions, these were discussed in supervision.

9. In this study, the controls' blood was not tested to assess whether or not they were carriers of the LiP gene. The predicted LiP carrier rate of 1 in 9 in this Northern Cape community means there was a chance some of the controls were LiP carriers. However, it is not yet established that being of a carrier status has any significance and no control displayed any LiP associated phonic, dermatological, or seizure-based symptoms.

It is also possible given the variance in presentation, that patients with LiP may indeed be without diagnostic symptoms or asymptomatic, and this again highlights the need for the controls' blood to be tested. However, the predicted incidence of LiP in the Northern Cape community is only 1 in $324^{12}$ which means the statistical chance of any of the controls having LiP is slight - even if it were established that an adult with LiP could be asymptomatic.

10. As yet, no standardized measure exists to assess for the severity of LiP. Variability in the disease is frequently mentioned. Skin conditions may be slight to overtly disfiguring, hoarseness of voice may be absent to so severe that one struggles to understand what is being said. Some may or may not have seizures 
and the frequency and severity and symptoms or the seizure presentation may also vary markedly. It is equally expected that brain calcification is not an "all-ornothing" affair, and may have differing severities. 


\section{Chapter 13}

\section{Conclusions and Recommendations for Future Research}

It is rare to find a person with bilateral amygdala damage without complex or asymmetrical brain impairment ${ }^{19 ; 20 ; 72}$. This paucity of patients with bilateral amygdala damage has traditionally limited our knowledge of the role played by the amygdala in living humans. In LiP, the damage to the amygdala can be relatively circumscribed, bilateral and symmetrical ${ }^{15}$, and thus allows a rare opportunity for an experimental study of the role of the amygdala in living humans.

Unfortunately, the biggest neuropsychiatric or neuropsychological studies done to date on patients with LiP, have never numbered more than ten subjects, and often only represent anecdotal studies or case examples. There has been no consistent standardized methodology and the education levels and other factors (e.g. medication, seizures, cosmetic consequences and social isolation and psychosis) affecting validity have seldom been carefully explored. Although our knowledge of amygdala functioning remains to many degrees confused speculation with contrary findings, most studies have slowly begun to generate a frequently presenting picture of possible bilateral amygdala involvement with consequent neuropsychiatric and neuropsychological sequelea. 
In this study on a large cohort of patients with LiP, there is evidence of epilepsy, psychosis, anxiety and depression disorders, neuropsychological difficulties (including memory problems and visuospatial organization difficulties) and problems in recognizing all facial expressions of emotion. Even without neuroimaging, these results confirm that neurological, neuropsychiatric and neuropsychological symptoms should be routinely considered and assessed for in the LiP population. It should be very exciting to do indepth scanning on this population and begin to unpack possible anatomical underpinnings. If as suspected the amygdala is shown to be involved in a significant number of the LiP subjects, then investigation into intra-amygdala and amygdala dynamic interactions with the rest of the brain may increase insight into possible condition-specific activations of distinct amygdala subnuclei. 


\section{Future research}

Future research is needed. In order to understand the neuropsychiatric and neuropsychological findings here better, it would be useful to have genetic and neuroimaging data. However, many subjects live in the remote rural areas of the Northern Cape with little access to secondary or tertiary hospitals, and obtaining such data presents significant logistical problems. However, in time, it is hoped that such data will become available.

From the start, this study was designed to be ongoing and it has always been envisaged that it will be the basis for significant future research. The most compelling research that needs to be done is to bring the LiP population to a tertiary hospital where more investigative work (fMRI, SPECT and Sleep EEG) can be done. Correlation between the neuroimaging and the neuropsychiatric and neuropsychological results can be investigated. Further genetic investigation is also envisioned. All the control subjects gave consent for blood samples to be taken to check for the presence or not of the LiP gene.

It is also envisioned that more elaborative neuropsychological tests (e.g. Stroop, Wisconsin Card Sorting Test, WAISIII) and other established tests of emotional recognition will be done. These should be multi-modal (e.g. visual and auditory). As amygdaloid nuclei constitute a part of the olfactory system ${ }^{17}$, odour-based tests should also be conducted. Paper and pen, computer-based, and skin conduction-based tests have all been demonstrated as useful tools of assessment. In real-life social situations, 
people 'read' emotional significance via a rich array of $\mathrm{cues}^{60}$ - e.g. relative location of people, body and head posture, direction of eye gaze, general visual context, tone of voice, volume and pace of speech. and more real-life judgements and assessments should be considered.

The development of the "amygdala" tests will also be done on all the Northern Cape LiP subjects. It has already been completed on all the Johannesburg LiP subjects and all the Northern Cape controls in anticipation of the LiP subjects being later able to complete these tests and thus normative data and matched controls for comparison are already available. These and other conventional 'amygdala' tests (including computerized and timed Ekman facial emotional recognition tests) can be obtained. Scales looking at behavioural inhibition and behavioural activation, and affective responses to impending reward or punishment will also be conducted-e.g. The Behavioural Inhibition Scale - Behavioural Activation Scale (BISBAS) ${ }^{244}$. Further tests allowing for the investigation of the encoding and retrieval of episodic emotional memories and the acquisition and expression of fear responses can be administered.

It is speculated but not as yet confirmed, that with time symptoms in LiP may progress ${ }^{3}$. How this progression works is unknown. If the risk for seizures or psychosis may increase with age, or if people are sequentially reassessed and display relatively static symptoms, is not as yet clearly understood. Three children under the age of 16 were assessed in this study. Ongoing follow up to track how this disease progresses will be particularly useful with these children. It is hoped that all the LiP subjects can be reassessed every five to ten years, so that the illness's progression can be better understood. 


\section{Reference List}

1. Urbach E, Wiethe C. Lipidosis cutis et mucosae. Virchows Arch Pathol Anat Physiol Klin Med 1929;273: 285-319

2. Hamada T, McLean WH, Ramsay M et al. Lipoid Proteinosis maps to $1 \mathrm{q} 21$ and is caused by mutations in the extracellular matrix protein 1 gene (EMC1). Hum Mol Genet 2002;11: 833-840

3. Aroni K, Lazaris AC, Papadimitriou K, et al. Lipoid Proteinosis of the oral mucosa: case report and review of the literature. Pathol Res Pract 1998;194: 844-859

4. Botha P. Oral lipoid proteinosis. SADJ 1999;54 (8): 371-373

5. Cote DN. Head and neck manifestations of lipoid proteinosis. Otoaryngol Head Neck Surg 1998;119: 144-145

6. Emsley R, Pastor L. Lipoid proteinosis presenting with neuropsychiatric manifestations. J Neurol Neurosurg Psychiatry 1985;48: 1290-1292

7. Bazopoulou-Kyrkanidou E, Tosios KI, Zabelis G, et al. Case report. Hyalinosis cutis et mucosae: gingival involvement. J Oral Pathol Med 1998;27:233-237 
8. Newton FH, Rosenberg RN, Lampert PW, et al. Neurological involvement in Urbach-Wiethe's disease (lipoid proteinosis). Neurology (Minneap) 1971;21: $1205-13$

9. Caccamo D, Jaen A, Telenta M, et al. Lipoid proteinosis of the small bowel. Arch Pathol Lab Med 1994;118: 572-574

10. Hofer PA. Urbach-Wiethe disease (Lipoglycoproteinosis;lipoid proteinosis; hyalinosis cutis et mucosae): A clinco-genetic study of 14 families from northern Sweden. Hereditas 1974;7: 209-218

11. Feiler-Ofry V, Lewy A, Regenbogen L, et al. Lipoid proteinosis (Urbach-Wiethe syndrome). Br J Opthalmol 1979;63: 694-698

12. Van Hougenhouck-Tulleken W, Chan I, Hamada T, et al. Clinical and molecular characterization of Lipoid Proteinosis in Namaqualand, South Africa. $\mathrm{Br} \mathrm{J}$ Dermatol 2004;151: 413-423

13. Böhme M, Wahlgren CF. Lipoid Proteinosis in three children. Acta Paediatr 1996;85: 1003-1005

14. Hofer PA. Urbach-Wiethe disease (lipoglycoproteinosis;lipoid proteinosis; hyalinosis et mucosae. A review. Acta Derm Venerol 1973;53 (Suppl 71): $1-52$ 
15. Tranel D, Hyman BT. Neuropsychological correlates of bilateral amygdala damage. Arch Neurol 1990;47: 349-355

16. Van Rooy CH, Swart JG, Pietrzak JT. Lipoïed-proteïnose: 'n Bespreking van 4 gevalle. S Afr Med J 1991;79: 160-162

17. Siebert M, Markowitsch HJ, Bartel P. Amygdala, affect and cognition: evidence from 10 patients with Urbach-Wiethe Disease, Brain 2003;126: 126-137

18. Ramsay M. Press release: Geneticists uncover the cause of a common genetic disorder in Namaqualand. Namakwa Weekblad / Weekly 2002;115: 9

19. Adolphs R, Tranel D, Damasio H, et al. Impaired recognition of emotion in facial expressions following bilateral damage to the human amygdala. Nature 1994;372: 669-672

20. Bechara A, Tranel D, Damasio H, et al. Double dissociation of conditioning and declarative knowledge relative to the amygdala and hippocampus in humans. Science 1995;269: 1115-1118

21. Adolphs R, Tranel D, Hamann S, et al. Recognition of facial emotion in nine individuals with bilateral amygdala damage. Neuropsychologia 1999;37: 11111117 
22. Markowitsch HJ, Von Cramon DY, Schuri U. Mnestic performance profile of a bilateral diencephalic infarct patient with preserved intelligence and severe amnesic disturbances. J Clin Exp Neuropsychol 1993;16: 627-652

23. Von Cramon DY, Markowitsch HJ, Schuri U. The possible contribution of the septal region to memory. Neuropsycholgia 1993;31: 1159-1180

24. Hamada T, Wessagowit V, South AP, et al. Extracellular matrix protein 1 gene (ECM1) mutations in lipoid proteinosis and genotype-phenotype correlation. $\mathrm{J}$ Investig Dermatol 2003;120: 345-350

25. Fujimoto N, Terlizzi J, Brittingham R, et al. Extracellular matric protein 1 interacts with the domain III of fibulin-1C and 1D variants through its central tandem repeat 2. Biochem Biophys Res Commun 2005;333 (4): 1327-1333

26. Costagliola C, Verolino M, Landolfo P, et al. Lipoid proteinosis (Urbach-Wiethe Disease). Opthalmologica 1999;213: 392-396

27. Costagliola C, Verolino M, Landolfo P, et al. Lipoid proteinosis (Urbach-Wiethe Disease). Opthalmologica 1999;213: 392-396

28. Bozdağ KE, Gül Y, Ķaraman A. Lipoid Proteinosis. Int J Dermatol 2000;39: 203204 
29. Al-Bitar Y, Samdani AJ. Lipoid proteinosis in two brothers with multiple organ involvement from Saudi Arabia. Int J Dermatol 2004;43: 360-361

30. Chaudhary SJ, Dayal PK. Hyalinosis cutis et mucosae: Review with a case report. Oral Radiol Endod 1995;80: 168-171

31. Botha MC, Beighton P. Inherited disorders in the Afrikaner population in southern Africa. Part II: Skeletal, dermal and hematological conditions; the Afrikaners of Gamkaskloof; demographic considerations. S Afr Med J 1983;64: 664-667

32. Schweitzer G, Jones B, Timme A. Upington disease: a familial dyschondroplasia. S Afr Med J 1971;45: 994-1000

33. Stine OC, Smith KD. The estimation of selection coefficients in Afrikaners: Huntington disease, porphyria variegata, and lipoid proteinosis. Am J Hum Genet 1990;46: 452-458

34. Heyl T. Lipoid proteinosis in South Africa. Dermatologica 1971;142: 129-132

35. Desmet S, Devos SA, Chan I, et al. Clinical and molecular abnormalities in lipoid proteinosis. Eur J Dermatol 2005;15 (5): 344-346

36. Cinaz P, Güvenir T, Gönlüşen G. Lipoid Proteinosis: Urbach-Wiethe disease. Acta Paediatr 1993;82: 892-893 
37. Disdier P, Harlé JR, Andrac L, et al. Specific xerostomia during Urbach-Wiethe disease. Dermatology 1994;188: 50-51

38. Teive HA, Pereira ER, Zavala JA, et al. Generalized dystonia and striatal calcifications with lipoid proteinosis. Neurology 2004;63 (11): 2168-2169

39. Chan I. The role of extracellular matrix protein 1 in human skin. Clin Exp Dermatol 2004;29 (1): 52-56

40. Acar A, Eryilmaz A, Gocer C, et al. Lipoid proteinosis of larynx: review of four cases. Int J Pediat Otorhinolaryn 2004;68: 1557-1561

41. Kleinert R, Cervos-Navarro J, Kleinert G, et al. Predominantly cerebral manifestation in Urbach-Wiethe's syndrome (lipoid proteinosis cutis et mucosae): a clinical and pathomorphological study. Clin Neuropathol 1987;6: 43-45

42. Holtz KH. Über Gehirn- und Augenveränderungen bei Hyalinosis cutis et mucosae (lipoid proteinose) mit autopsiebefund. Arch Klin Exp Derm 1962;214: 289-306.

43. Özbek SS, Akyar S, Turgay M. Case report: computed tomography findings in lipoid proteinosis: report of two cases. Br J Radiol 1994;67 (794): 207-209

44. E Silva R. Lipoid proteinosis (Urbach-Wiethe). Archiv Derm 1943;47: 301-326 
45. Crawford GM. Lipoid proteinosis generalized. Arch Derm 1946;53: 178-179

46. Cowan MA, Alexander S, Vickers HR, et al. Case of lipoid proteinosis. Brit Med J 1961;2: 557-560

47. Heyl T. Lipoid proteinosis: The clinical picture. Br J Dermatol 1963;75: 465-472

48. Caplan RM. Lipoid proteinosis: a review including some new observations. Univ Mich Med Cent J 1962;28: 365-377

49. MacKinnon DM. Hyalinosis cutis et mucosae (lipoid proteinosis). Acta Otolaryng 1968;65: 403-412

50. Steenkamp HC. Riglyne vir ' $n$ terapeutiese begeleidingsprogram vir lyers aan Urbach-Wiethe sindroom. Doctoral dissertation: Unpublished; 1997

51. Ghika-Schmia F, Ghika J, Vuilleumier P, et al. Bihippocampal damage with emotional dysfunction: Impaired auditory recognition of fear. Eur Neurol 1997;38: $276-283$

52. Hu S, Kuo TT, Hong HS. Lipoid proteinosis: report of a possible localized form on both hands and wrists. Int J Dermatol 2005;44 (5): 408-410

53. Wollina U, Konrad H, Schonlebe J. Lipoid proteinosis. Acta Dermatovenerol Alp Panonica Adriat 2004;13 (4): 131-133 
54. Lapiere M. In: Fitzpatrick TB, Eisen AZ, Wolf K, et al. eds. Dermatology in general medicine 4 ed. New York: McGraw-Hill; 1993:1937-1940

55. Rahalkar MD, Kelkar AB, Gharpuray MB. Lipoid proteinosis. Ind J Radiol Imag 2001;11: 85-87

56. McGrath JA. Translational benefits from research on rare genodermatoses. Australas J Dermatol 2004;45 (2): 89-93

57. Friedman L, Mathews RD, Swanepoel PD. Radiographic and computed tomographic findings in lipid proteinosis. A case report. S Afr Med J 1984;65: 734-735

58. Adolphs R, Tranel D, Damasio $\mathrm{H}$, et al. Fear and the human amygdala. J Neurosci 1995;15: 5879-5891

59. Adolphs R, Damasio H, Tranel D, et al. Cortical systems for the recognition of emotion in facial expressions. J Neurosci 1996;16: 7678-7687

60. Adolphs R, Tranel D. Amygdala damage impairs emotion recognition from scenes only when they contain facial expressions. Neuropsychologia 2003;41: 1281-1289 
61. Salloway S, Malloy P, Cummings JL, eds. The neuropsychiatry of limbic and subcortical disorders. Washington, DC: American Psychiatric Press; 1997

62. Izaki M, Horiuchi T, Hozaki H. Lipoidosis cutis et mucosae (lipoid proteinosis Urbach-Wiethe): Report of a case. Keio J Med 1954;3: 163-177

63. Grosfeld JCM, Spaas J, Van de Staak WJBM, et al. Hyalinosis cutis et mucosae. Dermatologica (Basel) 1965;130: 239-266

64. Oxbury JM, Oxbury SM. Memory and the human temporal lobes. In: Milner AD, ed. Comparative neuropsychology. Oxford: Oxford University Press; 1998:95-108

65. Ogden JA. Fractured minds: A case-study approach to clinical neuropsychology. New York: Oxford University Press; 1999

66. Horel JA. The Neuroanatomy of amnesia. A critique of the hippocampal memory hypothesis. Brain 1978;101: 403-445

67. Corkin S. Lasting consequences of bilateral medial temporal lobectomy: clinical course and experimental findings in H.M. Semin Neurol 1984;4: 249-259

68. Zola-Morgan S, Squire LR, Amaral DG. Human amnesia and the medial temporal region: enduring memory impairment following a bilateral lesion limited to field CA1 of the hippocampus. J Neurosci 1986;6: 2950-2967 
69. Zola-Morgan S, Squire LR, Amaral DG. Memory impairment in monkeys following lesions of the amygdala that spare adjacent cortical regions do not impair memory or exacerbate the impairment following lesions of the hippocampal formation. J Neurosci 1989;9: 1922-1936

70. Schnider A, Regard M, Landis T. Anterograde and retrograde amnesia following bitemporal infarction. Behav Neurol 1994;7: 87-92

71. Penfield W, Mathieson G. Memory: Autopsy findings on the role of the hippocampus in experiential recall. Arch Neurol 1974;31: 145-154

72. Markowitsch HJ, Calabrese P, Wurker M, et al. The amygdala's contribution to memory: a study of two patients with Urbach-Wiethe Disease. Neuroreport 1994;5: 1349-1352

73. Cahill L, Babinsky R, Markowitsch HJ, et al The amygdala and emotional memory. Nature 1995;377: 295-296

74. Calder AJ, Young AW, Rowland D, et al. Facial emotion recognition after bilateral amygdala damage: differently severe impairment of fear. Cognitive Neuropsychology 1996;13 (5): 699-745

75. Lezak MD, Howieson DB, Loring DW. Neuropsychological Assessment 4 ed. Oxford: Oxford University Press; 2004 
76. Gabriel M, Burhans L, Kashef A. Consideration of a unified model of amygdalar associative functions. Ann N.Y. Acad Sci 2003;985: 206-217

77. Alvarez EO, Ruarte MB. Histaminergic neurons of the ventral hippocampus and the baso-lateral amygdala of the rat: functional interaction on memory and learning mechanisms. Behav Brain Res 2002;128: 81-90

78. Aggleton JP, ed. The amygdala: A functional analysis 2 ed. Oxford: Oxford University Press; 2001

79. Kõks S, Planken A, Luuk $\mathrm{H}$, et al. Cat odour exposure increases the expression of wolframin gene in the amygdaloid area of rat. Neurosci Lett 2002;322: 116-120

80. Klüver H, Bucy PC. Preliminary analysis of functions of the temporal lobes in monkeys. Arch Neurol and Psychiatry 1939;42 (6): 979-1000

81. Amaral DG, Caitanio JP, Jourdain M, et al. The amygdala: is it an essential component of the neural network for social cognition? Neuropsychologia 2003;41 (4): $517-522$

82. Prather MD, Lavenex P, Mauldin-Jourdain ML. Increased social fear and decreased fear of objects in monkeys with neonatal amygdala lesions. Neuroscience 2001;106 (4): 653-658 
83. Büchel C, Dolan RJ. Classical fear conditioning in functional neuroimaging. Curr Opin Neurobiol 2000;10 (2): 219-223

84. Yilmazer-Hanke DM, Faber-Zuschratter H, Linke R, et al. Contribution of amygdala neurons containing peptides and calcium-binding proteins to fearpotentiated startle and exploration-related anxiety in inbred Roman high- and low-avoidance rats. Eup J Neurosci 2002;15: 1206-1218

85. Holland PC, Rescorla RA. The effect of two ways of devaluing the unconditioned stimulus after first- and second-order appetitive conditioning. J Exp Psychol Anim Behav Process 1975;1: 355-363

86. Holland PC. Event representation in Pavlovian conditioning: image and action. Cognition 1990;37: 105-131

87. Holland PC. Amount of training affects associatively-activated event representation. Neuropharmacology 1998;37: 461-469

88. Young MP, Scannell JW, Burns GAPC, et al. Analysis of connectivity: neural systems in the cerebral cortex. Reviews in the Neurosciences 2004;2: 227-249

89. Everitt BJ, Cador M, Robbins TW. Interactions between the amygdala and ventral striatum in stimulus-reward associations: studies using a second-order schedule of sexual reinforcement. Neuroscience 1989;30: 63-75 
90. Burns LH, Robbins TW, Everitt B. Differential affects of excitotoxic lesions of the basolateral amygdala, ventral subbulum and medial prefrontal cortex on responding with conditioned reinforcement and locomotor activity potentiated by intra-accumbens infusions of e-amphetamine. Behav Brain Res 1993;55: 167183.

91. Kilcross S, Robbins T, Everitt BJ. Different types of fear-conditioned behaviour mediated by separate nuclei within amygdala. Nature 1997;388: 377-380

92. Parkinson JA, Crofts JA, McGuigan M, et al. The role of the primate amygdala in conditioned reinforcement. J Neurosci 2001;21: 7770-7780

93. Nader K, Schafe GE, Le Doux JE. Fear memories require protein synthesis in the amygdala for reconsolidation after retrieval. Nature 2000;406 (6797): 686-687

94. Setlow B, Gallagher M, Holland PC. The basolateral complex of the amygdala is necessary for acquisition but not expression of CS motivational value in appetitive Pavlovian second-order conditioning. Eur J Neurosci 2002;15(11): $1841-1853$

95. Parkinson JA, Robbins TW, Everitt BJ. Dissociable roles of the central and basolateral amygdala in appetitive emotional learning. Eup J Neurosci 2000;12: $405-413$ 
96. Baxter MG, Murray EA. The amygdala and reward. Neuroscience 2002;3: 563573

97. Gallagher M, Graham PW, Holland PC. The amygdala central nucleus and appetitive Pavlovian conditioning: lesions impair one class of conditioned behaviour. J Neurosci 1990;10: 1906-1911

98. Han JS, McMahan RW, Holland P, et al. The role of an amygdala nigrostiatal pathway in associative learning. J Neursci 1997;17: 3913-3919

99. Pitkänen A. Connectivity of the rat amygdaloid complex. In: Aggleton JP, ed. The amygdala: A functional analysis 2 ed. Oxford: Oxford University Press; 2000:631654

100. Holland PC, Hatfield T, Gallagher M. Rats with basolateral amygdala lesions show normal increases in conditioned stimulus processing but reduced conditioned potentiation of eating. Behav Neurosci 2001;115: 945-950

101. Holahan MR, White NM. Conditioned memory modulation, freezing, and avoidance as measures of amygdala-mediated conditioned fear. Neurobiol Learn Mem 2002;77: 250-275

102. Davis M, Walker DL, Myers KM. Role of the amygdala in fear extinction measured with potentiated startle. Ann N.Y. Acad Sci 2003;985, 218-232 
103. Walker DL, Davis M. The role of the amygdala glutamate receptors in fear learning, fear-potentiated startle, and extinction. Pharmacol Biochem Behav 2002;71: 379-392

104. Everitt BJ, Cardinal RN, Parkinson JA, et al. Appetitive behavior: Impact of amygdala-dependent mechanisms of emotional learning. Ann N.Y. Acad Sci 2003;985: 233-250

105. Dolan RJ. Functional neuroimaging of the amygdala during emotional processing and learning. In: Aggleton JP, ed. The amygdala: A functional analysis 2 ed. Oxford: Oxford University Press; 2000:631-654

106. Davis M. Neurobiology of fear responses: The role of the amygdala. In: Salloway S, Malloy P, Cummings JL. The neuropsychiatry of limbic and subcortcal disorders. Washington, D.C.: American Psychiatric Press; 1997

107. LeDoux JE. Emotion and the limbic system concept. Concepts Neurosci 1991;2: 169-199

108. LeDoux JE. Emotional memory systems in the brain. Behav Brain Res 1993;58: $69-79$

109. McGaugh JL, Introini-Collison IB, Cahill LF, et al. Neuromodulatory systems and memory storage: role of the amygdala. Behav Brain Res 1993;58: 81-90 
110. McGaugh JL, Cahill L. Interaction of neuromodulatory systems in modulating memory storage. Behav Brain Res 1997;83: 31-38

111. Baxter MG, Parker A, Lindner CC, et al. Control of response selection by reinforcer value requires interaction of amygdala and prefrontal cortex. $\mathrm{J}$ Neurosci 2000;20: 4311-4319

112. Bechara A, Tranel D, Damasio H, et al. Failure to respond automatically to anticipated future outcomes following damage to prefrontal cortex. Cereb Cortex 1996;6: 215-225

113. Bechara A, Damasio H, Damasio AR, et al. Different contributions of the human amygdala and ventromedial prefrontal cortex. J Neursci 1999;19: 5473-5481

114. Gorman DG, Cummings JL. Hypersexuality following septal injury. Arch Neurol 1992;49: 308-310

115. Aggleton JP. The contribution of the amygdala to normal and abnormal emotional states. Trends Neurosci 1993;16: 328-333

116. Cahill L, McGaugh JL. Mechanisms of emotional arousal and lasting declarative memory. Trends Neurosc 1998;21:294-299

117. Kilcross S. The amygdala, emotion, and learning. Psychologist 2000;13: 2-507 
118. Rosen J, Schulkin J. From normal fear to pathological anxiety. Psychol Rev 1998;105: 325-350

119. Pincus JH, Tucker GJ. Behavioural neurology 4 ed. New York: Oxford University Press; 2003

120. Baron-Cohen S. Mindblindness. An essay on autism and theory of mind. Cambridge, MA: MIT Press;1995

121. Baron-Cohen S, Ring HA, Bullmore ET, et al. The amygdala theory of autism. Neurosci Behav Rev 2000;24: 355-364

122. Cador M, Robbins TW, Everitt B. Involvement of the amygdala in stimulus-reward associations: interaction with the ventral striatum. Neuroscience 1989;30: 77-86

123. Fudge JL, Powers JM, Habner SN, et al. Considering the role of the amygdala in psychotic illness: a clinicopathological correlation. J Neuropsychiatry Clin Neurosci 1998;10 (4): 383-394

124. Evangeli M Broks P. Face processing in schizophrenia. Parallels with the effects of amygdala damage. Cogn Neuropsychiatry 2000;5 (2): 81-105

125. Sachdev P, Brodaty H, Cheang D. Hippocampus and amygdala volumes in elderly schizophrenic patients as assessed by magnetic resonance imaging. Psychiatry Clin Neurosci 2000;54 (1): 105-113 
126. Haber SN, Fudge JL. The interface between dopamine neurones and the amygdala: Implications for schizophrenia. Schizophre Bull 1997;23 (3): 471-482

127. Armony JL, Dolan RJ. Modulation of spatial attention by fear-conditioned stimuli: an event-related fMRI study. Neuropsychologia 2002;40: 817-826

128. Bennett TI. Cognitive effects of epilepsy and anti-convulsant medications. In: Bennett TI, ed. The neuropsychology of epilepsy. New York: Plenum Press; 1992:73-95

129. Miller LA, Munoz DG, Finmore M. Hippocampal sclerosis and human memory. Arch Neurol 1993;50: 391-394

130. Hermann BP, Scidenberg M, Schoenfeld J, et al. Neuropsychological characteristics of the syndrome of mesial temporal lobe epilepsy. Arch Neurol 1997;54: 369- 376

131. Guerreiro C, Cendes F, Li LM, et al. Clinical patterns of patients with temporal lobe epilepsy and pure amygdalar atrophy. Epilepsia 1999;40: 453-461

132. Blake RV, Wroe SJ, Breen EK, et al. Accelerated forgetting in patients with epilepsy: Evidence for an impairment in memory consolidation. Brain 2000;123: $472-483$ 
133. Pegna AJ, Caldara-Schnetzer AS, Perrig SH, et al. Is the right amygdala involved in visuospatial memory? Evidence from MRI volumetric measures. Eur Neurol 2002;47: 148-155

134. Ekman P, Friesen WV. Pictures of facial affect. Palo Alto, CA: Consulting Psychologists Press; 1976

135. Blair RJR, Morris JS, Frith CD, et al. Dissociable neural responses to facial expressions of sadness and anger. Brain 1999;122: 883-393

136. Breiter $\mathrm{HC}$, off $\mathrm{NL}$, Whalen $\mathrm{PJ}$, et al. Response and habituation of the human amygdala during visual processing of facial expression. Neuron 1996;17: 875887

137. Kinomura S, Kawashima R, Yamada K, et al. Functional anatomy of taste perception in the human brain studied with positon emission tomography. Brain Res 1994;659: 263-266

138. Yaxley S, Rolls ET, Seinkiewicz ZJ. The responsiveness of neurons in the insular gustatory cortex of the macaque monkey is independent of hunger. Physiol Behav 1988;42: 223-229

139. LaBar KS, LeDoux JE, Spencer DD, et al. Impaired fear conditioning following unilateral temporal lobectomy in humans. J Neurosci 1995;15: 6846-6855 
140. Büchel C, Morris J, Dolan RJ, et al. Brain systems mediating aversive conditioning: an event-related fMRI study. Neuron 1998;20: 947-957

141. Adolphs R, Russell JA, Tranel D. A role for the human amygdala in recognizing emotional arousal from unpleasant stimuli. Psychol Sci 1999;10: 167-171

142. Schultz B, Fendt M, Schnitzler $\mathrm{H}$. Clonidine injections into the lateral nucleus of the amygdala block acquisition and expression of fear-potentiated startle. Eup $\mathrm{J}$ Neurosci 2002;15: 151-157

143. Sprengelmeyer R, Young AW, Schroeder U, et al. Knowing no fear. Proc R Soc Lond: Series B Biol Sci 1999;266: 2451-2456

144. Schmolck H, Squire L. Impaired perceptions of facial emotions following bilateral damage to the anterior temporal lobe. Neuropsychology 2001;15: $30-38$

145. Gray JM, Young AW, Barker WA, et al. Impaired recognition of disgust in Huntington's disease gene carriers. Brain 1997;120: 2029-2038

146. Calder AJ, Keane J, Manes F, et al. Impaired recognition and experience of disgust following brain injury. Nat Neurosci 2000;3: 1077-1078

147. Murphy FC, Nimmo-Smith I, Lawrence AD. Functional neuroanatomy of emotions: a meta-analysis. Cogn Affect Behav Neurosci 2003;3(3): 207-233 
148. Lawrence AD, Calder AJ, McGowan SV, et al. Selective disruption of the recognition of facial expressions of anger. NeuroReport 2002;13: 881-884

149. Davidson PSR, Glisky E. Is flashbulb memory a special instance of source memory? Evidence from older adults. Memory 2002;10 (2): 99-111

150. Abrisqueta-Gomez J, Bueno OFA, Oliveira MGM, et al. Recognition memory for emotional pictures in Alzheimer's patients. Acta Neurol Scand 2002;105: 51-54

151. Ikeda M, Mori E, Hirono N. Amnestic people with Alzheimer's Disease who remembered the Kobe earthquake. Br J Psychiatry 1998;172: 425-428

152. Aggleton JP. A description of the amygdalo-hippocampal interconnections in the macaque monkey. Exp Brain Res 1986;64: 515-526

153. Dolan RJ. Emotion, cognition and behavior. Science 2002;298: 1191-1194

154. Kihlstrom JF. The trauma-memory argument. Conscious Cogn 1995;4: 63-67

155. Kihlstrom JF. The psychological unconscious and the self. Ciba Found Symp 1993;74: 11147-1156

156. Quirk GJ, Gehlert DR. Inhibition of the amygdala: Key to pathological states? Ann N.Y. Acad Sci 2003;985: 263-272 
157. Breslau N, Davis GC, Andreski P, et al. Sex differences in posttraumatic stress disorder. Arch Gen Psychiatry 1997;54: 1044-1048

158. Kendler KS, Thornton LM, Prescott CA. Gender differences in the rates of exposure to stressful life events and sensitivity to their depressogenic effects. Am J Psychiatry 2001;158: 587-593

159. Tebartz van Elst L, Woermann F, Lemieux L, et al. Increased amygdala volumes in female and depressed humans: A quantitative magnetic resonance imaging study. Neurosci Lett 2000;281: 103-106

160. Cahill L. Sex-related influences of the neurobiology of emotionally influenced memory. Ann N.Y. Acad Sci 2003;985:163-173

161. Ernst M, Botha $\mathrm{K}$, Mouratidis $\mathrm{M}$, et al. Decision-making in a risk-taking task: $\mathrm{A}$ PET study. Neuropsychopharmacol 2001;26: 682-691

162. Greene JD, Sommerville RB, Nystrom LE, et al. An fMRI investigation of emotional engagement in moral judgment. Science 2001;293: 2105-2108

163. Vickrey BG, Hays RD, Graber J, et al. A health related quality of life instrument for patients evaluated for epilepsy surgery. Med Care 1992;30: 299-319

164. Birbeck GL, Kim S, Hays R, et al. Quality of life measures in epilepsy. How well can they detect change over time? Neurology 2000;54: 1822-1827 
165. Devinsky O, Vickrey B, Cramer J, et al. Development of the Quality of Life In Epilepsy Inventory. Epilepsia 1995;36 (11): 1089-11-4

166. Patrick DL, Deyo RA. Generic and disease-specific measures in assessing health status and quality of life. Med Care 1989;27 (3): S217-S232

167. Baker GA, Jacoby A, Smith DF, et al. D.W. Development of a novel scale to assess life fulfillment as part of the refinement of a quality of life model in epilepsy. Epilepsia 1994;35: 591-596

168. Hays RD, Prince-Embury S, Chen H. RAND-36 Health Status Inventory: Manual. San Antonio, TX: The Psychological Corporation; 1998

169. Sheehan D, Janavs J, Baker R, et al. Mini International Neuropsychiatric Inventory Plus. Tampa: University of South Florida; 2003

170. Kay SR, Opler LA. The positive negative dimension in schizophrenia: Its validity and significance. Psychiatr Dev 1987;5: 79-103

171. Kay SR, Fiszbeing A, Opler LA. The positive and negative symptoms scale (PANSS) for schizophrenia. Schizophr Bull 1987;13: 261-276

172. Sternberg RJ. Components of human intelligence. Cognition 1983;15 (1): 1-48 
173. Montgomery SA, Asberg M. A new depression scale designed to be sensitive to change. Br J Psychiatry 1979;134: 382-389

174. The Psychological Corporation. Wechsler Abbreviated Scale of Intelligence: Manual. Harcourt Brace \& Company, San Antonio; 1999

175. Claasen NCW, Krynauw AH, Paterson H, et al. A standardisation of the WAIS-III for English-speaking South Africans. Pretoria: Human Sciences Research Council; 2001

176. Human Sciences Research Council. South African Wechsler Adult Intelligence Scale. Johannesburg: Human Sciences Research Council; 1983

177. Benton AL, Sivan AB, Hamsher K de S, et al. Facial recognition: Stimulus and multiple choice pictures. Oxford: Oxford University Press; 1983

178. Bartlett MS, Hager JC, Ekman P. Measuring facial expressions by computer image analysis. Psychophysiology 1999;36: 253-263

179. Barkataki I. Finding sex differences. Psychologist 2006;19 (1): 14-16

180. Rey A. L'examen clinique en psychologie. Paris: Presses Universitaires de France; 1964. 
181. Wechsler D. Wechsler Memory Scale - Revised: Manual. San Antonio: The Psychological Corporation; 1987

182. Walker RG. The revised Hooper Visual Organization Test as a measure of brain damage. J Clin Psychol 1956;12 (4): 387-388

183. Ruff RM. Ruff Figural Fluency test: Professional manual. Odessa: Psychological Assessment Resources; 1996

184. Wilson BA, Alderman N, Burgess P, et al. Behavioural Assessment of the Dysexecutive Syndrome. Manual. Bury St Edmunds: Thames Valley Test Company; 1996

185. Broadbent DE, Cooper P, FitzGerald P, et al. The Cognitive Failures Questionnaire (CFQ) and its correlates. Brit J Clin Psychol 1982;21: 1-16

186. Ware JE, Sherbourne CD. The MOS 36-Item Short Form Health Survey (SF-36): Conceptual framework and item selection. Med Care 1992;30: 473-483

187. Ware JE Jr, Kosinski M, Bayliss MS, et al. Comparison of methods for the scoring and statistical analysis of SF-36 health profile and summary measures: summary of results from the Medical Outcomes Study. Med Care 1995;33 (Supl.4): AS264AS279 
188. Ware JE Jr. Patient-based assessment: tools for monitoring and improving healthcare outcomes. Behav Healthc Tomorrow 1996;5(3): 763-773

189. Ogden JA, McFarlane-Nathan G. Cultural bias in the neuropsychological assessment of young Maori men. N Z J Psychol 1997;26 (2): 2-12

190. Okazaki S, Sue S. Implications of test revisions for assessment with Asian Americans. Psychol Assess 2000;72: 272-280

191. Viljoen G, Levett A, Tredoux C, et al. Using the Bender Gestalt in South Africa: Some normative data for Zulu-speaking children. S Afr J Psychol 1994;24: 145151

192. Avenant TJ. The establishment of an individual intelligence scale for adult South Africans. Report on an exploratory study conducted with the WAIS-R on a sample of Blacks. Pretoria: Human Sciences Research Council; 1998

193. Shuttleworth-Jordan AB. On not reinventing the wheel: A clinical perspective on culturally relevant test usage in South Africa. S Afr J Psychol 1996;26 (2): 96-102

194. Shuttleworth-Edwards AB, Kemp RD, Rust AL, et al. Cross-cultural effects on IQ test performance: a review and preliminary normative indications on WAIS-III test performance. J Clin Exp Neuropsychol 2004;26 (7): 903-920 
195. Skuy M, Schutte E, Fridjhon P, et al. Suitability of published neuropsychological test norms for urban African secondary school students in South Africa. Pers Indiv Diff 2000;30: 1413-1425

196. Demsky YI, Gass CS, Golden CJ. Interpretation of VIQ-PIQ and intersubtest differences on the Spanish version of the WAIS. Assessment 1998;5: 25-30

197. Faulstich ME, McAnulty D, Carey MP, et al. Topography of human intelligence across race: Factorial comparison of black-white WAIS-R profiles for criminal offenders. Int J Neurosci 1987;35: 181-187

198. Lynn R, Dai XY. Sex differences on the Chinese standardization sample of the WAIS-R. J Genet Psychol 1993;75: 459-463

199. http://www.info.gov.za/aboutsa/landpeople.html - Site accessed 19 January 2006

200. Fillenbaum GG, Heyman A, Huber MS, et al. Performance of elderly African American and white community residents on the CERAD neuropsychological battery. J Int Neuropsychol Soc 2001;7: 502-509

201. Grieve KW, Viljoen S. An exploratory study of the use of the Austin maze in South Africa. S Afr J Psychol 2000;30: 14-18 
202. Vizi ES, Kiss JP. Neurochemistry and pharmacology of the major hippocampal transmitter systems: synaptic and nonsynaptic interactions. Hippocampus 1998;8: 566-607

203. Schmitz D, Gloveli T, Empson RM, et al. Comparisons of the effects of serotonin in the hippocampus and the entorhinal cortex. Mol Neurobiol 1998;17: 59-72

204. Moritz CH, Johnson SC, McMillan KM, et al. Functional MRI neuroanatomic correlates of the Hooper Visual Organization Test. J Int Neuropsychol Soc 2004;10 (7): 939-947

205. Bruce V, Young A. Understanding face recognition. Br J Psychol 1986; 77: 305327

206. Von Gunten A, Fox NC, Cipolotti L, et al. A volumetric study of hippocampus and amygdala in depressed patients with subjective memory problems. $\mathrm{J}$ Neuropsychiatry Clin Neurosci 2000;12: 493-498

207. Appleton R, Baker G, Chadwick D, et al (eds). Epilepsy 4 ed. London: Martin Dunitz; 2001

208. Baker GA, Jacoby A, eds. Quality of life in epilepsy: Beyond seizure counts in assessment and treatment. Amsterdam: Harwood Academic Publishers; 2000 
209. MacLean PD. Psychosomatic disease and the 'visceral brain': recent developments bearing on the Papez theory of emotion. Psychosom Med, 1949;11: 338-353

210. MacLean PD. Some psychiatric implications of physiological studies on frontotemporal portion of limbic system (visceral brain). Electroencephalogr Clin Neurophysiol 1952;4: 407-418

211. Reiner A. The triune brain in evolution: role in paleocerebral functions. Science 1990;250: 303-305

212. Calder AJ, Lawrence AD, Young AW. Neuropsychology of fear and loathing. Nat Rev Neurosci 2001;2: 352-363

213. Damasio A R. Emotion in the perspective of an integrated nervous system. Brain Res Rev 1998;26: 83-86

214. Mills CK. The cortical representation of emotion, with a discussion of some points in the general nervous system mechanism of expression in its relation to organic nervous disease and insanity. Proc Am Medico-Psychol Assoc 1912;19: 297-300

215. Sackeim HA, Gur RE. Emotions are expressed more intensely on the left side of the face. Science 1978;202: 434-436 
216. Bowers D, Bauer RM, Coslett HB, et al. Processing of faces by patients with unilateral hemispheric lesions. Dissociation between judgments of facial affect and facial identity. Brain Cogn 1985;4: 258-272

217. Borod JC, Koff E, Lorch MP, et al. Emotional and non-emotional facial behaviour in patients with unilateral brain damage. J Neurol Neurosurg Psychiatry 1988;51: 826-832

218. Ahern GL, Schomer DL, Kleefield J, et al. Right hemisphere advantage for evaluating emotional facial expressions. Cortex 1991;27: 193-202

219. Borod JC, Andelmlan F, Obler LK, et al. Right hemisphere specialization for the identification of emotional words and sentences: evidence from stroke patients. Neuropsychologia 1992;30: 827-844

220. Weintraub S, Mesulam MM, Kramer L. Disturbances prosody. A right-hemisphere contribution to language. Arch Neurol 1981;38: 742-744

221. Mandal MK, Mohanty A, Pandey R, et al. Emotion-specific processing deficit in focal brain-damaged patients. Int J Neurosci 1996;84: 87-95

222. Borod JC, Cicero BA, Obler LK, et al. Right hemisphere emotional perception: evidence across multiple channels. Neuropsychology 1998;12: 446-458 
223. Borod JC, Zgaljardic D, Tabert MH, et al. Asymmetries of emotional perception and expression in normal adults. In: Gainotti G, ed. Handbook of neuropsychology 2 ed. Amsterdam: Elsevier; 2001:181-205

224. Heller W, Nitschke JB, Miller GA. Lateralization in emotion and emotional disorders. Curr Dir Psychol Sci 1998;7: 26-32

225. Schneirla T. An evolutionary and developmental theory of biphasic processes underlying approach and withdrawal. In: Jones M, ed. Nebraska symposium on motivation. Lincoln: University of Nebraska Press;1959: 1-42

226. Kinsbourne M. Biological determinants of functional bisymmetry and asymmetry. In: Kinsbourne M, ed. Asymmetrical function of the brain. New York: Cambridge University Press; 1978:3-13

227. Lang PJ, Bradley MM, Cuthbert BN. Motivated attention: affect, activation, and action. In: Lang PJ, Simons RF, Balaban MT, eds. Attention and orienting: Sensory and motivational processes. Mahwah, NJ: Erlbaum; 1997:97-135

228. Davidson RJ, Irwin W. The functional neuroanatomy of emotion and affective style. Trends Cogn Sci 1999;3: 11-21

229. Green DP, Salovey P. In what sense are positive and negative affect independent? A reply to Tellegen, Watson, and Clark. Psychol Sci 1999;10: 304306 
230. Russell JA, Barrett LF. Core effect prototypical emotional episodes, and other things called emotions: dissecting the elephant. J Pers Soc Psychol 1999;76: 805-819

231. Watson D, Wiese D, Vaidya J, et al. The two general activation systems of affect: structured findings, evolutionary considerations, and psychobiological evidence. J Pers Soc Psychol 1999;76: 820-838

232. Carver CS, Sutton SK, Scheier MF. Action, emotion and personality: Emerging conceptual integration. Pers Soc Psychol Bull 2000;26: 741-751

233. Davidson RJ. Affective style and affective disorders: perspectives from affective neuroscience. Cogn Emotion 1998;12: 307-330

234. Davidson RJ, Sutton SK. Affective neuroscience: The emergence of a discipline. Curr Opin Neurobiol 1995;5: 217-224

235. Izard CE. The face of emotion. New York: Appleton-Century Crofts; 1971

236. Tomkins S. Affect theory. In: Scherer KR, Ekman P, eds. Approaches to emotion. Hillsdale, NJ: Erlbaum; 1982:63-195 
237. Davidson RJ. Affect, cognition and hemispheric specialization. In: Izard CE, Kagan J, Zajonc R, eds. Emotion, cognition and behavior. New York: Cambridge University Press; 1984:320-365

238. Cloninger C. A systematic method for clinical description and classification of personality variants. Arch Gen Psychiatry 1987;44: 573-588

239. Davidson RJ, Ekman P, Saron CD, et al. Approach-withdrawal and cerebral asymmetry: emotional expression and brain physiology. J Pers Soc Psychol 1990;58: 330-341

240. Ekman P. Basic emotions. In: Dalgleish T, Power MJ, eds. Handbook of cognition and emotion. Chichester, UK: Wiley; 1999:45-60

241. Panksepp J. Emotions as natural kinds within the mammalian brain. In: Lewis M, Haviland-Jones JM, eds. Handbook of emotions 2 ed. New York: Guilford; 2000:137-156

242. Costano M, Archer D. Interpreting the expressive behavior of others: The interpersonal perception task. J Nonverb Behav 1989;13 (4): 225-245

243. Canli T, Sivers H, Whitfield SL, et al. Amygdala response to happy faces as a function of extraversion. Science 2002;296: 2191 
244. Carver CS, White TL. Behavioral inhibition, behavioral activation and affective responses to impending reward and punishment: The BIS/BAS scales. J Pers Soc Psychol 1994;67 (2): 319-333

245. http://www.info.gov.za/province/overview/htm) - Site accessed 21 October 2005

246. http://www.info.gov.za/aboutsa/landpeople.html/nc - Site accessed 19 January 2006

247. http://www.cia.gov/cia/publications/factbook/geos/sf.html - Site accessed 17 October 2005

248. http://south-africa-tours.com/northern-cape.html - Site accessed 15 February 2006

249. http://south-africa-tours.com/northern-cape.html - Site accessed 21 October 2005

250. Kalahari District Council. Northern Cape Tourism pamphlet. Northern Cape Travel Planner: Kalahari District Council; 2003 


\section{APPENDIX I}

INFORMATION AND INFORMED CONSENT DOCUMENT 


\section{PATIENT INFORMATION AND CONSENT FORM}

Study title: $\quad$ The Neuropsychiatry and Neuropsychology of Lipoid

Proteinosis.

Investigators: Helena Thornton

Professor Dan Stein

Dr. James Butler

Dr. James Warwick

Dr. Gary Kroukamp

Dear volunteer

\section{INTRODUCTION}

You are being asked to participate in a research study. Please read the following information carefully and do not hesitate to ask questions now or at any time during the study. Your participation in the study is entirely voluntary.

\section{DESCRIPTION AND PURPOSE OF THE STUDY}

You are being invited to take part in a study carried out by the University of Stellenbosch. The purpose of this study is to understand some of the symptoms of Lipoid Proteinosis (LiP). This 
illness may cause no problems at all, or it may cause difficulties with memory, or feelings (e.g. anxiety) or thinking. We want to assess ALL patients with LIP to explore memory, thinking, feelings and behaviour. One other person who has daily contact with you (e.g. family member or other caregiver) will be asked to answer questions about your memory and feelings and behaviour. We hope to understand the way LIP works by looking at both those people who may have symptoms and those people who do not have symptoms. We will be doing pen and paper tests with people at their local clinic, and maybe later, you will be invited to come to Tygerberg Hospital in Cape Town for more tests. The study will take place at the Faculty of Health Sciences of the University of Stellenbosch, and will be conducted according to the Declaration of Helsinki and the guidelines for Good Clinical Practice (ICH). The research ethics committee of the University of Stellenbosch has approved the study.

If you are invited to come to come to Cape Town, you will have a type of brain scan, called a SPECT scan, which looks at blood flow in the brain. This scan will require a radioactive dye to be injected into you. The amount of radiation you will be exposed to is very small and is considered safe, but you will have some radiation exposure. (This investigation is frequently used in diagnostic procedures and is an acceptable, standard investigative procedure.) You may also have another brain scan called a MRI. With this one there are no injections and you are asked to lie still for approximately half an hour inside a machine. It may make loud knocking sounds.

\section{DISCOMFORT AND RISKS ASSOCIATED WITH THE STUDY}

You will need to lie flat in a machine and will have a picture of your brain taken. The machine may make quite a bit of noise, and it may be uncomfortable to lie still. 


\section{Potential Benefits}

Although this study may not benefit you now, it may benefit you and other patients in the future. This study may help clinicians to understand your condition and develop new treatments for patients with a similar condition.

\section{COMPENSATION FOR StUdy PARTicipation}

Tests and examinations required as part of the study will be provided at no cost to you or your medical aid.

While you will not be paid to take part in the study, your traveling costs will be reimbursed if necessary.

\section{COMPENSATION FOR POSSIBLE INJURY/DISABILITY}

You will be referred for medical treatment should this be necessary. You must therefore follow your doctor's instructions at all times and you immediately report any injury to the doctor conducting the study.

In case of an emergency that involves this trial, please contact Prof. Stein (0832639679). 


\section{CONFIDENTIALITY}

Your participation is regarded as strictly confidential. The results of the study will be published in the professional literature and made available to Subcommittee $C$ of the Research Committee, but your identity will not be revealed in any way.

\section{THE RIGHT TO ASK QUESTIONS /TO WITHDRAW FROM THE STUDY}

You have the right to ask questions at any time about any aspect of the study. Your participation in the study is entirely voluntary. You have the right to withdraw at any time. If you decide to withdraw from the study, this will have no influence on your future treatment, and will not jeopardize you in any way.

You are entitled to a signed copy of this document.

I have read and understood these pages, and have had the opportunity to ask questions.

Signed: on 20

Witness:

If you agree to take part, please complete the following section. 
INFORMED CONSENT DOCUMENT FOR A RESEARCH PROJECT

COMPILED ACCORDING TO GUIDELINES PROVIDED BY THE ETHICS COMMITTEE OF THE FACULTY OF HEALTH SCIENCES OF THE UNIVERSITY OF STELLENBOSCH

THE NEUROPSYCHI ATRY AND NEUROPSYCHOLOGY OF LI POID PROTEI NOSIS

DECLARATION BY PATIENT:

I, the undersigned (ID: ...)

(address)

A hereby declare that:

The Department of Psychiatry of the University of Stellenbosch invites me to participate in the above-mentioned research project.

It has been explained to me that psychiatric and psychometric (paper and pen) tests will be performed on me. One other person who has daily contact with me (e.g. family member or other caregiver), will be asked to answer questions about my memory and feelings and behaviour. The duration of testing is approximately four hours.

If I come for brain scans at the Medical School of the University of Stellenbosch, I will lie with my eyes closed in a darkened room. A doctor will then inject me with a medication that will help the machine to take a picture of my brain. This medication has some radioactivity, so that it is like having an X-Ray.

This testing will not affect my treatment in any way.

There is no special advantage or disadvantage in participating in this project.

I have been informed that all information will be treated as confidential, but will be used in a publication in a medical journal. My name will not appear in the publication and it will not be possible to identify me in this publication.

Although the results will be computed at a later stadium, I will have access to the results.

I have been informed that I may refuse participation in this project and that such denial will not effect my current and future treatment at this institution.

The information above has been explained to me in English.

I have not been forced into participation in this project and I can stop my participation at any moment without any consequences.

Participation in this project will not lead to any extra costs for me.

B I hereby give my voluntary permission to participate in the above-mentioned project.

Signed at

on $20 \ldots$

\section{PATI ENT'S SI GNATURE:}

\section{WITNESS:}


DECLARATI ON BY / ON BEHALF OF RESEARCHER

I, declare that I:

Explained the information contained in this document to He/She was requested to put questions to me in the event of any misunderstanding; Conducted this conversation in English.

Signed at: on 20

RESEARCHER / REPRESENTATIVE:

WITNESS:

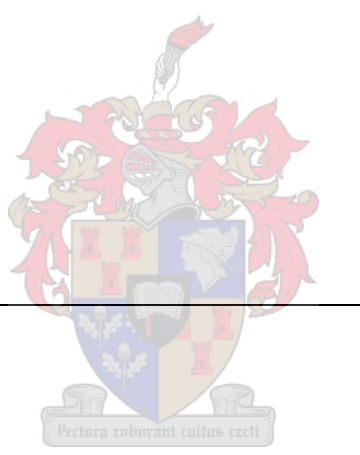




\section{INLIGTING- EN TOESTEMMINGSVORM VIR PASIëNT}

Titel van studie: Die Neuropsigiatrie en Neurosielkunde van Lipoïed-Proteïnose.
Navorsers:
Helena Thornton
Professor Dan Stein
Dr. James Butler
Dr. James Warwick
Dr. Gary Kroukamp

\section{INLEIDING}

Geagte Vrywilliger

$U$ word uitgenooi om deel te neem aan 'n navorsingstudie. Lees asseblief die volgende inligtingsvorm sorgvuldig deur, en moenie huiwer om nou of enige tyd gedurende die studie vrae te vra nie. $U$ deelname aan die studie is heeltemal vrywillig.

\section{BESKRYWING EN DOEL VAN STUDIE}

U word uitgenooi om aan 'n studie deel te neem aan die Universiteit van Stellenbosch. Die doel van die studie is om meer duidelikheid te verkry oor die simptome van Lipoïed- 
Proteïnose (LiP). Hierdie siekte kan òf geen probleme veroorsaak nie, òf $u$ kan moontlik probleme ervaar met u geheue, gevoelens (bv. angstigheid) of denkpatrone. Ons wil graag ALLE persone met LiP evalueer, meer om spesifiek na geheue, gevoelens, denkwyses en gedrag te kyk. ' $n$ Ander persoon wat daaglikse kontak met u hê (soos ' $n$ familielid of ander versorger) sal gevra word om vrae te beantwoord oor u geheue, gevoelens en optrede. Ons hoop om meer te verstaan hoe LIP werk deur na beide persone te kyk wat wél simptome ervaar, of nie. Daar sal pen en papier toetse uitgevoer word by die plaaslike kliniek, en moontlik later sal u uitgenooi word om na Tygerberg Hospitaal in Kaapstad te gaan vir verdere toetse. Die studie sal by die Fakulteit Gesondheidswetenskappe van die Universiteit van Stellenbosch plaasvind en word uitgevoer volgens die Deklarasie van Helsinki en die riglyne vir "Good Clinical Practice" (ICH). Die studie is deur die navorsingsetiekkomitee van die Universiteit van Stellenbosch goedgekeur.

Indien u uitgenooi word om na Kaapstad te kom, sal $u$ 'n tipe breinskandering ontvang, naamlik ' $n$ SPECT skandering wat kyk na die bloedvloei in die brein. Hierdie skandering verg dat $u$ met ' $n$ radio-aktiewe stof ingespuit sal word. Die hoeveelheid radiasie waaraan $u$ blootgestel word is baie klein en word as veilig bestempel, maar u word wel aan bestraling blootgestel. (Hierdie ondersoek word elke dag gebruik vir diagnostiese prosedures. Die ondersoek is ' $n$ aanvaarbare standaard ondersoek metode.) $U$ kan ook ' $n$ ander skandering naamlik ' $n$ MRI ondergaan. Hier word $u$ nie ingespuit nie, maar $u$ word gevra om binne ' $n$ masjien vir omtrent ' $n$ half uur stil te lê. Die masjien maak harde geluide. Die MRI is ' $n$ standaard ondersoek prosedure. 


\section{ONGEMAK EN RISIKO'S WAT MET DIE STUDIE GEASSOSIEER WORD}

U sal op u rug in die MRI masjien lê terwyl ' $n$ foto van u brein geneem word. Die masjien maak redelike harde klanke en dit kan ongemaklik wees om so lank stil te lê.

\section{POTENSIËLE VOORDELE VAN DIE STUDIE}

Alhoewel daar nie ' $n$ onmiddellike voordeel is nie, daar kan miskien toekomstige voordele strek. Hierdie studie mag bydrae tot die ontwikkeling van nuwe behandelings vir persone met soortgelyke toestande.

\section{VERGOEDING VIR DEELNAME AAN DIE STUDIE}

Alle toetse en ondersoeke wat deel maak van hierdie studie sal gratis aan $u$ of $u$ mediesefonds voorsien word.

U sal geen vergoeding ontvang vir $u$ deelname aan die studie nie, maar u reiskostes sal aan u terugbetaal word indien nodig.

\section{VERGOEDING VIR MOONTLIKE BESERING/ONGESKIKTHEID}

U sal wel vir mediese behandeling verwys word indien nodig. $U$ moet dus $u$ geneesheer se instruksies noukeurig volg te alle tye en onmiddellik enige beserings aan u studiegeneesheer rapporteer. 
Stel asseblief $u$ huisdokter in kennis van $u$ deelname aan hierdie studie. Ons sal u psigiater op hoogte hou met die studie en u vordering. In geval van nood, skakel Prof. Stein (0832639679).

\section{VERTROULIKHEID}

Alle persoonlike inligting wat ingewin word met die studie word streng vertroulik hanteer. Ons beplan om die uitslag van hierdie studie in professionele joernale te publiseer, aan die Subkomitee $\mathrm{C}$ van die Navorsingskomitee bekend te maak, maar dit sal nie $\mathrm{u}$ naam of $\mathrm{u}$ identiteit op enige manier bekend maak nie.

\section{DIE REG OM VRAE TE VRA/ OM TE ONTTREK VAN DIE STUDIE}

Dit is $u$ reg om te enige tyd vrae te vra oor die studie.

Dit is $u$ reg om enige tyd van die studie te onttrek. Indien $u$ van die studie sou onttrek, sal sodanige staking nie op enige manier $u$ toekomstige behandeling by hierdie of enige ander inrigting benadeel nie.

$\mathrm{U}$ is geregtig op ' $\mathrm{n}$ getekende kopie van hierdie dokument. 
Ek het hierdie bladsye gelees, verstaan, en die geskiktheid gehad het of vrae te vra.

Geteken:

op

20

Getuie:

Indien $u$ instem om deel te neem, voltooi asseblief die onderstaande afdeling. 
INGELIGTE TOESTEMMINGSDOKUMENT VIR 'N NAVORSINGSPROJEK

SAAMGESTEL VOLGENS RIGLYNE VOORSIEN DEUR DIE ETIESE KOMITEE VAN DIE UNIVERSITEIT VAN STELLENBOSCH SE FAKULTEIT GESONDHEIDSWETENSKAPPE

\section{E NEUROPSI GI ATRI E EN NEUROSI ELKUNDE VAN LI POÏ ED-PROTEÏ NOSE}

VERKLARING DEUR PASIËNT:

Ek, die ondergetekende,

(ID: ...)

(adres)

A. Verklaar dat:

Die Departement Psigiatrie van die Universiteit van Stellenbosch my genooi het om aan die bogenoemde projek deel te neem.

Dit is aan my verduidelik dat psigiatriese en psigometriese (papier-en-pen) toetse op my toegepas sal word. ' $\mathrm{n}$ Ander persoon wat daaglikse kontak met my het (soos ' $n$ familielid of ander versorger) sal gevra word om vrae te beantwoord oor my geheue, gevoelens en optrede. Die toetsing sal ongeveer vier uur duur.

Indien ek na die Mediese Skool van die Universiteit van Stellenbosch kom vir 'n breinskandering sal ek met toe oë in 'n donker kamer lê. ' $n$ Dokter sal my inspuit met ' $n$ kleurmiddel wat die masjien heLiP om ' $n$ foto van my brein te neem. Hierdie kleurmiddel is radio-aktief, dit is soos om ' $n$ X-straal te neem.

Die toetsing sal geen effek op my behandeling hê nie.

Daar is geen spesiale voordeel of nadeel verbonde aan my deelname aan hierdie studie nie.

Alle inligting sal vertroulik hanteer word. Die resultate van hierdie studie sal in ' $n$ mediese tydskrif gerapporteer word. My naam sal nie in hierdie publikasie genoem word nie en dit sal nie moontlik wees om my te identifiseer nie.

Die resultate van hierdie studie word later verwerk en ek kan toegang daartoe kry.

Ek kan weier om aan hierdie projek deel te neem en dit sal nie my huidge of toekomstige behandeling by hierdie inrigting belemmer nie.

Al die bostaande inligting is in Afrikaans aan my verduidelik.

Ek word nie gedwing om deel te neem aan hierdie projek nie en kan my deelname te eniger tyd sonder enige nagevolge staak.

Deelname aan hierdie projek sal nie enige ekstra onkostes vir my meebring nie.

B. Ek gee hiermee vrywillig toestemming tot deelname aan die bostaande projek.

Geteken te

op

20

PATIËNT SE HANDTEKENING:

GETUIE: 


\section{VERKLARI NG DEUR / NAMENS NAVORSER}

Ek, verklaar dat ek:

Die inligting vervat in hierdie dokukument aan verduidelik het.

Hy / sy gevra is om vrae te vra sodat enige onduidelikhede opgeklaar kan word; Hierdie gesprek in Afrikaans plaasgevind het.

Geteken te

op $20 \ldots \ldots \ldots . . . .$.

NAVORSER/ VERTEENWOORDI GER:

GETUI E:

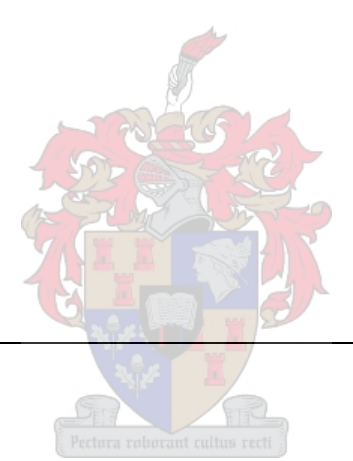




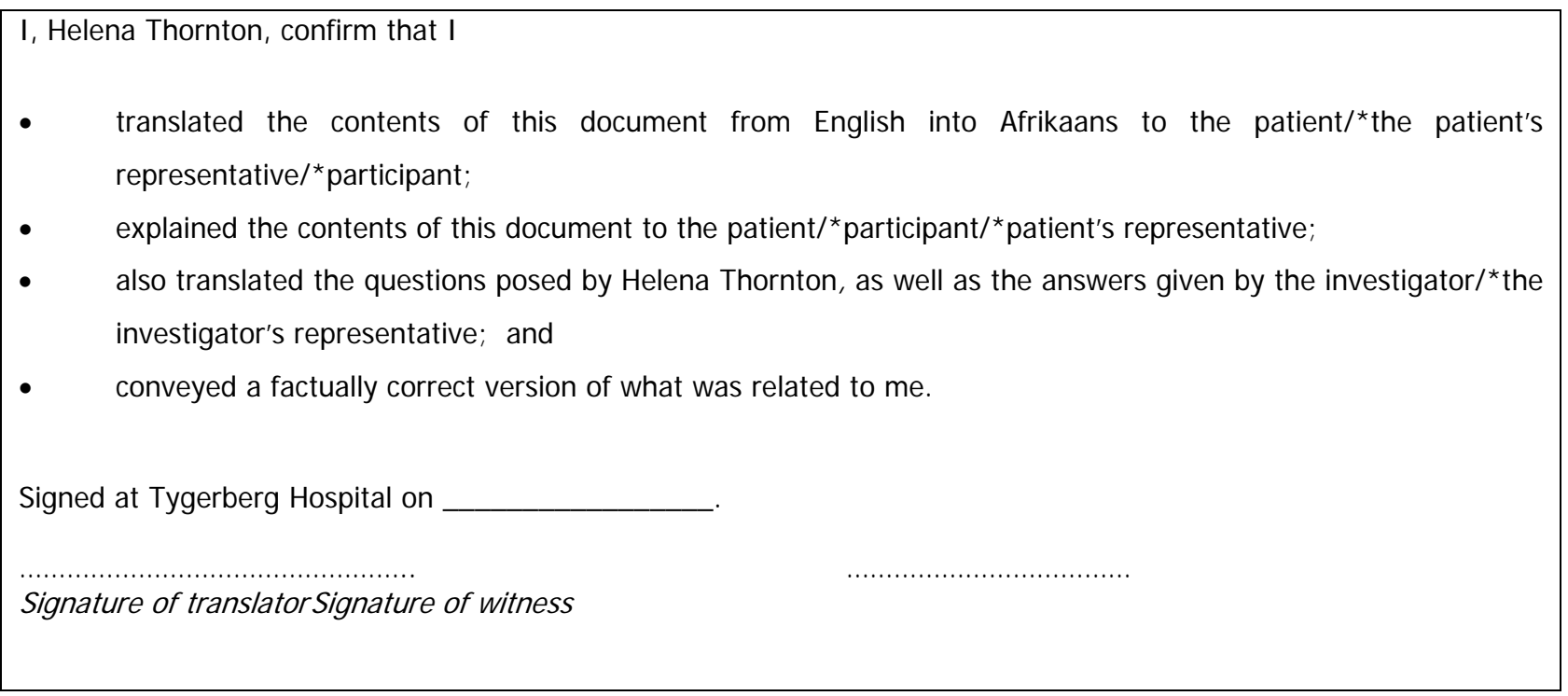

I MPORTANT MESSAGE TO THE PARTI CI PANT :

Dear participant,

Thank you for your participation in this study. Should, at any time during the study,

- $\quad$ an emergency arise as a result of the research, or

- you require any further information with regard to the study,

kindly contact Helena Thornton at (021) 9389227 or of Prof. Stein 0832639679.

\section{BELANGRI KE BOODSKAP AAN DIE DEELNEMER:}

Beste deelnemer,

Dankie vir u deelname aan hierdie studie. Indien daar gedurende enige tydstip van die studie,

- 'n noodgeval ontstaan a.g.v. die navorsing of

- u enige verdere informasie benodig rakende die studie,

kontak gerus vir Helena Thornton by (021) 9389227 of Prof. Stein 0832639679. 
APPENDIX II

\section{DEVELOPING 'AMYGDALA TESTS'}




\section{DEVELOPING 'AMYGDALA TESTS'}

Although the research was designed to use existing standardized neuropsychological and neuropsychiatric tests and batteries, it was soon decided to add (time-allowing) some tests specifically designed for exploration of amygdala-functioning. Half-way into the data collection, 'amygdala tests' began to be added at the end, but were not administered if the time was up or participants were too tired. Approximately 5 patients with Lip completed these tests, and most of the controls. In future research, all the LiP subjects will be assessed on these and other tests.

Knowing that the amygdala may be involved in the recall of particular emotive memory, a paragraph recall test matching in form and administration to the WMS-R's Logical Memory (LM) was designed. In the LM, a person must listen to two stories and try and recall 25 small facts and descriptions told in each story. After a delay, a delayed recall is asked for.

Emotional Memory (EM) was therefore constructed, with the LM content changed to be a highly emotive story. In the first story line, children are fleeing an abusive father, and in the second one, a mother is trying to find her baby in a burning house. Delayed recall (EMII) was also done. 
A second 'amygdala test' was requesting the participant to draw the face of someone who was happy, and recall a time in their life when they felt very happy. The same was done for someone who was sad, someone who was angry and someone who was afraid. These pictures would need to be analyzed qualitatively.

Two more 'amygdala tests' were also developed; the Aeroplane Accident, and The Ferryman. Each was designed to be emotionally laden and filled with emotive and 'moral' decision-making. 
Onmiddelike Geheur:

Ek gaan vir u ' $n$ storietjie van ' $n$ paar reëls lees. Luister goed en probeer dit onthou net soos ek dit sê, so na aan dieselfde woorde as wat jy kan onthou. As ek klaar is, moet $u$ vir my alles oorvertel wat ek vir $u$ gelees het. $U$ moet alles vertel wat $u$ kan onthou, selfs as is u nie seker nie. Is u gereed?

Andre en sy klein boetie, Henrie, het van die huis af weggehardloop. Hulle pa was altyd dronk en het hulle geslaan. Die vorige aand is hulle geslaan totdat hulle oë blou was en hulle lippe gebloei het, en hulle het gevrees vir hulle lewens. Hulle was te bang om hulle pa - wat baie sterk en wreed was - te stop. Hulle wou hulle ma, wat vyf maand vantevore verdwyn het, vind. Hulle het gedink dat sy in die dorp langsaan hulle was, maar hulle het in die geheim geglo dat hulle pa haar vermoor het.

Andre I en sy klein boetie, I Henrie, I het van die huis af weggehardloop. I Hulle pa / was altyd dronk / en het hulle geslaan. I Die vorige aand I is hulle geslaan / totdat hulle oë blou was / en hulle lippe gebloei het, I en hulle het gevrees vir hulle lewens. I Hulle was te bang / om hulle pa I - wat baie sterk I en wreed was- I te stop. I Hulle wou hulle ma, I wat vyf maand / vantevore verdwyn het, I vind. I Hulle het gedink / dat sy in die dorp langsaan hulle was, I maar hulle het in die geheim geglo / dat hulle pa haar vermoor het. 
EMIb

Janet het skielik wakker geskrik. Die kamer was vol rook! Daar was brand!! Sy kon nie asemhaal nie! Toe het sy aan haar baba, Jessica, gedink en baie bang geraak. Sy het geskreeu!! Sy het na die deur gehardloop maar die rook was te dig en sy kon niks sien nie. Sy het gegryp na haar baba se wiegie. Haar baba was slap. Lewe haar baba nog?? Sy was te bang om te dink.

Janet / het skielik / wakker / geskrik. / Die kamer / was vol rook! / Daar was brand!! / Sy kon nie asemhaal nie! / Toe het sy aan haar baba, / Jessica, I gedink / en baie / bang geraak. / Sy het geskreeu!! / Sy het na die deur I gehardloop / maar die rook / was te dig / en sy kon niks sien nie. I Sy het gegryp I na haar baba se wiegie. I Haar baba was slap. I Lewe haar baba nog?? I Sy was te bang / om te dink.

EMI $(a+b)$ Raw score: 
EMII: Latere Oorvertel:

Vertel weer vir my die storie wat ek jou gelees het.

Andre I en sy klein boetie, I Henrie, I het van die huis af weggehardloop. I Hulle pa / was altyd dronk / en het hulle geslaan. I Die vorige aand / is hulle geslaan I totdat hulle oë blou was / en hulle lippe gebloei het, I en hulle het gevrees vir hulle lewens. I Hulle was te bang / om hulle pa I - wat baie sterk I en wreed was- I te stop. I Hulle wou hulle ma, I wat vyf maand I vantevore verdwyn het, I vind. I Hulle het gedink / dat sy in die dorp langsaan hulle was, I maar hulle het in die geheim geglo / dat hulle pa haar vermoor het.

Janet / het skielik / wakker / geskrik. I Die kamer / was vol rook! / Daar was brand!! / Sy kon nie asemhaal nie! / Toe het sy aan haar baba, I Jessica, I gedink / en baie I bang geraak. I Sy het geskreeu!! / Sy het na die deur I gehardloop / maar die rook / was te dig / en sy kon niks sien nie. I Sy het gegryp / na haar baba se wiegie. I Haar baba was slap. I Lewe haar baba nog?? I Sy was te bang / om te dink.

EMII $(a+b)$ Raw score: 


\section{DIE VLIEGTUIGONGELUK (THE AEROPLANE ACCIDENT)}

$\mathrm{U}$ is op ' $\mathrm{n}$ vliegtuig wat aan die brand geslaan het. (You are on a plane that has cought fire.)

1. Hoe voel almal? (How is everyone feeling?)

2. Wat dink jy? (What are you thinking?)

3. Hoe voel jy? (What are you feeling?)

Teken 'n prent van wat gebeur: (Draw a picture of what is happening.) 
Jy het ' $n$ vliegtuigongeluk oorleef. Julle het in die woestyn geland en daar is slegs twee ander oorlewendes; 'n seuntjie, Piet, wat 4 jaar oud is en wat 'n gebreekte been het, en ' $n$ vrou, Mary, wat 20 jaar oud is en wat ses maande swanger is. (You have survived a plane crash. You have landed in the desert and there are only two other survivors; a boy, Piet, of 4 years old with a broken leg, and a woman, Mary, of 20 years, who is six months pregnant.)

4. Hoe voel jy? (How are you feeling?)

5. Hoe voel die ander? (How are the others feeling?)

Die seuntjie, Piet, begin huil. (The little boy, Piet, begins to cry.)

6. Hoekom dink jy huil hy? (Why do you think he is crying?)

Die woestyn is baie warm en julle het net drie blikkies coca-cola. Piet en Mary wil albei iets hê om te drink. Jy is in beheer. (The desert is very hot and you have only three cans of coca-cola. Both Piet and Mary want to drink something. You are in charge.)

7. Wat besluit jy om te doen? (What do you decide to do?)

8. Hoekom? (Why?) 
Die volgende dag sien jy'n slang. Die slang is giftig. Jy het 'n mes. (The next day you see a snake. The snake is poisonous. You have a knife.)

9. Wat doen jy? (What do you do?)

Teken asseblief ' $n$ prent. (Please draw a picture.) 
10. Besluit jy om vir hulp te gaan soek? (Do you decide to go for help?)

11. Gaan jy aleen? Neem jy die ander saam met jou? (Do you go alone? Do you take the others with you?)

12. Hoekom of hoekom nie? (Why or why not?)

13. Hoe voel jy? (How are you feeling?)

14. Hoe voel die ander? (How are the others feeling?)

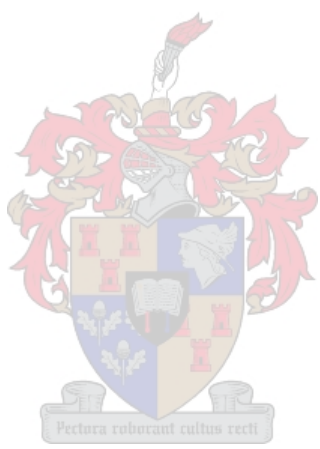


Julle word gered. (You are rescued.)

15. Hoe voel almal? (How does everyone feel?)

Teken asseblief ' $n$ prent: (Please draw a picture.) 


\section{ANNA, HAAR MAN EN DIE VISSERMAN}

Anna bly in Appelvallei, wat van Lemoenvallei geskei word deur 'n breë rivier. Die enigste manier om oor die rivier te kom, is deur die boot wat deur die visserman beheer word. (Anna lives in Appleville which is separated from Orangeville by a big river. The only way to cross the river is by the ferry, run by the Fisherman.)

Anna en die visserman het eers met mekaar uitgegaan. Hulle het uitgemaak omdat hy altyd siek was. Anna het toe met iemand van Lemoenvallei getrou. (Anna and the fisherman used to be girlfriend and boyfriend. Then they broke up because he was always sick. Anna married someone from Orangeville instead.)

Anna hoor dat haar man in 'n ongeluk was. (Anna hears her husband has been in an accident.)

[1. Hoe voel Anna?] (How is Anna feeling?)

Anna vra die visserman om haar oor die rivier te neem. Sy het geen geld nie. Die visserman sê dat hy haar net oor die rivier sal neem as sy eers saam met hom slaap. (Anna asks the fisherman to take her across the river. She has no money. The fisherman says he will only take her across the river if Anna first sleeps with him.)

[2. Wat doen Anna?] (What does Anna do?)

[3. Hoe voel Anna?] (How does Anna feel?) 
Anna slaap saam met die "ferry" en hy neem haar daarna oor die rivier na Lemoenvallei. Haar man is veilig. Dit was ' $n$ valse gerug. (Anna sleeps with the fisherman who then takes her across the river to Orangeville. Her husband is safe. It has been a false report.)

4. Hoe voel Anna?] (How does Anna feel?)

Anna vertel haar man wat die visserman haar maak doen het. (Anna tells her husband what the fisherman made her do.)

[5. Hoe voel hy?] (How does he feel?)

[6. Wat doen hy?] (What does he do?) 
Anna se man het 'n geveg met die visserman. Hy maak die visserman dood. (Anna's husband has a fight with the fisherman. He kills the fisherman.)

[7. Hoe voel Anna?] (How does Anna feel?)

[8. Hoe voel haar man?] (How does Anna's husband feel?)

In die tronk kry hy VIGS. (In prison he gets AIDS.)

[9. Hoe voel hy?] (How does he feel?)

[10. Vertel hy vir Anna daarvan?] (Does he tell Anna?)

Hy vertel vir Anna dat hy VIGS het. (He tells Anna he has AIDS.)

[11. Hoe voel Anna?] (How does Anna feel?)

[12. Hoekom?] (Why?) 


\section{APPENDIX III}

HISTORY OF THIS STUDY

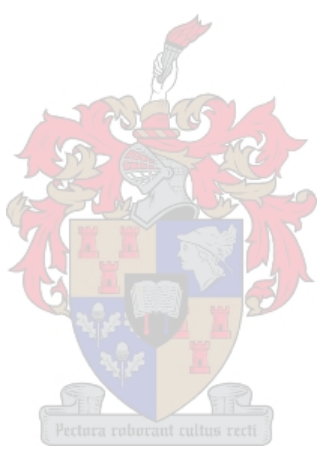




\section{HISTORY OF THIS STUDY}

In 2000, Helena Thornton, heading the neuropsychological services at the Neuropsychiatric and Neuropsychology Clinic at Tygerberg Hospital, Cape Town, received a referral from the Neurology Department to see a gentleman with lipoid proteinosis. The 25-year-old patient had a hoarse voice, skin papules and a five-year history of intractable simple and complex partial seizures coming from the right anterior temporal lobe. On MRI he had bilateral circumscribed amygdala calcification. The patient was worked up for epilepsy surgery (ES) and went on to have a right temporal lobectomy. The following year, another patient with LiP was referred to Neuropsychology for ES workup.

Due to rarity of their illness, their results were presented at the September 2001 South African Clinical Neuropsychology Association (SACNA) conference.

In 2002, Helena Thornton was invited to join a research team led by Molecular Dermatologists from St Thomas's Hospital (Professor John McGrath and Dr Takahiro Hamada), London, and Professor Michele Ramsay of the Genetics Department of the University of the Witwatersrand (WITS) and the Human Genetics teat of the National Health Laboratory Services (NHLS), to join them in Namaqualand in the Northern Cape. They were conducting genetic research on an identified group of LiP subjects, who had first been tracked by Dr Hymie Gordon and Ms Edelstein (in the 1960s) and Professor Trefor Jenkins, Genetics, WITS (now retired) ${ }^{18}$. Many of the LiP people participating in 
the study reported seizure or other neuropsychiatric presentation (e.g. psychosis), and a formal research area was envisaged.

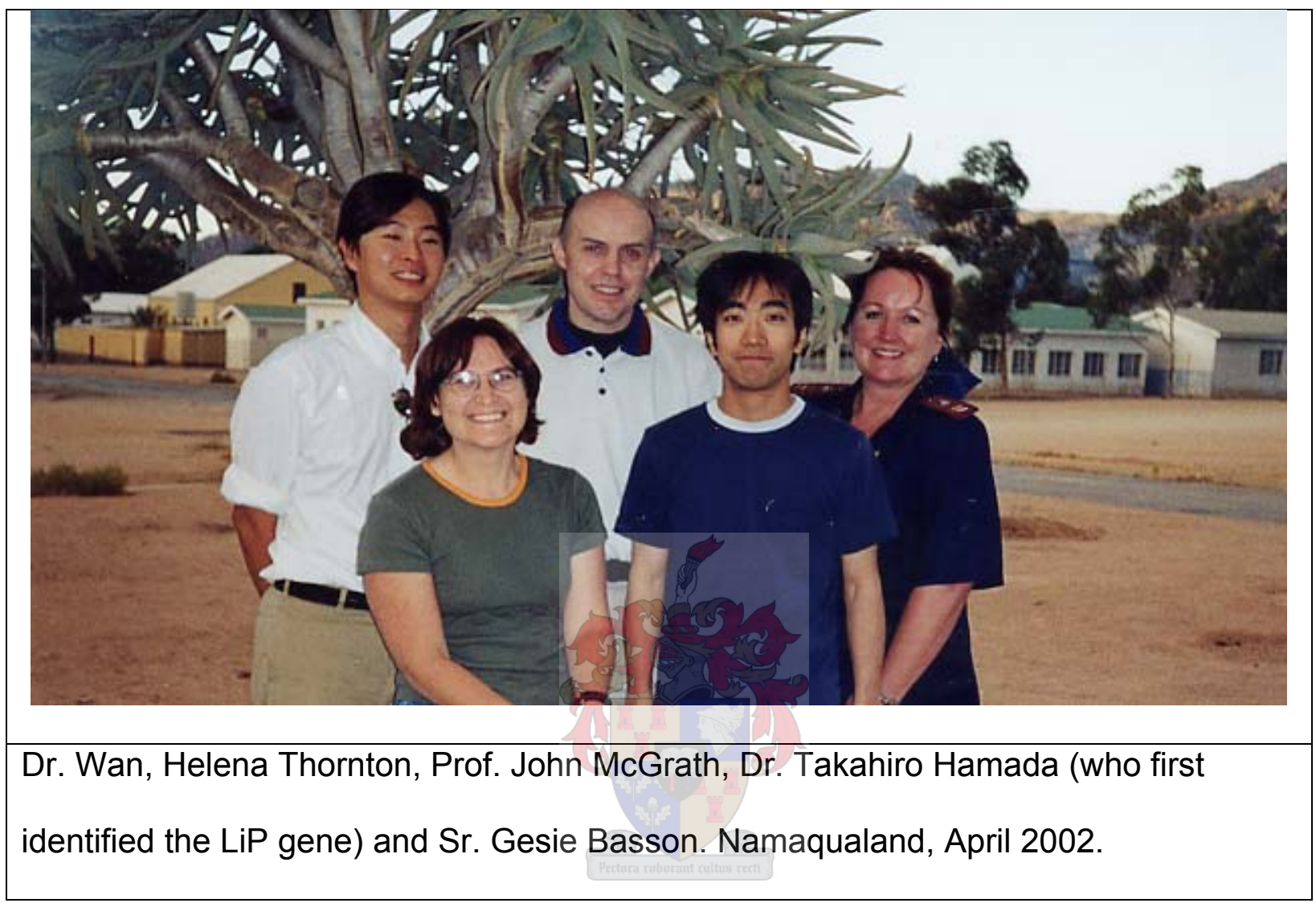

The trip also served to highlight feasibility regarding interest (all people informally interviewed felt they would be interested in future research concentrating on their feelings and memory), logistics (language, travel, accommodation.) and validity of possible test measures. One immediate foreseen difficulty was the fact that many of the subjects had little or no formal education, and immediately the need for a control group for all neuropsychological measures was realized. 
During the rest of 2002, funding was applied for, ethic approval obtained, informed consent documents written (see Appendix I). Subjects signed written, informed consent before study-related procedures were undertaken.

Erika Steenberg, Renee de Witt, Lindie Cloete, Elspeth Burke, Lydia van Niekerk, Melany Hendriks and Debbie Alexander, all qualified clinical psychologists, volunteered as Research Assistants. Three of the clinical psychologists were in their Community year and in every case, their job released them to participate in the study. Thus community hospitals from Cape Town, Western Province, Qatu (Military Hospital) in the Northern Cape and KwaZulu Natal became involved in the study. All were trained in the Neuropsychology battery and only Afrikaans home-language clinicians were trained in the clinical interviews. All were trained in providing basic genetic counseling and assessing which subjects needed psychiatric or psychological follow-up.

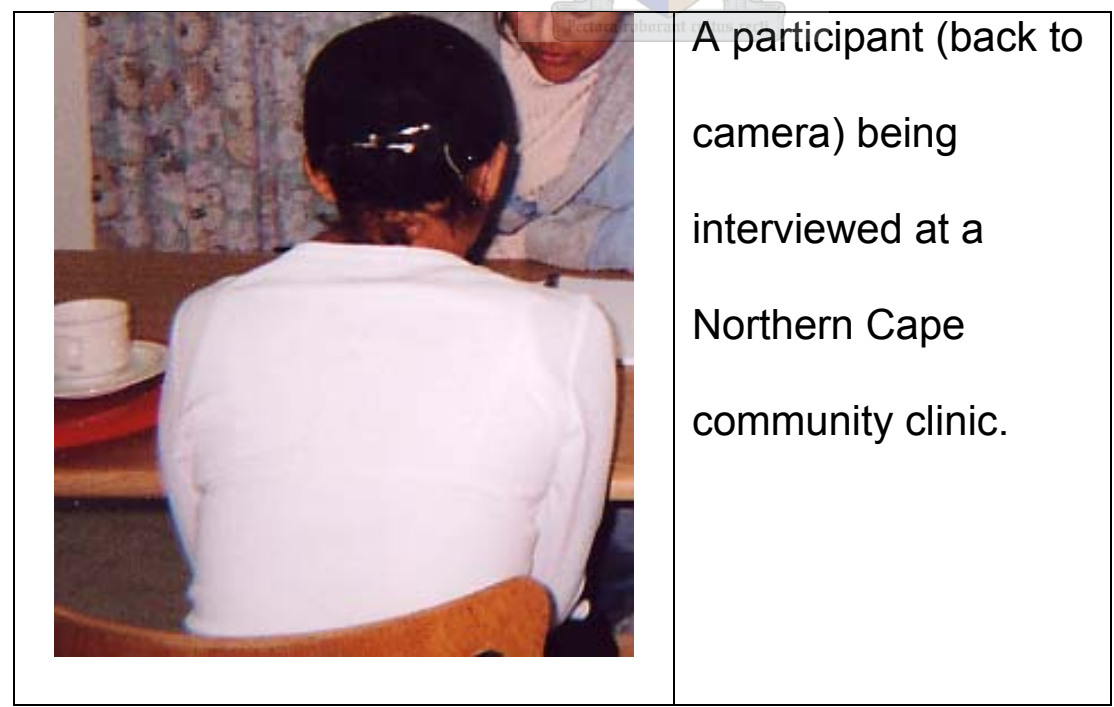

Two subjects were psychotic. When the community nurses explained a psychiatrist only visited their clinic once a year and requested a mental health assessment, they were 
assessed by the clinical psychologists and were referred to Kimberly Hospital where they were admitted and treated. The nurses also requested the clinical services for a child (neither LiP subject nor a control subject) who was suspected to have mental retardation. One person was severely clinically depressed, and referred on to the community social worker for follow-up. 
APPENDIX IV

THE NORTHERN CAPE 


\section{THE NORTHERN CAPE}

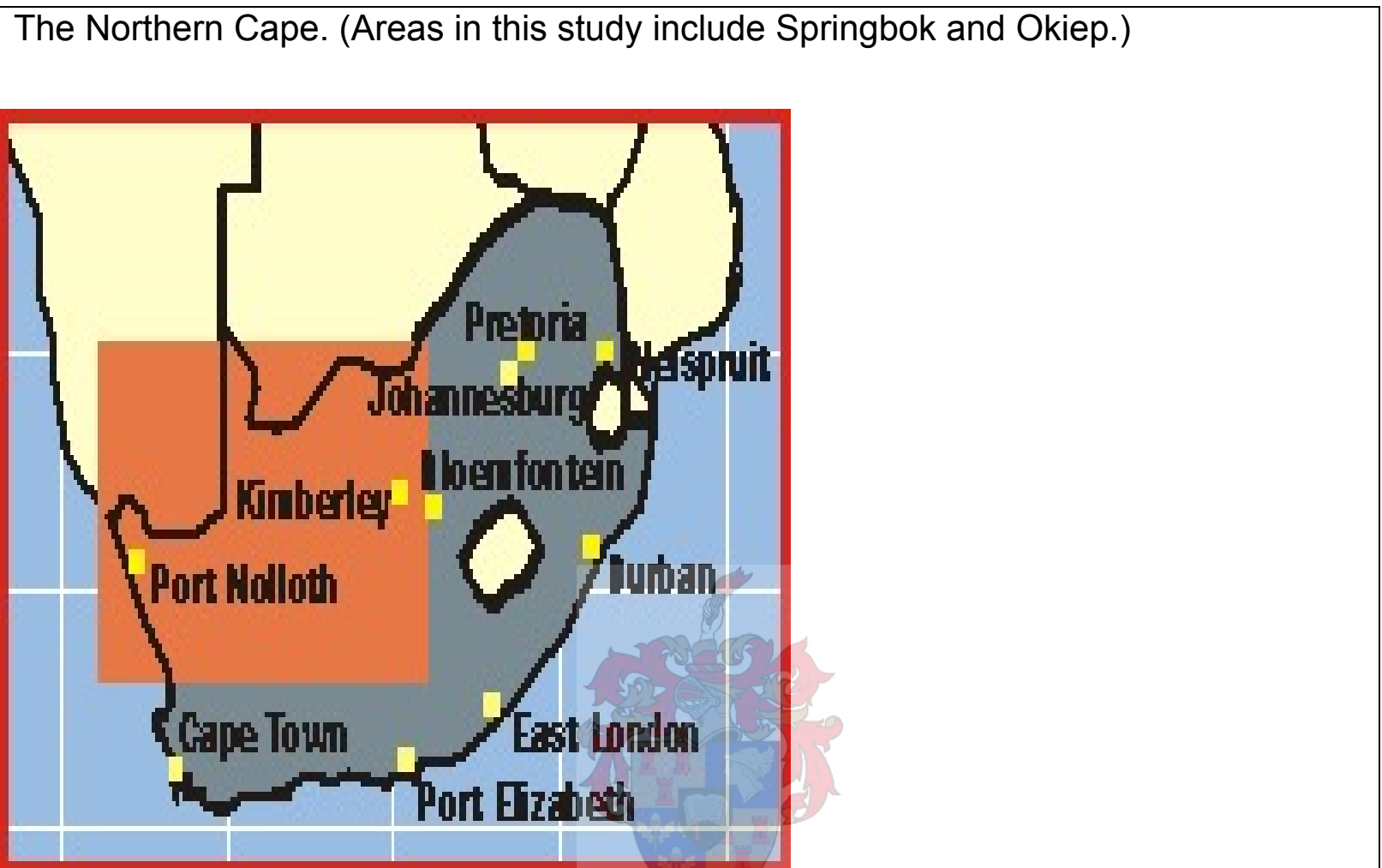

Stretching from the southern Kalahari scenery to the northern Richtersveld mountain dessert, the Northern Cape is vast and sparsely populated. Less than one million people are thought to live in an area of $361830 \mathrm{~km}^{2}$ of land. In other words, it is South Africa's least populated province, but still accounts for close to a third of the country's $\operatorname{area}^{245}$. 


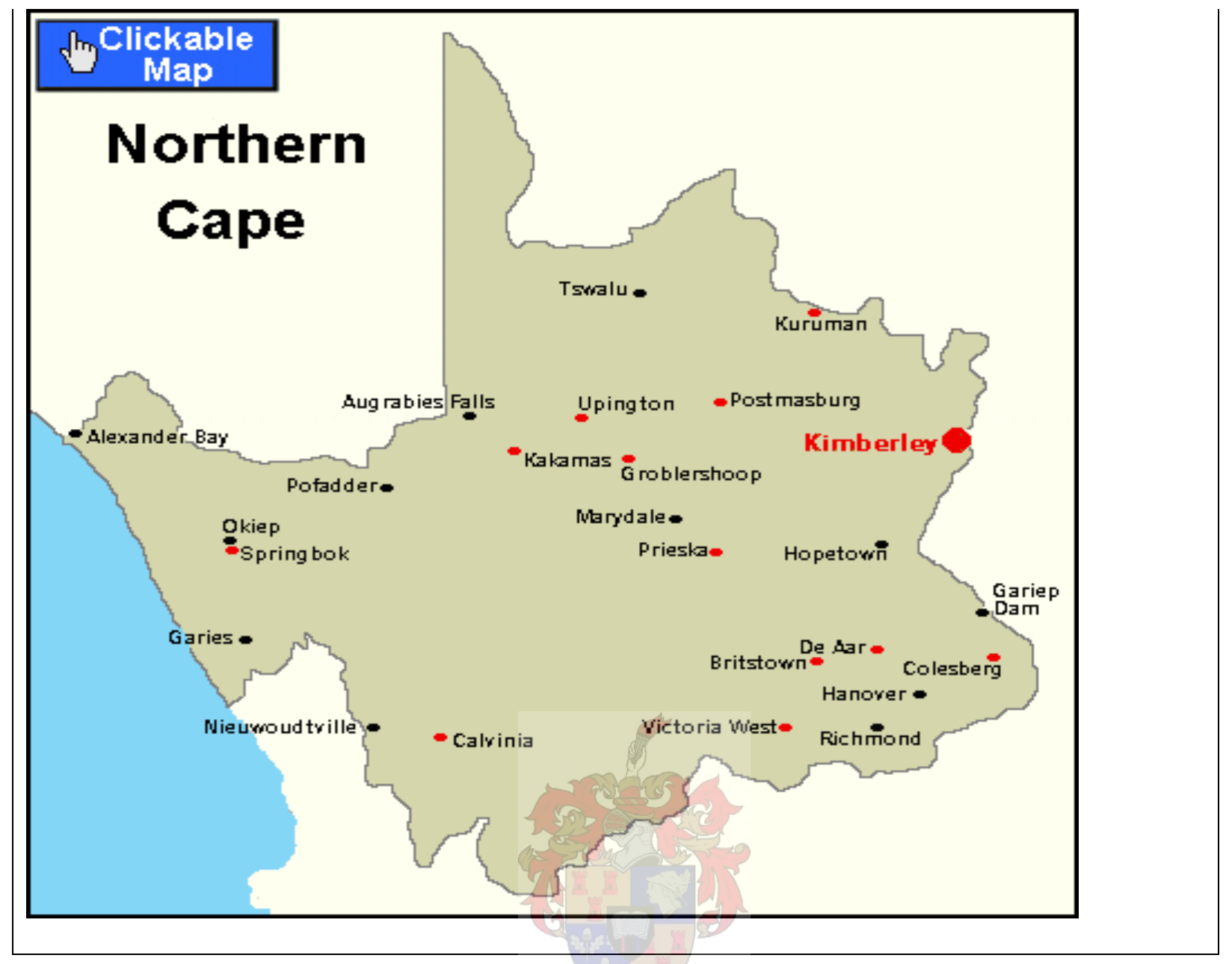




\section{Northern Cape}

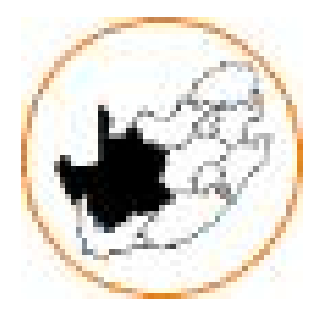

\begin{tabular}{|l|l|l|}
\hline Capital: & \multicolumn{2}{|l|}{ Kimberley } \\
\hline Principal languages: & Afrikaans & $68,0 \%$ \\
\hline & Setswana & $20,8 \%$ \\
\hline & isiXhosa & $6,2 \%$ \\
\hline Population: & 818848 (Mid-Year Estimates, 2003 [PDF]) \\
\hline Area $\left(\mathrm{km}^{2}\right)$ : & 361830 \\
\hline$\%$ of total area: & $29,7 \%$ \\
\hline GDPR at current prices (2002): & R225 46 million \\
\hline$\%$ of total GDP: & $2,0 \%$ \\
\hline
\end{tabular}

A description of the Northern Cape downloaded from the government of the Northern Cape's website is as follows ${ }^{246:}$

The Northern Cape lies to the south of its most important asset, the mighty Orange River, which provides the basis for a healthy agricultural industry. The landscape is characterised by vast arid plains with outcroppings of haphazard rock piles. The cold Atlantic Ocean forms the western boundary ${ }^{246-250}$.

This region covers the largest area of all the provinces and has the smallest population. Its major airports are situated at Kimberley, the capital, and Upington. The Northern Cape is serviced by an excellent road network, which makes its interior easily accessible from South Africa's major cities, harbours and airports. 
Important towns are Upington, centre of the karakul sheep and dried-fruit industries, and the most northerly wine-making region of South Africa; Springbok, in the heart of the Namaqualand spring-flower country; Kuruman, founded by the Scottish missionary Robert Moffat; and De Aar, hub of the South African railway network. Sutherland is the coldest town in the country and host to the southern hemisphere's largest astronomical observatory, the multinational-sponsored Southern African Large Telescope.

Other important Northern Cape towns include the sheep-farming towns of Carnarvon, Colesberg, Kenhardt and Prieska.

Apart from a narrow strip of winter-rainfall area along the coast, the Northern Cape is a semi-arid region with little rainfall in summer. The weather conditions are extreme cold and frosty in winter, with extremely high temperatures in summer.

The largest part of the province falls within the Nama-Karoo Biome, with a vegetation of low shrubland and grass, and trees limited to water courses. The area is known worldwide for its spectacular display of spring flowers which, for a short period every year, attracts thousands of tourists.

This Biome is home to many wonderful plant species, such as the elephant's trunk (halfmens), tree aloe (kokerboom) and a variety of succulents.

The province has several national parks and conservation areas. The Kalahari Gemsbok National Park, together with the Gemsbok National Park in Botswana, is Africa's first transfrontier game park, known as the Kgalagadi Transfrontier Park. It is one of the largest nature-conservation areas in southern Africa and one of the largest remaining protected natural ecosystems in the world. The Park provides unfenced 
access to a variety of game between South Africa and Botswana, and has a surface area of more than 3,6 million hectares (ha).

The Ai-Ais-Richtersveld Transfrontier Conservation Park spans some of the most spectacular scenery of the arid and desert environments in southern Africa. Bisected by the Orange River, which forms the border between South Africa and Namibia, it comprises the Ai-Ais Hot Springs Game Park in Namibia, and the Richtersveld National Park in South Africa. Some of the distinctive features in the area include the Fish River Canyon (often likened to the Grand Canyon in the United States of America) and the AiAis hot springs. This arid zone is further characterised by a unique and impressive variety of succulent plant species.

Nowhere is the Orange River more impressive than at the Augrabies Falls, which ranks among the world's greatest cataracts on a major river. The Augrabies Falls National Park was established to preserve this natural wonder.

\section{The people}

The Northern Cape is sparsely populated and houses some 818848 people on 361830 $\mathrm{km}^{2}$ of land (Mid-Year Estimates, 2003). About $68 \%$ of the population speaks Afrikaans. Other languages spoken are Setswana, isiXhosa and English ${ }^{246}$.

The official unemployment rate of the Northern Cape is 27,5\% (Labour Force Survey, September 2003). 
The last remaining true San (Bushman) people live in the Kalahari area of the Northern Cape. The area, especially along the Orange and Vaal rivers, is rich in San rock engravings. A good collection can be seen at the McGregor Museum in Kimberley. The province is also rich in fossils.

Agriculture and industry

The Northern Cape is displaying a tremendous growth in value-added activities, including game-farming.

Food production and processing for the local and export market is growing significantly.

Underpinning the growth and development plan of the province are the investment projects that link up with the existing plans of the Namaqua Development Corridor. The focus is on the beneficiation and export of sea products.

The economy of a large part of the Northern Cape, the interior Karoo, depends on sheep-farming, while the karakul-pelt industry is one of the most important in the Gordonia district of Upington.

The province has fertile agricultural land. In the Orange River Valley, especially at Upington, Kakamas and Keimoes, grapes and fruit are intensively cultivated.

Wheat, fruit, peanuts, maize and cotton are produced at the Vaalharts Irrigation Scheme near Warrenton. 


\section{Mining}

The Northern Cape is rich in minerals. The country's chief diamond pipes are found in the Kimberley district. In 1888, the diamond industry was formally established with the creation of De Beers Consolidated Mines. Alluvial diamonds are also extracted from the beaches and the sea between Alexander Bay and Port Nolloth.

The Sishen Mine near Kathu is the biggest source of iron ore in South Africa, while the copper mine at Okiep is one of the oldest mines in the country. Copper is also mined at Springbok and Aggenys. The province is also rich in asbestos, manganese, fluorspar, semi-precious stones and marble.

Until recently, the majority of small-to medium-scale alluvial operations were concentrated along or near the current Vaal River system. With the rapidly depleting deposits available for mining, there has been a gradual shift towards the Orange River system. Two recent larger-scale investments also show continued prospects in this sector.

Since 2000, the Northern Cape Office of the Department of Minerals and Energy has issued some 190 mining licences, mostly to small-scale operations able to employ local people. The majority of these licences (75\%) are for diamonds. Licences are also issued for tiger-eye, salt, sand and gravel, manganese and rose quartz. 


\section{Northern Cape - South Africa}

The Northern Cape is South Africa's least populous province but still accounts for close to a third of the country's area. The Northern Cape is a wild, untamed region where nature still rules; the geographic remoteness and harsh, dry climate have hindered (thankfully) human settlement of the land. The result is vast tracks of pristine wilderness where hardy flora and fauna have enjoyed a little peace and quiet, apart from the occasional intrepid soul.

People might have stayed away altogether were it not for the large quantities of diamond-bearing rock discovered first in the fields of Kimberley (on the eastern side of the province, now known as the Diamantveld) and later in alluvial deposits at the mouth of the Orange River on the Atlantic seaboard.

\section{The Weather in Northern Cape}

The Northern Cape's weather is typical of desert and semi-desert areas. This is a large, dry region of fluctuating temperatures and varying topographies. The scant annual rainfall of the Northern Cape $(50-400 \mathrm{~mm})$ is unreliable and very much lower than evaporation and, in January, afternoon temperatures are usually between 33-40 Celsius.

In 1939, at Goodhouse on the Orange River, an all-time high of $47.8^{\circ}$ Celsius was recorded. Though somewhat unusual, summer temperatures do sometimes top the $40^{\circ}$ Celsius mark. Winter days are warm - the onset of night bringing dew and frost to 
supplement the low rainfall. Sutherland, in the Hantam Karoo, is one of the coldest towns in southern Africa. Its average minimum is $-6^{\circ}$ Celsius. In winter, snow often blankets its surrounding mountains ${ }^{246-250}$. 


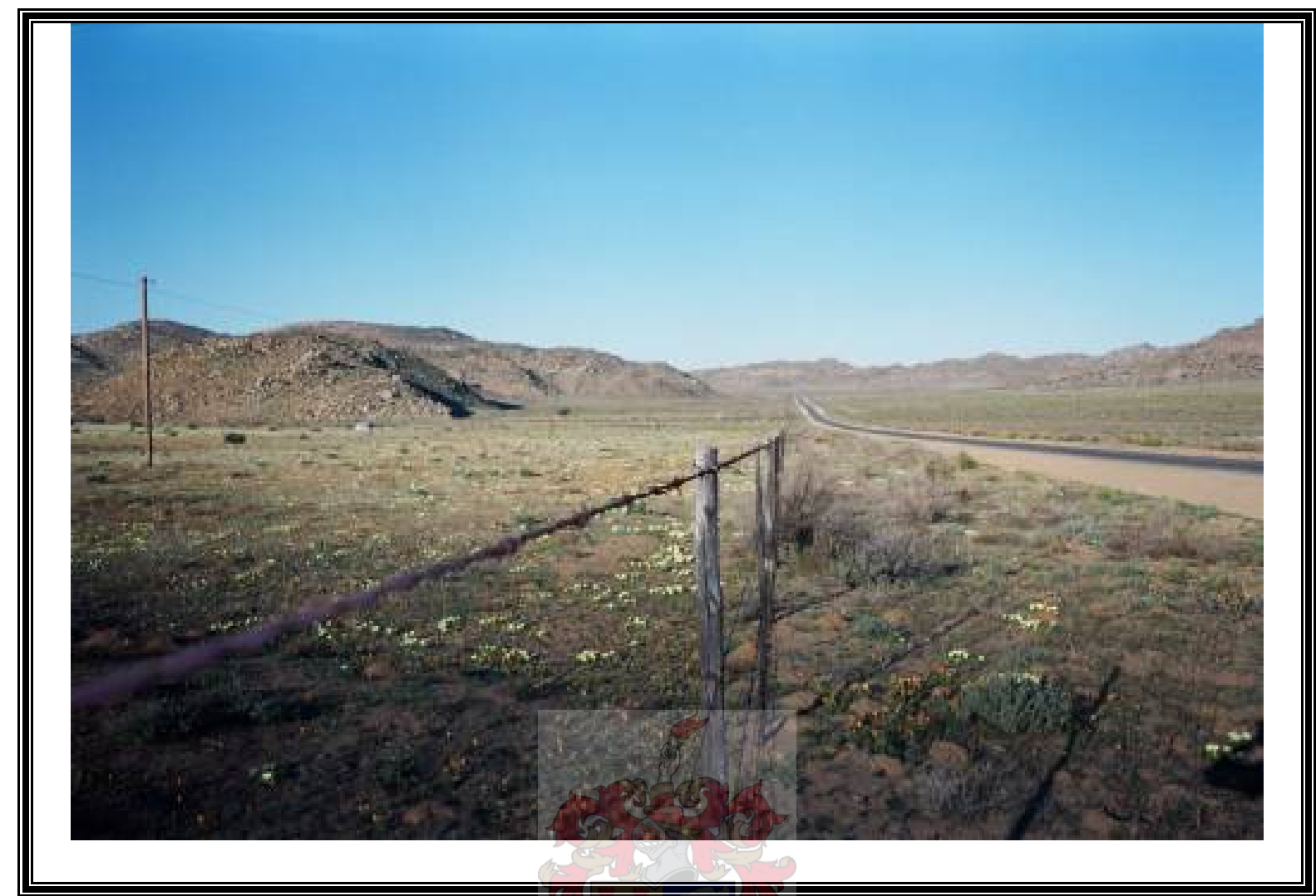

From Cape Town to Namibia, the N7 national road stretches as far as the eye can see. As it leaves the Western Cape behind, so it leaves behind water and greenery.

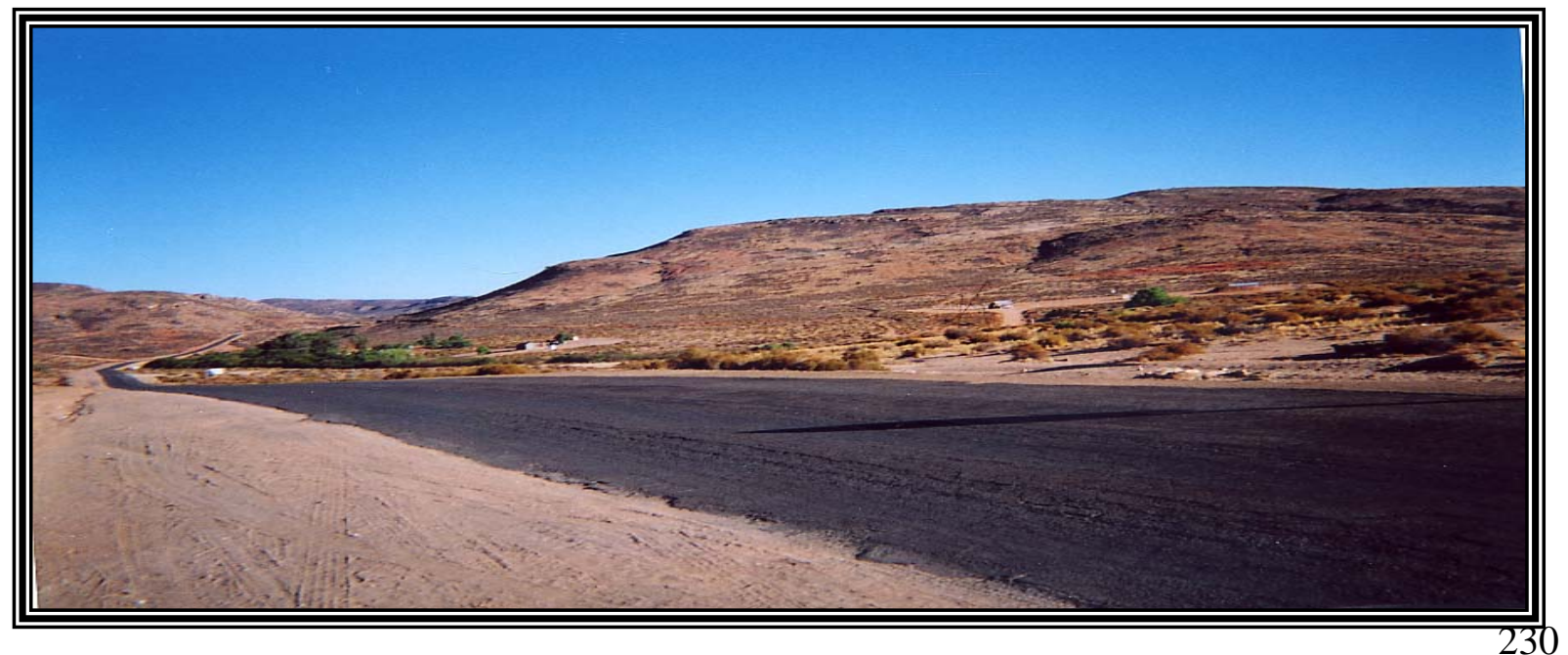


The road tends to become potholed and the cats' whiskers and lights and markings often become absent. For kilometers there may be no habitation, or tiny dwellings, where residents often live in the heat and dust and boundaryless vistas that blossom in spring. Rainfall is less than 50 to $400 \mathrm{~mm}$ per year, mostly in winter. In summer the temperatures can reach into the forties - the highest recorded temperature was $47.8^{\circ} \mathrm{C}$ - and in winter, as low as $-6^{\circ} \mathrm{C}$. The remoteness and harsh dry climate has hindered human settlement. For a large part of the Northern Cape (the interior Karoo), the economy relies on sheep farming. The karakul pelt industry is one of the foremost agricultural activities in the Gordonia district of Upington ${ }^{247-250}$.

Logistically, it was sometimes challenging accessing the places where the subjects resided. I am deeply indebted to the community nurses in the Northern Cape who volunteered their time and their driving (e.g. driving us 1.5 hours, across the passes from Okiep to Komaggas and then later, back again). The following photographs give an impression of the areas in which the research took place.

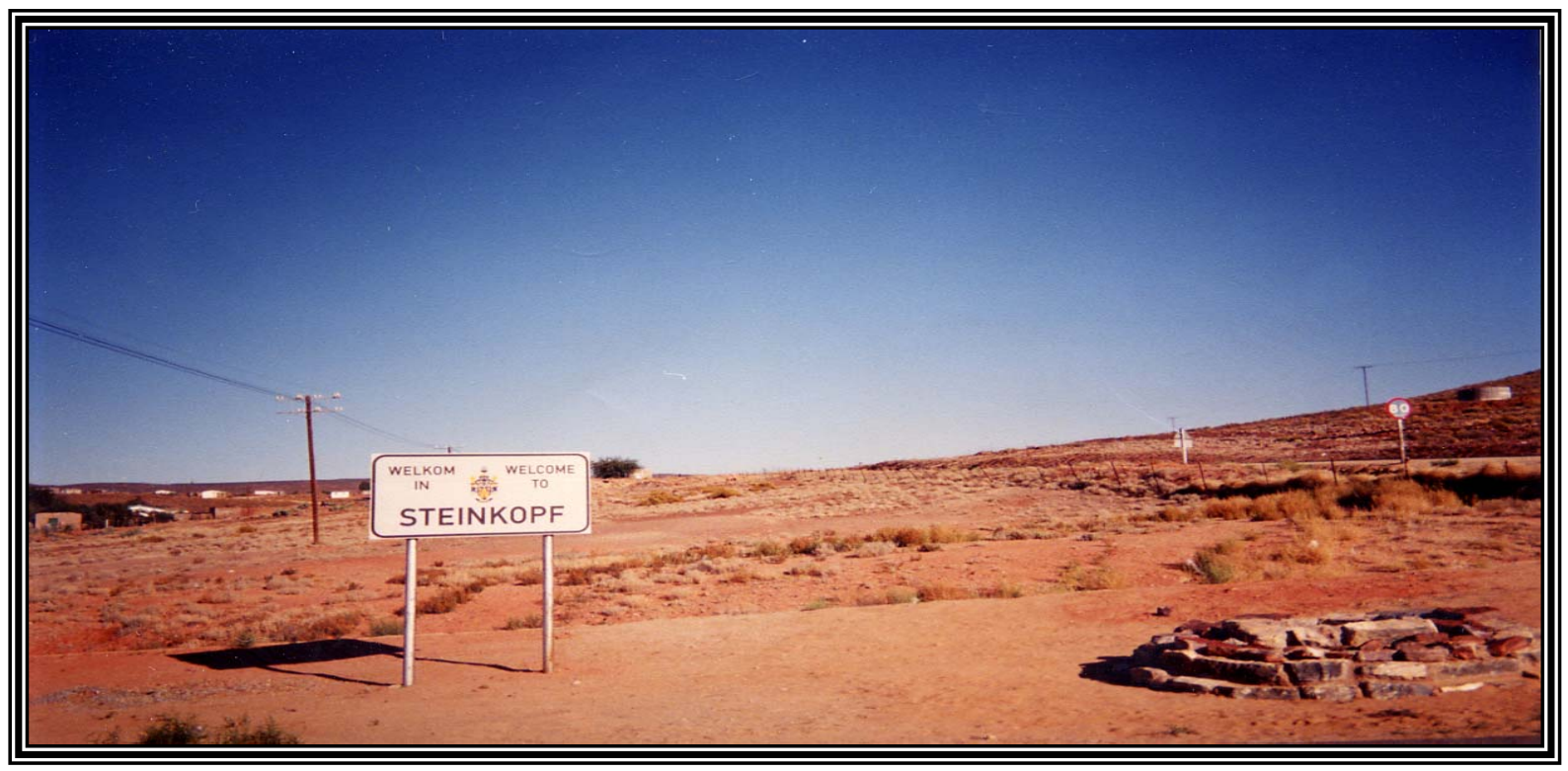



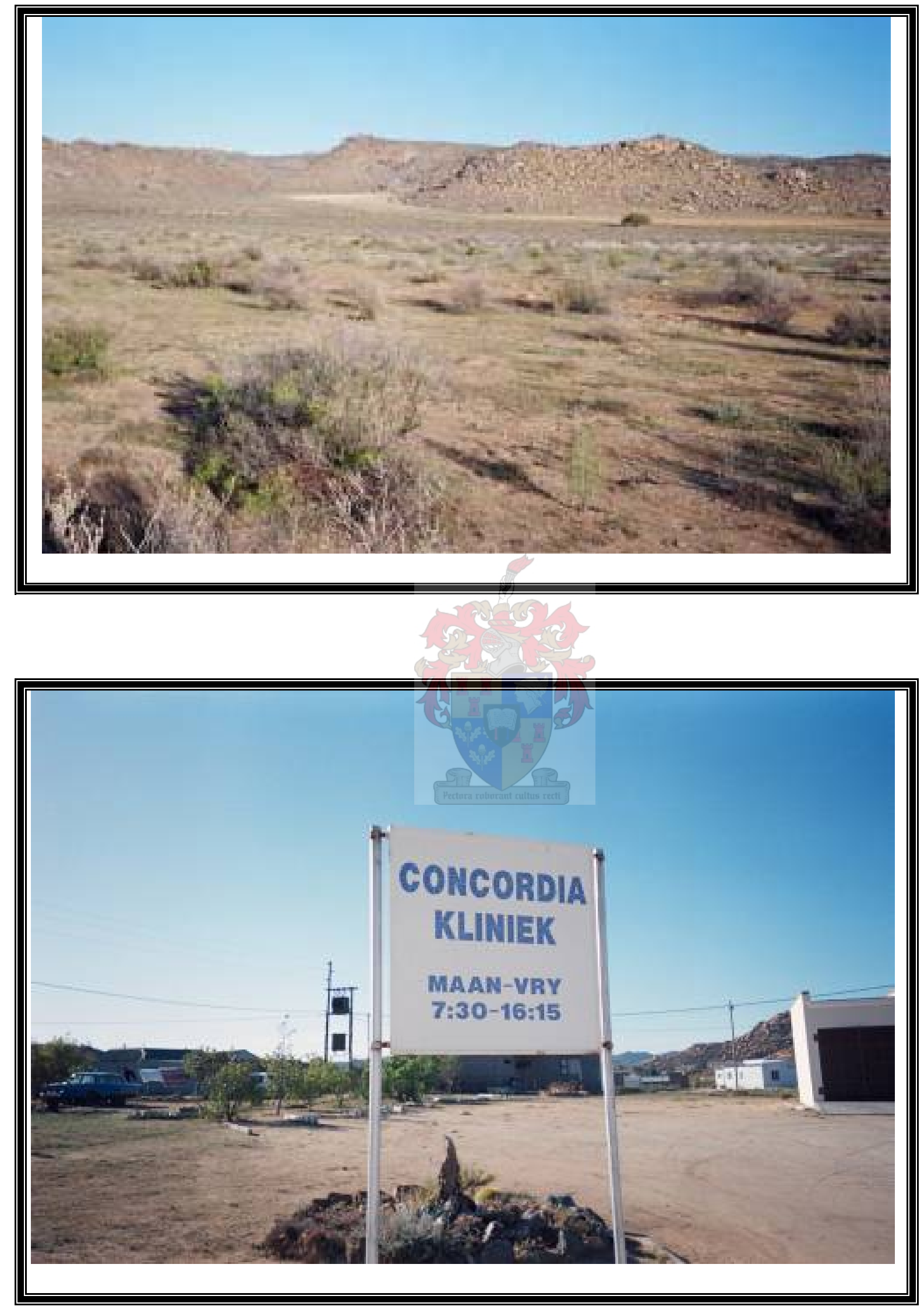

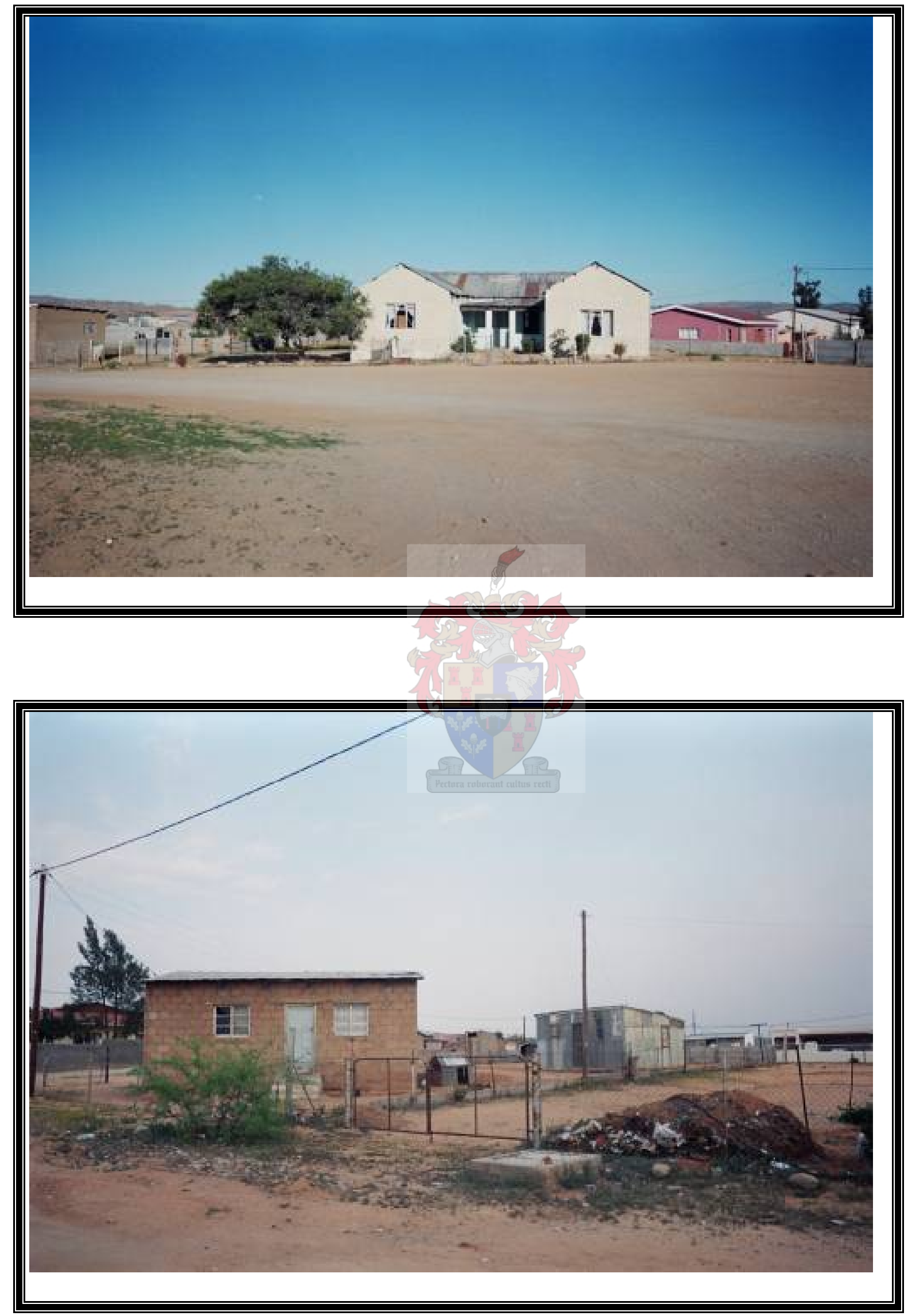

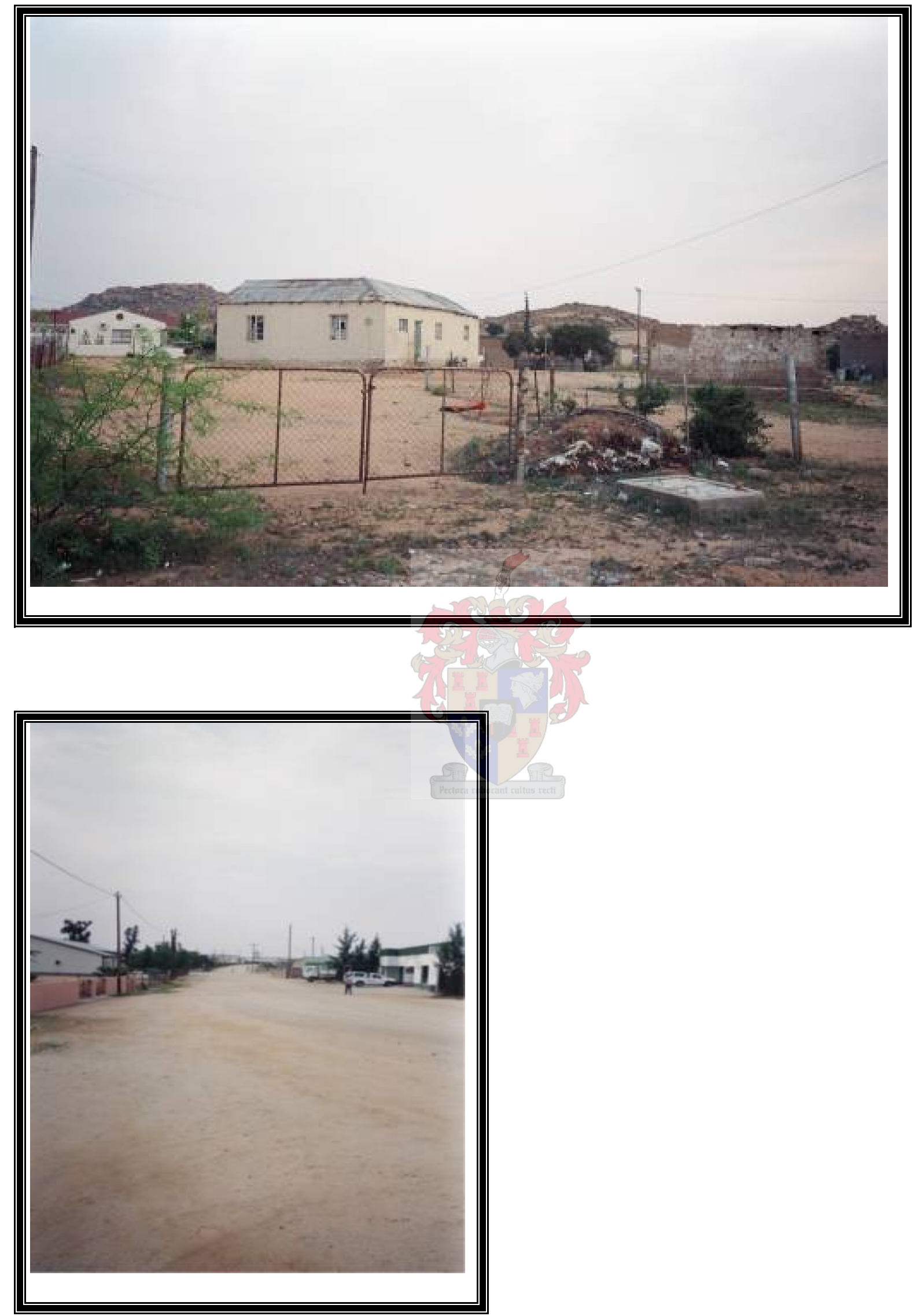